\title{
THE EFFECTS OF WATER TEMPERATURE ON FATTY ACID CONTENT IN THE DIATOM, NAVICULA PELLICULOSA
}

\author{
Ellen Cameron \\ Honours BSc, University of Waterloo, 2014
}

\author{
A thesis \\ presented to Ryerson University \\ in partial fulfillment of the \\ requirements for the degree of \\ Master of Science \\ in the Program of \\ Molecular Science
}

Toronto, Ontario, Canada, 2017

(C) Ellen Cameron 2017 


\section{AUTHOR'S DECLARATION FOR ELECTRONIC SUBMISSION OF A THESIS}

I hereby declare that I am the sole author of this thesis. This is a true copy of the thesis, including any required final revisions, as accepted by my examiners.

I authorize Ryerson University to lend this thesis to other institutions or individuals for the purpose of scholarly research

I further authorize Ryerson University to reproduce this thesis by photocopying or by other means, in total or in part, at the request of other institutions or individuals for the purpose of scholarly research.

I understand that my thesis may be made electronically available to the public. 


\section{ABSTRACT \\ THE EFFECTS OF WATER TEMPERATURE ON FATTY ACID CONTENT IN THE DIATOM, NAVICULA PELLICULOSA}

Ellen Cameron, Master of Science, 2017

Molecular Science, Ryerson University

Algae are critical to aquatic ecosystems and provide nutritious food to primary consumers due to their ability to synthesize essential fatty acids, in particular, long-chain polyunsaturated fatty acids (LC-PUFA). Aquatic ecosystems are experiencing increases in surface water temperatures as a result of anthropogenic climate change. Elevated water temperatures can potentially cause thermal stress for algae and disrupt critical physiological and biochemical mechanisms. As a response to temperature changes, fatty acid composition in membranes shifts in order to maintain membrane fluidity. To gain a better understanding of how elevated temperature influences fatty acid composition, growth experiments of a cosmopolitan freshwater diatom species, Navicula pelliculosa, were performed in a temperature-controlled laboratory environment. Diatom cultures were grown under different thermal regimes to examine the effects of temperature and time on LC-PUFA content. Temperature treatments were found to elicit an asymmetrical response in FA content, potentially resulting in reduced LC-PUFA availability. 


\section{ACKNOWLEDGEMENTS}

I would like to express my sincere gratitude to my advisor Dr. Michael Arts for giving me the opportunity to work on this project. I would like to thank him for his guidance throughout every step of my thesis and for helping me to develop my research skills. I would also like to thank Dr.

Stefanie Colombo for providing me with input and guidance on interpreting my results, my writing and statistical analysis.

I would like to thank the rest of my thesis committee, Drs. Janet Koprivnikar and Lesley Campbell, for providing feedback and encouragement.

I thank my fellow lab mates, in both the Arts and Campbell labs, for the support they provided. 


\section{TABLE OF CONTENTS}

Preface

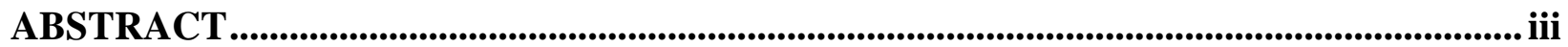

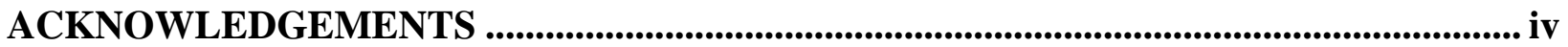

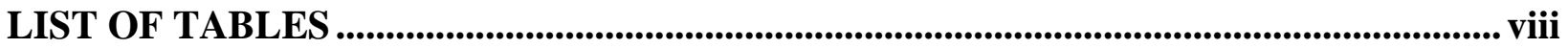

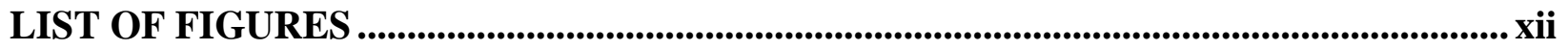

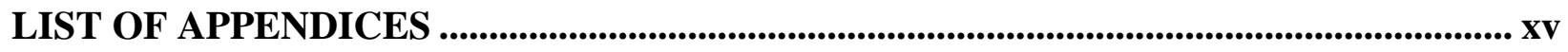

Chapter 1

Literature Review: The Effects of Climate Change on Algae,

Freshwater Ecosystems, and Fatty Acids....................................................................................... 1

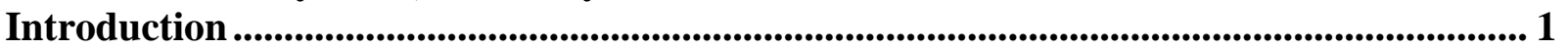

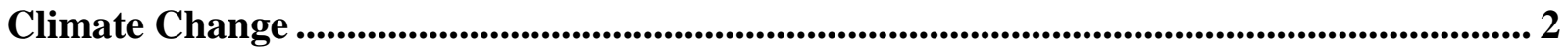

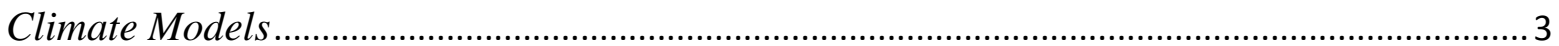

Freshwater Ecosystems and Climate Change ................................................................. 4

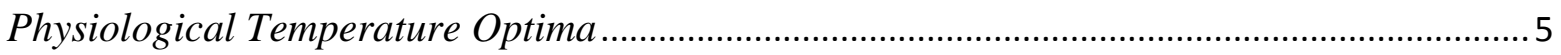

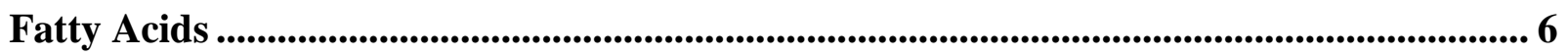

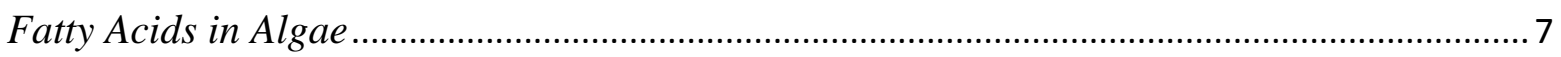

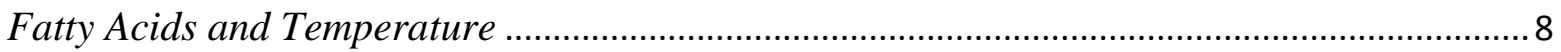

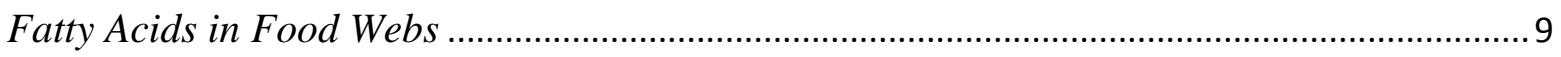

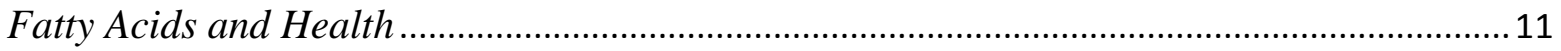

\section{Chapter 2}

The Effects of Fluctuating Water Temperatures and Time on

Fatty Acid Content in Navicula pelliculosa ........................................................................ 19

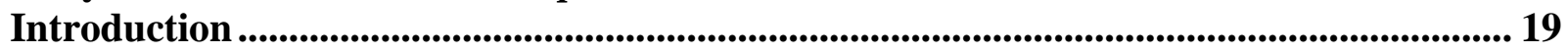

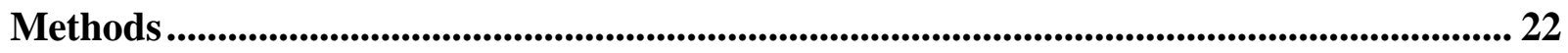

Culturing of Navicula pelliculosa (CPCC 552) .................................................................... 22

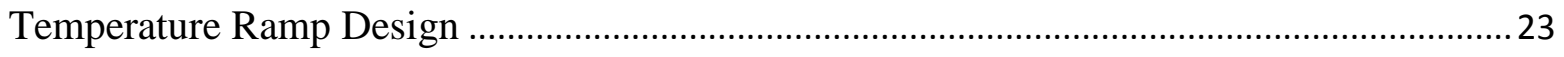

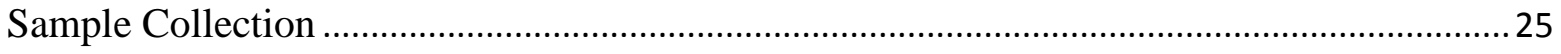

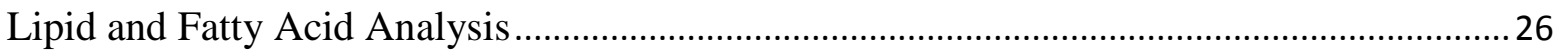


Statistical Analysis

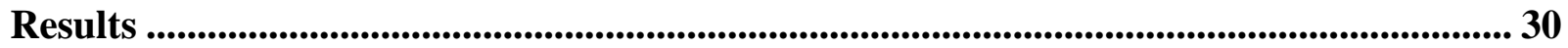

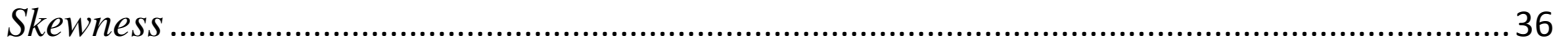

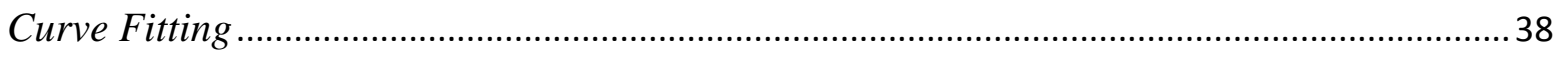

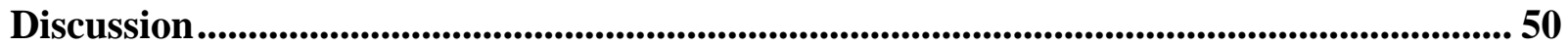

\section{Chapter 3}

The Effects of Long Term Heat Exposure on Fatty Acid Content

Recovery in Navicula pelliculosa .............................................................................56

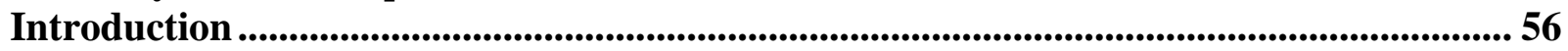

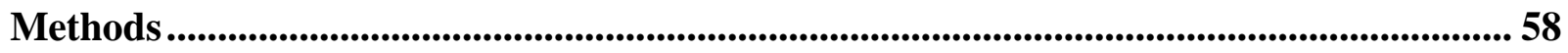

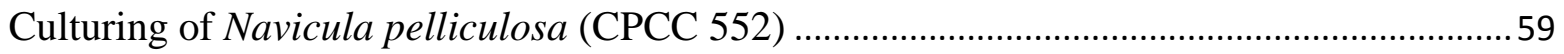

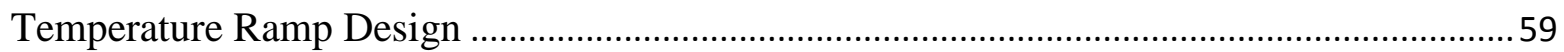

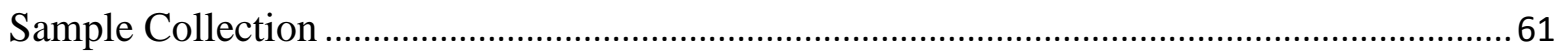

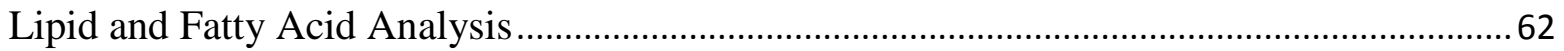

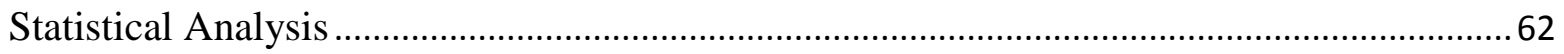

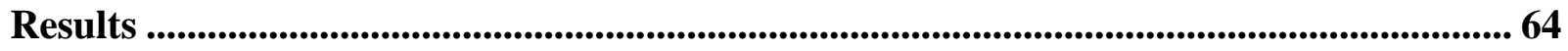

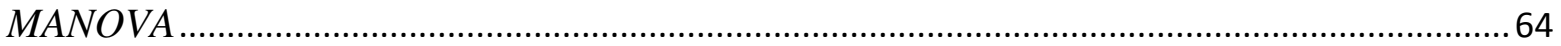

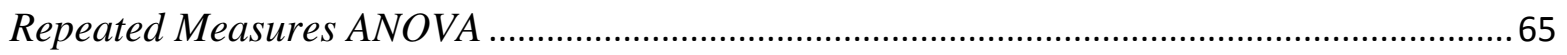

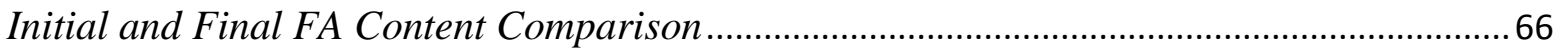

Long-Term Temperature F.A Content and Short-Term Temperature F.A Content

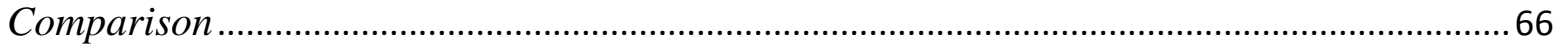

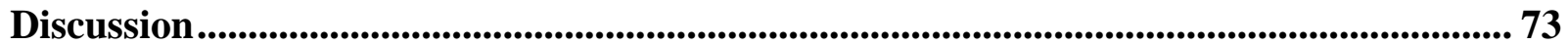

\section{Chapter 4}

Summary and Research Recommendations ............................................................................ 81

Summary .................................................................................................................................. 81

Research Recommendations ..................................................................................... 83 
Appendix 1: Common Abbreviations and Fatty Acid Categorization

Appendix 2: Navicula pelliculosa Growth Conditions............................................................. 88

Appendix 3: 2015 Pond Temperatures in Ontario

Appendix 4: Complete Fatty Acid Profiles- Short Term Temperature Ramp (Temperature Ramp \#1, Chapter 2).

Appendix 5: Complete Fatty Acid Profiles- Long-Term Temperature Ramp (Temperature Ramp \#2, Chapter 3). 98

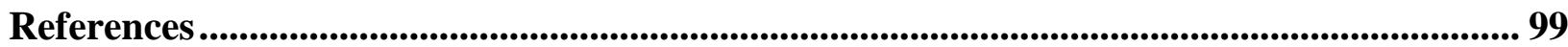




\section{LIST OF TABLES}

Table 2.1: Multivariate analysis results for the overall effects of predictors (time, temperature, combined time and temperature) on fatty acid content across all groups (saturated fatty acids, monounsaturated fatty acids, polyunsaturated fatty acids).

Table 2.2: Multivariate analysis results for the overall effects of predictors (time, temperature, combined time and temperature) on individual fatty acid content (EPA, DHA, 16:1n-7, 18:1n-9, and 18:0)

Table 2.3: Univariate analysis results for the effect of temperature treatment on each major fatty acid group (saturated fatty acids, monounsaturated fatty acids and polyunsaturated fatty acids; d.f=3) and individual fatty acids (EPA, DHA, 16:1n-7, 18:1n-9, and 18:0; d.f=3) used in order to determine the individual effect that temperature has on fatty acid content within major fatty acid groups

Table 2.4: Univariate analysis results for the effect that of time on each major fatty acid group (saturated fatty acids, monounsaturated fatty acids and polyunsaturated fatty acids; d.f=5) and individual fatty acids (EPA, DHA, 16:1n-7, 18:1n-9, and 18:0; d.f=5) used in order to determine the individual effect that time has on fatty acid content within major fatty acid groups.....

Table 2.5: Repeated measures multivariate analysis for different effectors on fatty acid content in fatty acid groups (saturated fatty acids, monounsaturated fatty acids and polyunsaturated fatty acids) to determine the overall effect that time, temperature, fatty acid group and a combination of these variables has on fatty acid content changes.

Table 2.6: Overall effects of temperature treatment and FA type while time is controlled to determine the individual and combined overall effects on fatty acid content in fatty acid groups (saturated fatty acids, monounsaturated fatty acids and polyunsaturated fatty acids).

Table 2.7: Repeated measures ANOVA for different effectors on fatty acid content in specific fatty acids (EPA, DHA, 16:1n-7, 18:1n-9 and 18:0) to determine the overall effect that time, temperature, fatty acid group and a combination of these variables has on fatty acid content changes.

Table 2.8: Overall effects of temperature treatment and fatty acid type while time is controlled to determine the individual and combined overall effects on fatty acid content in specific fatty acids (EPA, DHA, 16:1n-7, and 18:1n-9).

Table 2.9: Paired t-test performed between initial three time points $\left(t=0, t=2, t=4\right.$ at $\left.22-25^{\circ} \mathrm{C}\right)$ and final three time points $\left(\mathrm{t}=12, \mathrm{t}=24, \mathrm{t}=48\right.$ at $\left.25-22^{\circ} \mathrm{C}\right)$. For saturated fatty acids (SFA), polyunsaturated fatty acids (PUFA), 18:0, EPA and DHA, a one-tailed t-test (d.f.=8) was used 
due to the known response to changing temperatures. Monounsaturated fatty acids (MUFA), 16:1n-7 and 18:1n-9 used a two-tailed t-test (d.f.=8).

Table 2.10: Time independence skewness across temperatures. Positive values indicate right skewness, while negative values indicate left skewness. Highly skewed is represented by values exceeding 1 for right-skewed, and values lower than -1 for left-skewed. Symmetrical distributions are represented by values falling between -0.5 to 0.5 . Bolded values indicate distributions found to be highly skewed 44

Table 2.11: Temperature independence skewness across time. Right skewness is represented by positive values. Left skewness is represented by negative values. Highly skewed is represented by values exceeding 1 for right-skewed, and values lower than -1 for left-skewed. Symmetrical distributions are represented by values falling between -0.5 to 0.5 . Bolded values indicate distributions found to be highly skewed

Table 2.12: Curve fitting results using raw replicate data for time independence. Significant values indicate that the probability of the data distribution fitting to the curve was not due to random sampling and that data distributions follow the respective cubic polynomial function. . 45

Table 2.13: Curve fitting results using raw replicate data for time independence. Significant values indicate that the probability of the data distribution fitting to the curve was not due to random sampling and that data distributions follow the respective cubic polynomial function. . 45

Table 3.1: Multivariate analysis results for the overall effects of predictors (time, temperature, combined time and temperature) for fatty acid content across (saturated fatty acids, monounsaturated fatty acids, polyunsaturated fatty acids).

Table 3.2: Multivariate analysis results for the overall effects of predictors (time, temperature, combined time and temperature) for individual fatty acid content (EPA, DHA, 16:1n-7, 18:1n-9, and 18:0).

Table 3.3: Univariate analysis results for the effect of temperature treatment on each major fatty acid group (saturated fatty acids, monounsaturated fatty acids and polyunsaturated fatty acids; d.f.=1) and individual fatty acids (EPA, DHA, 16:1n-7, 18:1n-9, and 18:0; d.f=3) used in order to determine the individual effect that temperature has on fatty acid content within major fatty acid groups.

Table 3.4: Univariate analysis results for the effect of time had on major fatty acid group (saturated fatty acids, monounsaturated fatty acids and polyunsaturated fatty acids; d.f=1) and 
individual fatty acids (EPA, DHA, 16:1n-7, 18:1n-9, and 18:0; d.f=3) used in order to determine the individual effect that time has on fatty acid content within major fatty acid groups 68

Table 3.5: Repeated measures multivariate analysis for different effectors on fatty acid content in fatty acid groups (saturated, monounsaturated and polyunsaturated) to determine the overall effect that time, temperature, fatty acid group and a combination of these variables has on fatty acid content changes.

Table 3.6: Overall effects of temperature treatment and fatty acid group while time is controlled to determine the individual and combined overall effects on fatty acid content in fatty acid groups (saturated fatty acids, monounsaturated fatty acids and polyunsaturated fatty acids)...... 68

Table 3.7: Repeated measures multivariate analysis for different effectors on fatty acid content in specific fatty acids (EPA, DHA, 16:1n-7, 18:1n-9 and 18:0) to determine the overall effect that time, temperature, fatty acid group and a combination of these variables has on fatty acid content changes.

Table 3.8: Overall effects of temperature treatment and FA type while time is controlled to determine the individual and combined overall effects on fatty acid content in specific fatty acids (EPA, DHA, 16:1n-7, and 18:1n-9).

Table 3.9: T-test results for comparison of initial control conditions to $t=48 \mathrm{~h}$ at $25-22^{\circ} \mathrm{C}$. Control conditions consisted of cultures grown at $22^{\circ} \mathrm{C}$. A one tailed t-test was used for saturated fatty acids (SFA), polyunsaturated fatty acids (PUFA), EPA and DHA due to the directional response expected. A two-tailed t-test was used for monounsaturated fatty acids (MUFA), 16:1n7 and 18:1n-9. The comparison on the initial control fatty acid content to the $t=48 \mathrm{~h}$ shows whether fatty acid content experiences a full recovery after long-term temperature exposure. ... 69

Table 3.10: T-test results for comparison of initial control conditions to $t=72 \mathrm{~h}$ at $25-22^{\circ} \mathrm{C}$. Control conditions consisted of cultures grown at $22^{\circ} \mathrm{C}$. A one tailed t-test was used for saturated fatty acids (SFA), polyunsaturated fatty acids (PUFA), EPA and DHA due to the directional response expected. A two-tailed t-test was used for monounsaturated fatty acids (MUFA), 16:1n7 and 18:1n-9. The comparison on the initial control fatty acid content to the $t=72 \mathrm{~h}$ shows whether fatty acid content experiences a full recovery after long-term temperature exposure. ... 70

Table 3.11: Long-term versus short-term conditions at $28-25^{\circ} \mathrm{C}$. Fatty acid content values at $\mathrm{t}=24 \mathrm{~h}$ and $\mathrm{t}=48 \mathrm{~h}$ at $28-25^{\circ} \mathrm{C}$ during the short-term temperature ramp were compared to $\mathrm{FA}$ content values at $\mathrm{t}=24 \mathrm{~h}$ and $\mathrm{t}=48 \mathrm{~h}$ at $28-25^{\circ} \mathrm{C}$. The comparison of long term-conditions to short-term conditions determines whether there is a difference in the rate of fatty acid recovery. 
Table 3.12: Long-term versus short-term conditions at $25-22^{\circ} \mathrm{C}$. Fatty acid content values at $\mathrm{t}=24 \mathrm{~h}$ and $\mathrm{t}=48 \mathrm{~h}$ at $25-22^{\circ} \mathrm{C}$ during the short-term temperature ramp were compared to fatty acid content values at $\mathrm{t}=24 \mathrm{~h}$ and $\mathrm{t}=48 \mathrm{~h}$ at $25-22^{\circ} \mathrm{C}$. The comparison of long term-conditions to short-term conditions determines whether there is a difference in the rate of fatty acid recovery. 


\section{LIST OF FIGURES}

Figure 1.1: A schematic representation of the short-term temperature ramp including two increasing temperature steps and two decreasing temperature steps 14

Figure 1.2: A schematic representation of the long-term temperature ramp, including two increasing temperature steps, a long holding period at the maximum temperature of $28^{\circ} \mathrm{C}$, followed by two decreasing temperature steps

Figure 1.3: Schematic representation of symmetrical fatty acid concentration changes as a function of temperature and time combined resulting in no net gain or net loss of fatty acids.... 16

Figure 1.4: Schematic representation of asymmetrical fatty acid concentration changes as a function of temperature and time combined resulting in a net loss of PUFA concentrations and net gain of SFA

Figure 1.5: Schematic representation of asymmetrical fatty acid concentrations function of temperature and time combined resulting in a net gain in PUFA concentrations and net loss in SFA concentrations

Figure 2.1: Short-term temperature ramp including temperature holding periods of 48 hours. The temperature treatments are broken into two increasing temperature steps: $\# 1\left(22-25^{\circ} \mathrm{C}\right)$ and $\# 2$ $\left(25-28^{\circ} \mathrm{C}\right)$, followed by two decreasing temperature steps: $\# 3\left(28-25^{\circ} \mathrm{C}\right)$ and $\# 4\left(25-22^{\circ} \mathrm{C}\right) 25$

Figure 2.2: Average fatty acid methyl ester (FAME) content values for the initial three and final three sampling times across fatty acid groups. Error bars denote the standard deviation. Groups marked with the same letter (capital for temperature, lower case for time) are significantly different from each other (Tukey post-hoc) ............................................................................ 42

Figure 2.3: Average fatty acid methyl ester (FAME) content values for the initial three and final three sampling times across EPA and DHA. Error bars denote the standard deviation. Groups marked with the same letter (capital for temperature, lower case for time) are significantly different from each other (Tukey post-hoc).

Figure 2.4: Average fatty acid methyl ester (FAME) content values for the initial three and final three sampling times for 16:1n-7 and 18:1n-9. Error bars denote the standard deviation. Groups marked with the same letter (capital for temperature, lower case for time) are significantly different from each other (Tukey HSD) 
Figure 2.5: Average fatty acid methyl ester (FAME) Content across all temperature treatments at sampling time $\mathrm{t}=6 \mathrm{~h}$. Error bars denote standard deviation. Groups marked with the same letter are significantly different from each other (Tukey HSD). 46

Figure 2.6: Average fatty acid methyl ester (FAME) Content across all temperature treatments at sampling time $\mathrm{t}=6 \mathrm{~h}$ for EPA (left-hand axis) and DHA (right-hand axis). Error bars denote standard deviation values. Groups marked with the same letter are significantly different from each other (Tukey HSD). 46

Figure 2.7: Average fatty acid methyl ester (FAME) Content across all temperature treatments at sampling time $\mathrm{t}=6 \mathrm{~h}$ for 16:1n-7 (left-hand axis) and 18:1n-9 (right-hand axis). Error bars denote standard deviation values. Groups marked with the same letter are significantly different from each other (Tukey HSD).

Figure 2.8: Cubic polynomial curve fitted to the average saturated fatty acid (SFA) Content (three replicates for each temperature treatment step) at $\mathrm{t}=6 \mathrm{~h}$ across temperature treatments. Error bars denote the standard deviation values.

Figure 2.9: Cubic polynomial curve fitted to the average monounsaturated fatty acid (MUFA) (three replicates for each temperature treatment step) at $\mathrm{t}=6 \mathrm{~h}$ across temperature treatments. Error bars denote the standard deviation values.

Figure 2.10: Cubic polynomial curve fitted to the average polyunsaturated (PUFA) (three replicates for each temperature treatment step) at $\mathrm{t}=6 \mathrm{~h}$ across temperature treatments. Error bars denote the standard deviation values.

Figure 2.11: Cubic polynomial curve fitted to the average EPA (three replicates for each temperature treatment step) at $\mathrm{t}=6$ across temperature treatments. Error bars denote the standard deviation values.

Figure 2.12: Cubic polynomial curve fitted to the average DHA (three replicates for each temperature treatment step) at $\mathrm{t}=6 \mathrm{~h}$ across temperature treatments. Error bars denote the standard deviation values.

Figure 2.13: Cubic polynomial curve fitted to the average saturated fatty acid (SFA) content for $22-25^{\circ} \mathrm{C}$ (three replicates for each time point) across seven sampling times $(\mathrm{t}=0, \mathrm{t}=2, \mathrm{t}=4, \mathrm{t}=6$, $\mathrm{t}=12, \mathrm{t}=24, \mathrm{t}=48 \mathrm{~h}$ ). Error bars denote the standard deviation values. 
Figure 2.14: Cubic polynomial curve fitted to the average DHA content for $22-25^{\circ} \mathrm{C}$ across (three replicates for each time point) across six sampling times $(\mathrm{t}=2, \mathrm{t}=4, \mathrm{t}=6, \mathrm{t}=12, \mathrm{t}=24, \mathrm{t}=48$ h). Error bars denote the standard deviation values.

Figure 2.15: Cubic polynomial curve fitted to the average EPA Content for $22-25^{\circ} \mathrm{C}$ (three replicates for each time point) across seven sampling times $(\mathrm{t}=0, \mathrm{t}=2, \mathrm{t}=4, \mathrm{t}=6, \mathrm{t}=12, \mathrm{t}=24, \mathrm{t}=48$ h). Error bars denote the standard deviation values

Figure 3.1: Long term heat exposure temperature ramp including a two week holding period at $28^{\circ} \mathrm{C}$. Prior to reaching the maximum temperature of $28^{\circ} \mathrm{C}$, cultures were exposed to an incremental temperature increase. Following the two week exposure to $28^{\circ} \mathrm{C}$, temperatures were deceased to $25^{\circ} \mathrm{C}$ for $48 \mathrm{~h}$, and then to $22^{\circ} \mathrm{C}$ for $72 \mathrm{~h}$.

Figure 3.2: Average fatty acid methyl ester (FAME) concentration values for the control condition and $\mathrm{t}=48 \mathrm{~h}$ sampling time for saturated fatty acids, monounsaturated fatty acids and polyunsaturated fatty acids. Error bars denote standard deviations.

Figure 3.3: Average fatty acid methyl ester (FAME) concentration values for the control condition and $\mathrm{t}=48 \mathrm{~h}$ sampling time for EPA and DHA. Error bars denote standard deviations. Groups marked with a * were significantly different at $\mathrm{P}<0.05$

Figure 3.4: Average fatty acid methyl ester (FAME) concentration values for the control condition and $\mathrm{t}=72 \mathrm{~h}$ sampling time for saturated fatty acids, monounsaturated fatty acids and polyunsaturated fatty acids.. Error bars denote standard deviations. Groups marked with a * were significantly different at $\mathrm{P}<0.05$

Figure 3.5: Average fatty acid methyl ester (FAME) concentration values for the control condition and $\mathrm{t}=72 \mathrm{~h}$ sampling time for EPA (left-axis) and DHA (right-axis). Error bars denote standard deviations. Groups marked with a * were significantly different at $\mathrm{P}<0.05$.

Figure 3.6: Average fatty acid methyl ester (FAME) content values for the control condition and $\mathrm{t}=72 \mathrm{~h}$ sampling time for 16:1n-7 (left-axis) and 18:1n-9 (right-axis). Error bars denote standard deviations. Groups marked with a * indicate a significant difference. 


\section{LIST OF APPENDICES}

Appendix 1: Common Abbreviations and Fatty Acid Categorization .................................... 87

Appendix 2: Navicula pelliculosa Growth Conditions ........................................................ 88

Appendix 3: 2015 Pond Temperatures in Ontario .................................................................. 91

Appendix 4: Complete Fatty Acid Profiles- Short Term Temperature Ramp (Temperature Ramp

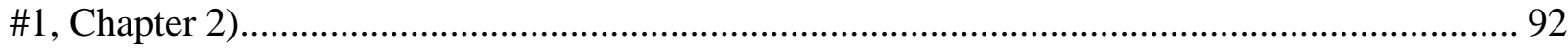

Appendix 5: Complete Fatty Acid Profiles- Long-Term Temperature Ramp (Temperature Ramp

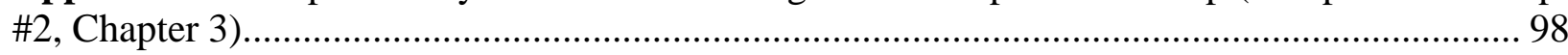




\section{Chapter 1 \\ Literature Review: The Effects of Climate Change on Algae, Freshwater Ecosystems, and Fatty Acids}

\section{Introduction}

Algae are critical to the survival of life on Earth (Chapman, 2013; Guiry, 2012; Guschina and Harwood, 2009). They contribute to half of global primary productivity and serve as a nutritional and energy resource for aquatic primary consumers, which gives them a globallyimportant role in aquatic ecosystems (Chapman 2013; Guschina and Harwood, 2009; Lands, 2009). Algae occur in a variety of environments ranging from oceans to moist soils and come in a variety of different shapes and sizes, ranging from unicellular microscopic phytoplankton to large sea weeds (Gamal, 2009).

Diatoms belong to the class Bacillariophyceae, and which contains an estimated 200,000 species (Armbrust, 2009; Dixit et al., 1992). Diatoms have frustules, rigid porous cell walls made up of silicon dioxide, giving them a distinct morphological structure (Chapman, 2013; Armbrust, 2009). They are critical components in freshwater systems and contribute to $20 \%$ of global primary productivity (Ruhland et al., 2015; Armbrust, 2009). Diatoms provide primary consumers with a high quality nutritional food, particularly lipids, which often contain high amounts of eicosapentaenoic acid (EPA; 20:5n-3) and docosahexaenoic acid (DHA; 22:6n-3) (Guo et al., 2016; Winder et al., 2009). Diatoms are common and abundant in different environmental conditions (i.e., varying water temperatures, freshwater, and marine environments) (Ruhland et al., 2015). However; their global distribution is also often influenced and limited by such environmental variables (Pajunen et al., 2016a). Depending on the region, 
seasonal diatom succession may be seen with blooms occurring in the spring and autumn due to optimal conditions of light, temperature and silica availability being met (Winder et al., 2009). Diatoms, like many other organisms, have specific physiological optima (Dixit et al., 1992). Although diatom populations can tolerate changing environmental conditions, environmental variation that is too far outside of optimal conditions can influence the success of diatom populations (Ruhland et al., 2015). For example, changes in temperature outside of physiological optima may influence a diatom populations' ability to survive and thrive in a given environment (Ruhland et al., 2015).

\section{Climate Change}

Anthropogenic (i.e., $\mathrm{CO}_{2}$ emissions and aerosols) and natural pressures (i.e., volcanic activity and ocean circulation patterns) both influence long term climate variability patterns (Rhein et al., 2013; Crowley, 2000). Climate change manifests itself through various physical responses (i.e., temperature changes, precipitation changes, ocean salinity) in land, air, and water (Cubasch et al., 2013). Greenhouse gas emissions have been identified as one of the main pressures that contribute to temperature change by exerting a warming effect (Bush et al., 2014). For example, atmospheric greenhouse gases increased by 7.5\% from 2005 to 2011 (Harmann et al., 2013). One thing is clear, if greenhouse gas emissions continue to increase in the upcoming years, so will temperature (Bush et al., 2014).

Temperature increases have been recorded in both surface air temperatures and surface water temperatures (Cubasch et al., 2013). From 1950-2010, temperature changes across Canada have increased by up to $5^{\circ} \mathrm{C}$ in some regions seasonally, with mean annual temperatures increasing by $1.5^{\circ} \mathrm{C}$ (Vincent et al., 2012). As a result of air temperature increases, there has also been a subsequent decrease in snow cover and permafrost coverage area and thickness (Cubasch 
et al., 2013). Surface air temperatures have continued to successively increase with each decade, causing faster increases in daily minimum temperatures than daily maximums (Bush et al., 2014; Harmann et al., 2013; Hegerl et al., 2004).

Along with increases in average surface air temperature, extreme climate events are also projected to be affected by climate change (Hegerl et al., 2004; Meehl et al., 2000). Extreme heat events (i.e. defined as days when the temperature exceeds $30^{\circ} \mathrm{C}$ in the summer) have increased and are predicted to continue to increase (Kharin et al., 2007; Vincent and Mekis, 2006), while

extreme cold events have decreased (Bush et al., 2014; Hegerl et al., 2004). Extreme heat events have a direct negative impact on ecosystems by affecting organism health due to deviations from temperature optima ranges (Kharin et al., 2007; Vincent and Mekis, 2006). Mid- to highlatitudes have experienced higher increases in warming of cold temperatures, with minimum winter temperatures increasing by more than $5^{\circ} \mathrm{C}$ since 1900 at certain sites during the winter (Vincent et al., 2012) and northern regions of Canada have experienced the highest rates of warming, with minimum temperatures increasing across all seasons ranging up to $3.5^{\circ} \mathrm{C}$ (Bush et al., 2014; Kharin et al., 2007; Vincent et al., 2012).

\section{Climate Models}

Predicted changes in temperature for the future are highly dependent on emission rates and different climate models account for different emission scenarios (Bush et al., 2014). While predictions of long-term climate change patterns are possible, there is uncertainty in these models due to the underlying variability in natural anthropogenic pressures (Collins et al., 2013).

Under low emissions (B1) in the CMIP3 multi-model (IPCC Annual Report 4) for Canada, the majority of temperature warming is predicted to occur in autumn and winter in the 
northern regions of Canada, in both mid- and late-century (Bush et al., 2014), potentially reaching a maximum increase of $7^{\circ} \mathrm{C}$, in comparison to average values recorded from 1961-1990 (Bush et al., 2014). However, when looking at the mid-high level emissions scenario (A2) detrimental temperature warming is seen across the majority of Canada in late century winter, with predictions for temperature increases of up to $10^{\circ} \mathrm{C}$ occurring across the northern regions in comparison to average values recorded from 1961-1990 (Bush et al., 2014). The mid-high level emissions scenario (A2) predicts warming of $6^{\circ} \mathrm{C}$ occurring across the majority of the southern regions in late century (Bush et al., 2014).

The CMIP5 multi-model (used in IPCC Annual Report 5) builds on the basis used in CMIP3, but works to include more variables of climate change to provide a more comprehensive examination of predicated climate conditions (Taylor et al., 2012). CMIP5 contains both near term climate projections (10-30 years), as well as long-term climate change projections (centuries) (Taylor et al., 2012). Both near term and long-term models, as in CMIP3, employ increasing atmospheric carbon dioxide values as the main driving force of climate change (Taylor et al., 2012). For near term projections of CMIP5, temperature increases are consistent across varying scenarios (Collins et al., 2013). For long term projections, temperature increases are seen to be the highest in the RCP8.5 scenario with temperature increases occurring at greater than $0.3^{\circ} \mathrm{C}$ per decade (Collins et al., 2013). However, in scenario RCP2.6, temperatures stabilize after 2050 and then begin to decline (Collins et al., 2013).

\section{Freshwater Ecosystems and Climate Change}

Climate change is an increasing concern in aquatic environments, with freshwater ecosystems in particular experiencing physical and chemical changes (Rhein et al., 2015; Woodward et al., 2010; Harley et al., 2006). Increased water temperatures have the potential to 
shift phytoplankton community structure because of optimal growth temperatures in phytoplankton species (Paerl and Huisman, 2009). Warmer waters also have the potential to affect zooplankton community composition, which, in turn, will affect the nutritional resources available for higher trophic levels (Gladyshev et al., 2011). Climate change is expected to have impacts on biological activity in freshwater ecosystems by disrupting organisms' physiology, species biodiversity, community structure, and overall productivity of the system (Ruhland et al., 2015; Wilby et al., 2010). Freshwater organisms are particularly at risk for loss in abundance and biodiversity (Heino et al., 2009; Sala et al., 2000).

\section{Physiological Temperature Optima}

Ectothermic organisms have an optimal temperature that allows them to maximize their physiological performance and which also influences their ability to survive in different environmental conditions (Pajunen et al., 2016b; Angiletta et al., 2009). Temperature is a limiting variable that influences algal growth, because of the effects it has on chemical and physiological pathways (Raven and Geider, 1988). Aquatic systems are exposed to rapid daily temperature fluctuations, seasonal changes, and long-term climatic changes which all influence growth, physiology and distribution of algal populations (Andersen et al., 2013; Moisan et al., 2002; Davison, 1991). Since different algal species have different optimal conditions, this influences seasonal phytoplankton succession patterns and global distribution patterns (Butterwick et al., 2005). Specifically temperate algal species generally have an optimal growth temperature ranging between 25 to $30^{\circ} \mathrm{C}$ (Ji et al., 2016; Allakhverdiev et al., 2008) and cyanobacteria species are generally able to survive in warmer water temperatures (Paerl and Paul, 2012). Photosynthetic rates have been shown to increase with increasing temperature up to an optimal point after which photosynthetic rates will decrease, indicating non-optimal growth 
conditions for algae (Andersen et al., 2013; Davison, 1991). Similar to photosynthetic rates, growth rates are seen to decrease when temperature optima are exceeded, resulting in decreased productivity (Andersen et al., 2013). Cellular membranes are composed of lipids and proteins in a bilayer with nonpolar groups contained on the inner portion surrounded by polar groups (Singer and Nicolson, 1972). The cellular membrane requires fluidity in order to maintain biological function (Marsh, 2010). Algae control the composition of their cellular membranes in order to maintain homeostasis at varying temperatures (on either side of their temperature optima), by modifying the structure of fatty acids within the membrane (Guschina and Harwood, 2009).

\section{Fatty Acids}

Fatty acids are categorized into different groups based on their chemical bonds (Honeyfield and Maloney, 2015). Saturated fatty acids (SFA) do not have double bonds and are 'saturated' with hydrogen atoms, whereas unsaturated fatty acids have double bonds between carbon atoms (Pottel et al., 2014). Unsaturated fatty acids are further classified based on the degree of unsaturation. Where monounsaturated fatty acids (MUFA) contain one double bond, polyunsaturated fatty acids (PUFA) contain two or more double bonds (Chen et al., 2013). Long-chain polyunsaturated fatty acids (LC-PUFA) are described as having two or more double bonds and are 20 or more carbons in length (Chen et al., 2013). Omega groups of fatty acids are determined by the location of the first double bond from the methyl end, for example, the first double bond in omega-3 (also called n-3) fatty acids is located at the third carbon from the methyl end (Cadler, 2015).

Desaturase and elongase enzymes are used to convert precursors into important PUFA (Pottel et al., 2014; Masclaux et al., 2012). Desaturase enzymes insert a double bond in the carbon 
chain by removing a hydrogen from a methylene group thus forming an unsaturated compound (Buist, 2004). Elongase enzymes serve to lengthen the carbon chain through the addition of two carbon units to the growing acyl chain (Meyer et al., 2004). Together, the desaturase and elongase enzymes produce the critically important PUFA, modified from alpha-linolenic acid (ALA; 18:3n3) and linoleic acid (LNA; 18:2n-6) (Masclaux et al., 2012). In vertebrates, LNA can be converted into a long-chain omega-6, arachidonic acid (ARA; 20:4n-6) through $\Delta 6$-desaturase, elongase and $\Delta 5$-desaturase activity (Hixson et al., 2015). ALA can be converted into long-chain omega-3 fatty acids, eicosapentaenoic acid (EPA) and docosahexaenoic acid (DHA) (Hixson et al., 2015; Pereira et al., 2004). ALA can be converted to EPA through $\Delta 6$-desaturase, elongase and $\Delta 5$-desaturase (Hixson et al., 2015). It can further be converted into DHA through the Sprecher pathway using elongase, $\Delta 6$-desaturase and $\beta$-oxidation (Hixson et al., 2015).

The conversion pathway leading to the production of EPA and DHA in algae differs from the enzymatic conversion pathway found in vertebrates (Pereira et al., 2004). Some lower eukaryotes are able to convert the omega- 6 intermediates into omega- 3 fatty acids through $\omega 3$ desaturase activity (Pereira et al., 2004). An alternate conversion pathway is also seen from ALA to EPA involving elongase and $\Delta 8$-desaturase to reach the precursor eicosatetraenoic acid (ETA; 20:4n-3) (Pereira et al., 2004). Otherwise the conversion of EPA to DHA occurs through elongase and $\Delta 4$-desaturase activity as opposed to the Sprecher pathway outlined above for vertebrate conversion (Pereira et al., 2004).

\section{Fatty Acids in Algae}

Primary producers, such as plants and algae, have the necessary biochemical competency to synthesize important fatty acids (Koussoropolis et al., 2013). Algae are the dominant producers of n-3 LC-PUFA (Gladyshev et al., 2013; von Elert, 2002); therefore, aquatic 
ecosystems are the main source of n-3 LC-PUFA (Hixson et al., 2015; Brenna and Carlson, 2014; Gladyshev et al., 2012).

Different algae taxa produce different fatty acids in varying proportions and amounts (Perhar et al., 2013). Certain algae taxa characteristically contain higher amounts of PUFA than other taxa (Sushchik et al., 2004; von Elert 2002). For example, diatoms and cryptophytes generally produce high amounts of EPA and DHA (Gladyshev et al., 2013; Burns et al., 2011), while green algae produce mainly ALA and LNA (Burns et al., 2011). Cyanobacteria characteristically known to have low nutritional value from the perspective of n-3 PUFA, and do not produce EPA and DHA (Paerl and Paul, 2012; Burns et al., 2011).

\section{Fatty Acids and Temperature}

Homeoviscous adaptation allows poikilothermic organisms adapt to different water temperatures (Gladyshev et al., 2011; Schlechtriem et al., 2006). Homeoviscous adaptation is the process by which membrane fluidity is maintained by changing the composition of fatty acids (Gladyshev et al., 2011; Sinensky, 1974). Changing the chain length and incorporating double bonds allows for rapid adaptations of poikilothermic organisms to fluctuating temperatures (Oger and Cario, 2013). In order to maintain fluidity at high temperatures, short chain lengths and saturated fatty acids are favoured due to the melting point (Marsh, 2010). Membrane function is

supported by maintaining fluidity and preventing it from becoming hyper-fluid or rigid (Anacleto et al., 2014; Sperfield and Wacker, 2012). Unsaturated fatty acids are incorporated into the membrane at lower temperatures in order to maintain membrane fluidity (Usui et al., 2012; Murray et al., 2010). PUFA have a low melting point, which is why they are predominant in membrane composition at lower temperatures (Sperfield and Wacker, 2012; Arts and Kohler, 2009). As such, EPA and DHA are more prevalent in aquatic organisms in cooler waters 
(McMeans et al., 2015). The alteration of fatty acid composition as an effect of temperature alters the demands for different fatty acids at varying temperatures (McMeans et al., 2015; Sperfield and Wacker, 2012). Thus, a pattern of fatty acid incorporation in cell membranes is often observed depending on water temperature; whereby, increased PUFA are produced in cooler temperatures, and increased SFA are produced in warmer temperatures (Marsh, 2010). Longer chain lengths and higher degrees of unsaturation contribute to a lower melting point (Marsh, 2010). Saturated fatty acids have a higher melting point due to intermolecular interactions which thermodynamically favours the increased incorporation of saturated fatty acids at higher temperatures (Marsh, 2010). With this process, there is the potential for there to be a loss of PUFA when water temperature increases (Gladyshev et al., 2015, McMeans et al., 2015).

\section{Fatty Acids in Food Webs}

In aquatic ecosystems, algae play an important role as a nutritional resource and contributes to the health of other aquatic organisms and terrestrial organisms, including humans (Chapman, 2013; Guiry, 2012; Guschina and Harwood, 2009; Lands, 2009). The ability for algae to synthesize essential PUFA makes them a necessary nutritional component for consumers (Guschina and Harwood, 2009; Harwood and Guschina, 2009; Lands, 2009). As such, the fatty acid composition of algae is often used as a measurement to determine the nutritional quality of phytoplankton (Arendt et al., 2005).

Animals are able to produce SFA and MUFA but cannot produce LC-PUFA efficiently enough to satisfy optimal physiological requirements (Arts et al., 2001). Furthermore, vertebrates do not have the $\omega 3$-desaturase enzyme and cannot insert a double bond in pre-existing PUFA precursors at this position (Honeyfield and Maloney, 2015; Gladyshev et al., 2011). Vertebrates 
also do not have $\Delta 12$-desaturase or $\Delta 15$-desaturase to convert oleic acid (18:1n-9) into LNA or ALA respectively (Hixson et al., 2015). Therefore, consumers must rely on dietary sources for obtaining essential fatty acids because there is an insufficient rate of synthesis and conversion of important LC-PUFA such as EPA and DHA (Persson and Verde, 2006; von Elert, 2002). The reliance of consumers on obtaining LC-PUFA from dietary sources often creates a constraint on growth when food quality is low (Wacker and von Elert, 2004; von Elert, 2002).

Nutritional energy and components are available to be transferred up the trophic levels (von Elert, 2004). In aquatic ecosystems, zooplankton connects primary producers to high level consumers and thus broker the transfer of valuable PUFA up the trophic levels (Persson and Verde, 2006). In this way consumption of PUFA in aquatic invertebrates directly influences fish health (Gladyshev et al., 2015). Different phytoplankton species dominate phytoplankton communities at different times during each season (Sushchik et al., 2003). Due to the differences in phytoplankton communities seen seasonally, the trophic transfer varies depending on season (Hartwich et al., 2013; Sushchik et al., 2003). Generally, diatoms dominate phytoplankton communities in the spring and are not as prevalent in the summer (Hartwich et al., 2013). Due to these shifts in phytoplankton communities depending on season, PUFA availability changes as well (Hartwich et al., 2013).

Since algae are the main producers of PUFA, terrestrial organisms also rely, to varying extents, on the aquatic derived sources (Gladyshev et al., 2009). The transfer of aquatic PUFA to terrestrial ecosystems is done via direct consumption (i.e. consuming fish or shellfish) or through amphibiotic insects (where the larval form of the insect is aquatic but the adult stage is terrestrial) (Hixson et al., 2015; Gladyshev et al., 2013). Fish provide humans with an accumulated content of PUFA from algae derived sources (Pottel et al., 2014). 


\section{Fatty Acids and Health}

PUFA (in particular, EPA and DHA) play an important role in physiological processes (Gladyshev et al., 2015; Masclaux et al., 2014; Schlotz et al., 2013; von Elert, 2002). PUFA are required for growth, reproduction and survival in many organisms (Tocher, 2010; Kanazawa, 1997). Deficiency of PUFA from the diet can lead to decreased growth and increased mortality rates in organisms (Tocher, 2010). Different organisms (influenced by species, age and environmental conditions) have different dietary requirements for fatty acids (Tocher, 2010). For example, certain juvenile freshwater fish can meet EFA requirements with ALA, but juvenile freshwater fish have a strict requirement for EPA and DHA (Tocher, 2010).

DHA is found in high concentrations in neural membranes and the retina (Horrocks and Farooqui, 2004). DHA found in neural tissues contributes to membrane fluidity of neural cell membranes, which is critical for signal transduction (Carlson et al., 2013). While DHA is important for neural health throughout life, it is vital in the development of the vertebrate fetal brain and retina (Swanson et al., 2012). DHA has been shown to improve the mental development and cognitive ability of the human infant in pregnant and breast feeding women (Carlson et al., 2013; Yashodara et al., 2009). DHA continues to be a critical dietary component to maintain neurological health in adult humans and during aging (Carlson et al., 2013). DHA is also linked to cardiovascular health through many mechanisms (Engler and Engler, 2006). DHA supplementation has been shown to reduce blood pressure (Engler and Engler, 2006). DHA encourages healthy neural development and is particularly important in infant brain development (Lav et al., 2012; Arts et al., 2001). Fish larval stages have also shown a need for dietary DHA sources due to the rapidly developing vision and neural tissue (Tocher, 2010). Fish larvae have also shown increased survival under stressful conditions when fed DHA (Kanazawa, 1997). 
The high omega 6/omega 3 PUFA ratio found in the Western diet contributes to increased rates of cardiovascular and inflammatory diseases (Calder, 2006; Simpolous, 2002). Eicosanoids are a group of hormones (containing leukotrienes, thromboxanes and prostaglandins) playing important roles in reproduction and the immune system (Martin-Crezuburg et al., 2010; Calder, 2006). When EPA is consumed, it competes with ARA for the formation of leukotrienes (Calder, 2006; Simpolous, 2002). EPA decreases the formation of leukotriene $\mathrm{B}_{4}$ (a strong inflammation inducer), and encourages the production of leukotriene $\mathrm{B}_{5}$ (a weak inflammation inducer) (Calder, 2006; Simopolous, 2002). Along with decreasing production of inflammation inducers, EPA has also been shown to decrease cell surface adhesion resulting in anti-inflammatory effects (Calder, 2006). Many studies have been done showing that the availability of EPA has been shown to limit growth in zooplankton (Martin-Creuzburg et al., 2010), and specifically Daphnia (Schlotz et al., 2013; Gladyshev et al., 2008; von Elert, 2002). With predicted decreases in EPA and DHA availability as a result of temperature warming, this in turn could result in adverse physiological and growth effects in aquatic consumers and humans.

\section{Focus of Research}

Although previous studies have quantified fatty acid composition of algae when exposed to a variety of sustained temperatures (see Pasquet et al., 2014; Fuschino et al., 2011), there is no information on the nature of the temporal response (i.e., raising the temperature and returning back to the original temperature), as would be observed in a natural environment. In addition,

there is currently no foundational knowledge on the direct response of fatty acid composition and recovery potential in algae when exposed to fluctuations in elevated temperatures. The results collected from the temperature controlled experiments will provide insight on the effects that 
elevated temperatures as a result of climate change may have on fatty acid composition in algae and, in general, for overall fatty acid availability.

The effects of increasing temperatures on fatty acid composition as well as on the recovery from long term heat exposure were determined. The freshwater diatom, Navicula pelliculosa (referred to, hereafter, as $N$. pelliculosa), was used as my model organism. $N$. pelliculosa has a wide distribution range, is easy to culture in a laboratory setting and produces EPA and DHA. N. pelliculosa is found in global aquatic ecosystems, including both marine and freshwater environments, ranging from locations in Europe (Baltic Sea, Britain, Georgia, Germany, Netherlands, Romania, and Spain), North American regions (including the Great Lakes and various regions within the United States) and has also been recorded in Victoria, Australia (Guiry, 2017). Temperature ramps were designed to contain four temperature changes (two decreases in temperature and two increases in temperature), with holding points after each temperature change, as depicted in Figure 1.1 and Figure 1.2 below. In order to assess the temporal response on fatty acid composition due to temperature fluctuation, two temperature treatment ramps were designed based on environmental values. Temperature ramp \#1 (Fig. 1.1) focuses on the effects that short term temperature fluctuation may have on fatty acid composition, with each temperature held for 48 hour periods and a maximum temperature of $28^{\circ} \mathrm{C}$ before being lowered to the initial temperature of $22^{\circ} \mathrm{C}$. Temperature ramp \# 2 (Fig 1.2) focused on the effects that long term maintenance of elevated temperatures may have on algal fatty acid composition, with the maximum temperature of $28^{\circ} \mathrm{C}$ held for a two week period before being lowered. To assess the temporal effects that temperature has on fatty acid composition, particularly the rate of shifts, samples were collected at designated time points. 


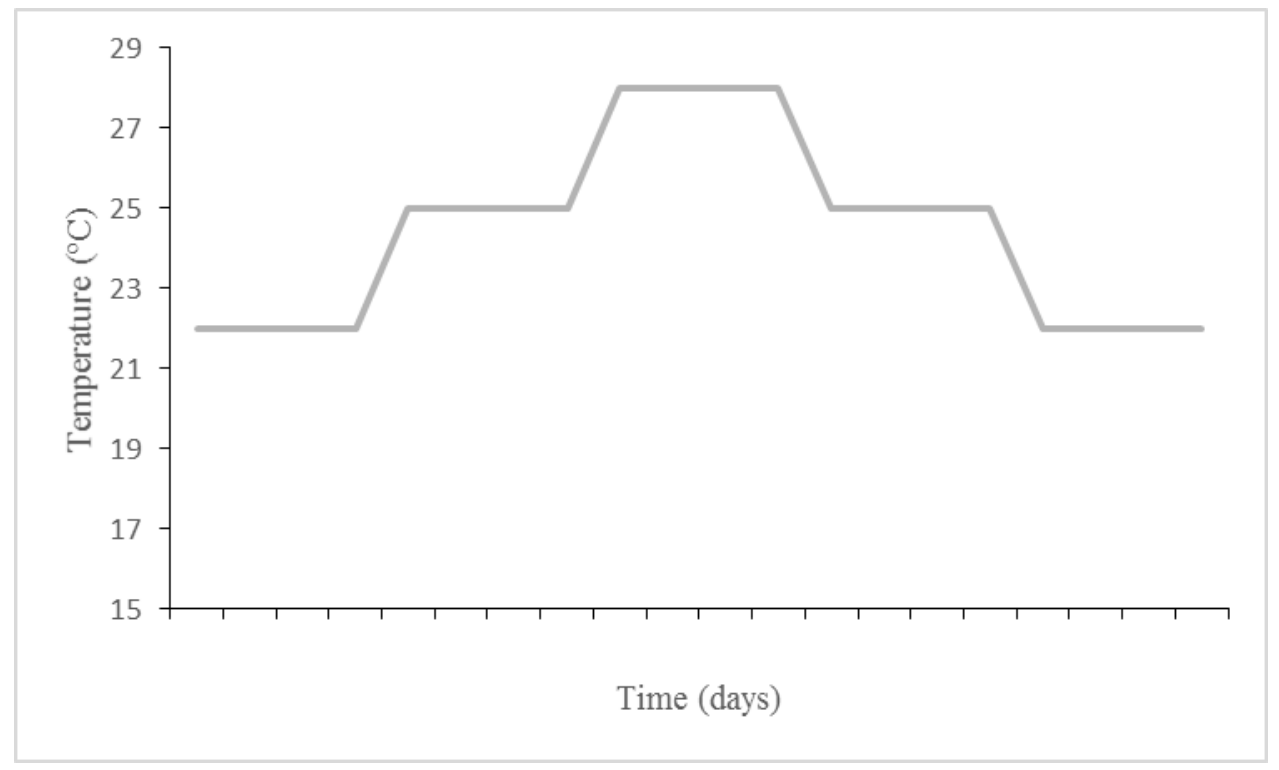

Figure 1.1: A schematic representation of the short-term temperature ramp including two increasing temperature steps and two decreasing temperature steps

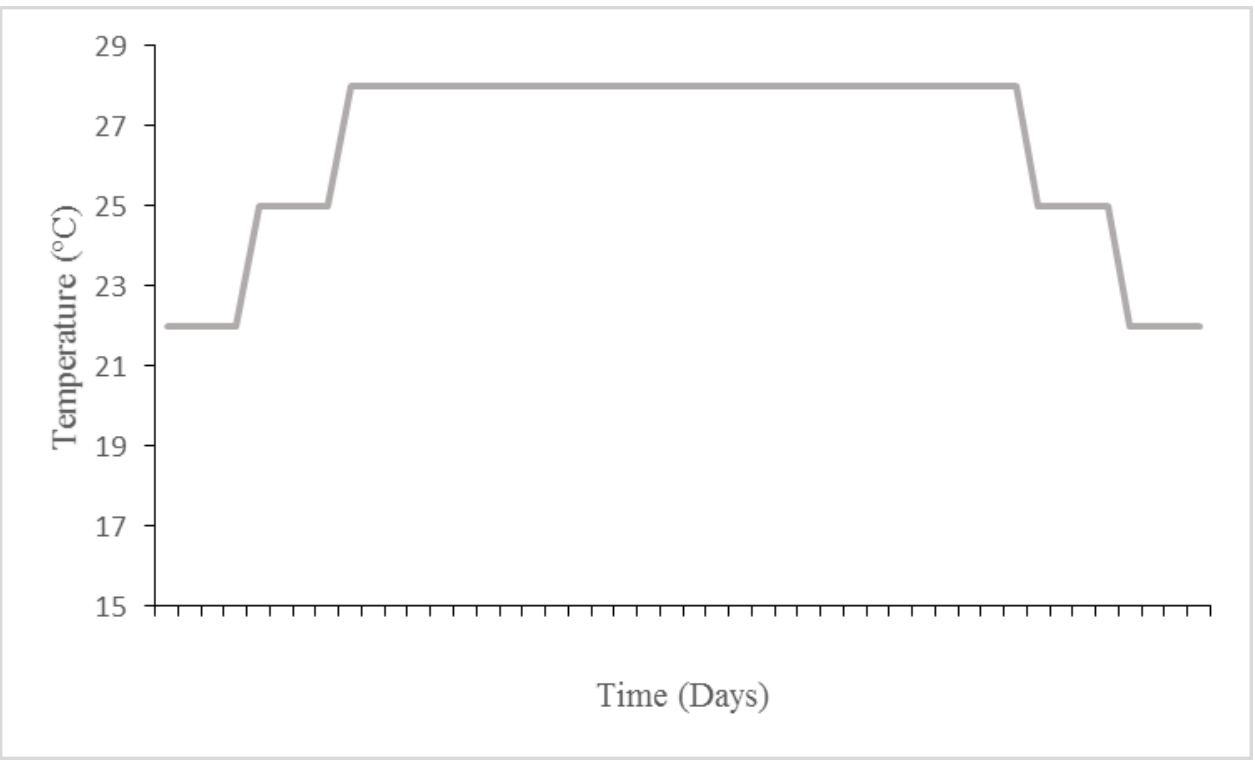

Figure 1.2: A schematic representation of the long-term temperature ramp, including two increasing temperature steps, a long holding period at the maximum temperature of $28^{\circ} \mathrm{C}$, followed by two decreasing temperature steps

I hypothesized that as a result of increasing temperatures in Temperature Ramp \# 1, there would be a decrease in LC-PUFA content in collected samples in order to maintain membrane fluidity at elevated temperatures. I expected that the fatty acid profile would not change 
immediately in response to the temperature change but would show the majority of change before the $24 \mathrm{~h}$ mark with a plateau of change occurring at $24 \mathrm{~h}$ onwards. Previous research (Fuschino, 2010) suggested that fatty acid content plateaus at the $24 \mathrm{~h}$ mark after temperature change. The net response of fatty acid composition as a response to temperature and time has three options (Figs. $1.3-1.5$ ). The change in fatty acid composition from the temperature ramp can be symmetrical resulting in no change in total fatty acid availability after ramping (Fig. 1.3). In non-symmetrical cases, there will either be a net decrease in PUFA (Fig. 1.4) or net increase in PUFA (Fig. 1.5). I also hypothesized that when the temperature is lowered after the $28^{\circ} \mathrm{C}$ holding point in Temperature Ramp \# 1 that there will be a non-symmetrical response in fatty acid composition change resulting in a net loss in LC-PUFA and gain in SFA (Fig. 1.4) caused by thermal stress. From Temperature Ramp \# 2, I hypothesized that there will be higher net losses of PUFA and a highly asymmetrical response in fatty acid composition during the two week holding period at $28^{\circ} \mathrm{C}$ due to thermal stress caused by the extended high heat period. Furthermore, I expected when the temperature is subsequently lowered after this period that there will be a net loss in LC-PUFA (Fig. 1.4) due to a decreased response of fatty acid composition change as a result of long term heat exposure. 


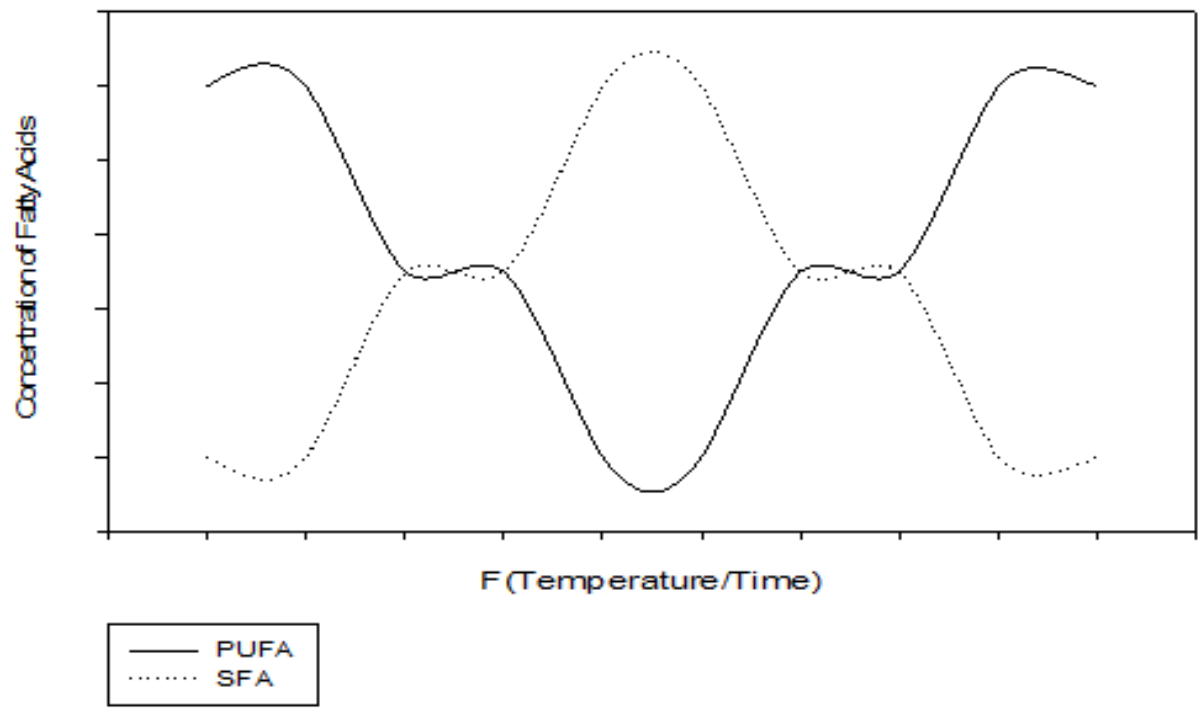

Figure 1.3: Schematic representation of symmetrical fatty acid concentration changes as a function of temperature and time combined resulting in no net gain or net loss of fatty acids. 


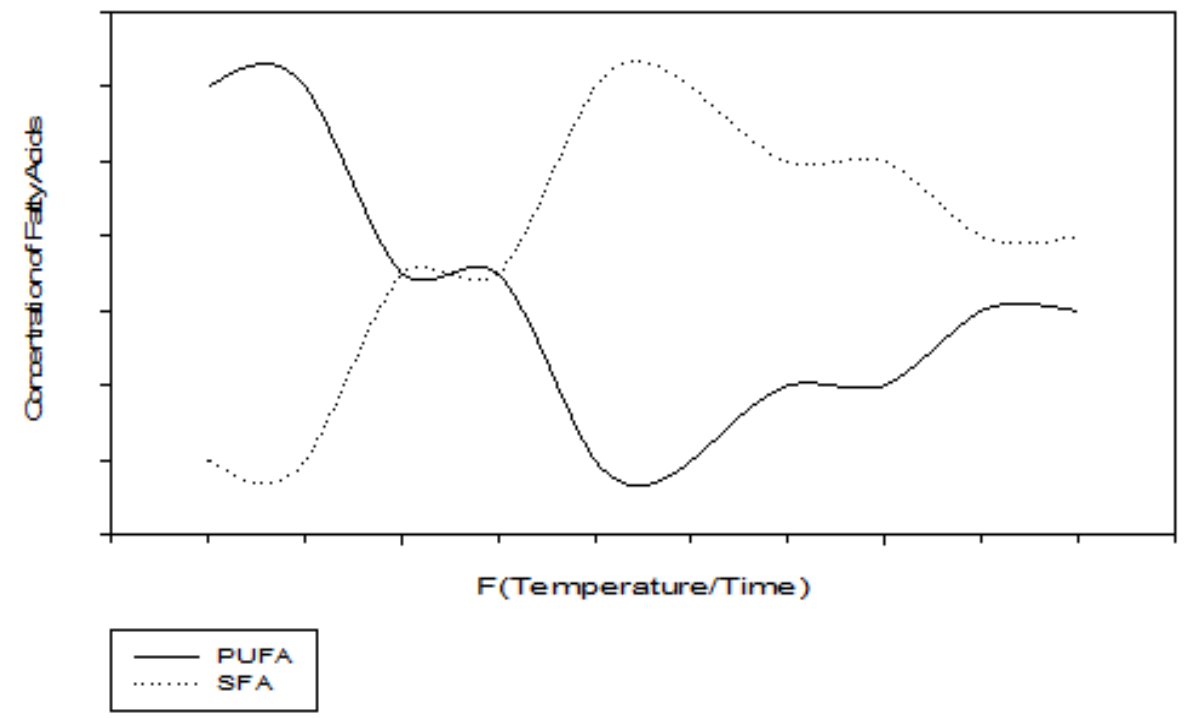

Figure 1.4: Schematic representation of asymmetrical fatty acid concentration changes as a function of temperature and time combined resulting in a net loss of PUFA concentrations and net gain of SFA

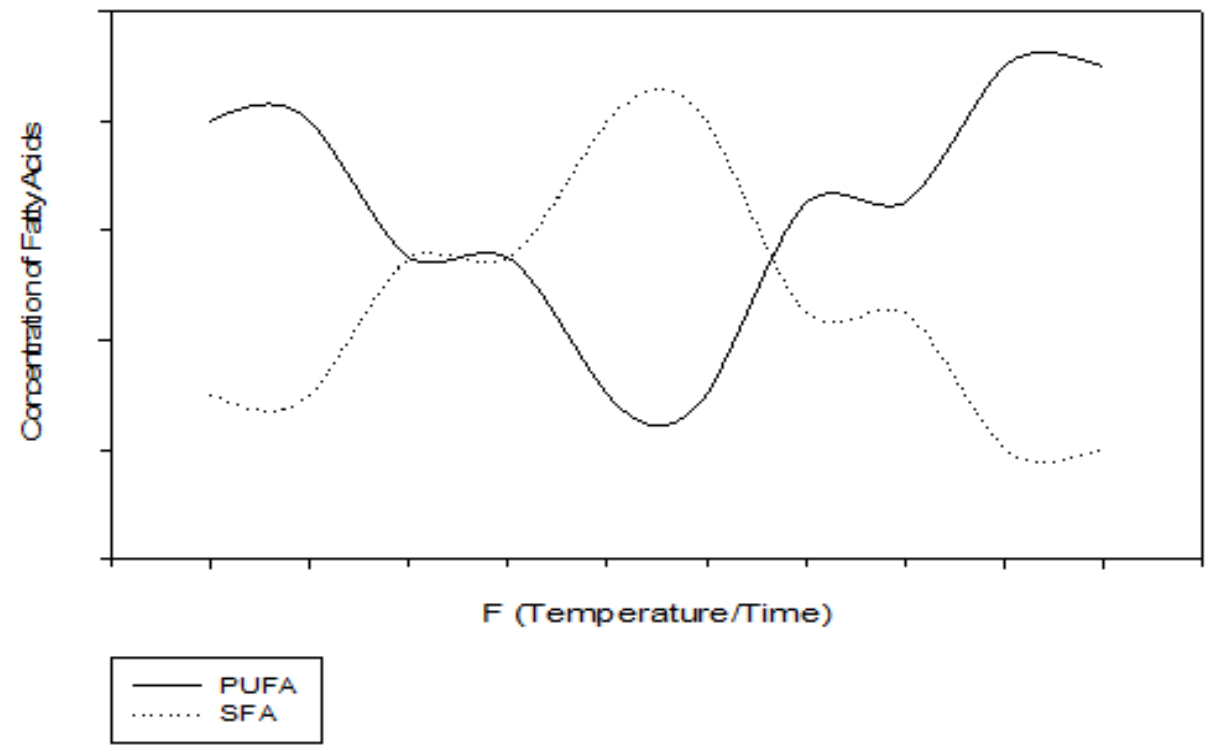

Figure 1.5: Schematic representation of asymmetrical fatty acid concentrations function of temperature and time combined resulting in a net gain in PUFA concentrations and net loss in SFA concentrations

Along with fatty acid analysis, diatom population growth rates were studied in response to the temperature change. Growth curves were constructed by measuring the absorbance using a spectrophotometer, and were further supported by performing cell counts. Measuring the rate of growth at each temperature allowed me to see further responses of $N$. pelliculosa to elevated 
temperatures. I hypothesized that there will be a decrease in growth rate in response to elevated temperature due to sub-optimal growth conditions, such as growth temperatures of $28^{\circ} \mathrm{C}$ (see Appendix 1 for information on growth temperatures of $N$. pelliculosa).

Due to the effects that climate change has on temperatures in freshwater systems, it is critical to determine how this will affect algal populations, and especially the LC-PUFA producing algal populations such as diatoms. A net decrease in LC-PUFA after temperature fluctuations would mean that there is decreased availability of LC-PUFA to other organisms. Decreased availability in lower trophic levels has the potential to result in decreased LC-PUFA concentrations in aquatic organisms (i.e. fish and clams) that humans rely on for dietary requirements of long chain omega-3 fatty acids. Determining the effect that water temperature will have on algal fatty acid composition will give us a better understanding of overall fatty acid availability globally. 


\section{Chapter 2}

\section{The Effects of Fluctuating Water Temperatures and Time on}

\section{Fatty Acid Content in Navicula pelliculosa}

\section{Introduction}

In aquatic ecosystems, algae serve as a source of energy and nutrients to primary producers and several tiers of consumers (Hixson et al., 2015; Gladyshev et al., 2009; Kainz et al., 2004). Algae have the necessary biochemical activity to synthesize essential fatty acids and are the dominant producers of long-chain polyunsaturated fatty acids (LC-PUFA; Peng et al., 2014; Pereira et al., 2004). As a result, aquatic ecosystems are a primary source of LC-PUFA (Colombo et al., 2016; Hixson et al., 2015). Fatty acid (FA) content varies across algae taxa. Characteristically, diatoms, cryptophytes, and dinoflagellates contain high amounts of eicosapentaenoic acid (EPA; 20:5n-3) and docosahexaenoic acid (DHA; 22:6n-3) (Burns et al., 2011; Ahlgren et al., 1990). FA are transferred up trophic levels in the aquatic food web, from primary producers (algae) to primary consumers (such as aquatic invertebrates), facilitating the transfer of energy to higher consumers (Parrish, 2013; Gladyshev et al., 2008). LC-PUFA contribute to the physiological health of vertebrates including promoting growth, reproduction and development (Citation). However, vertebrates have limited capacity to synthesize LC-PUFA from the metabolic precursors to meet their physiological requirements, and therefore often rely on dietary sources for pre-formed LC-PUFA (Gladyshev et al., 2013).

FA are incorporated into membranes where they contribute to membrane fluidity (Hazel and Williams, 1990). Homeoviscous adaptation is the process by which FA content is modified 
in response to temperature to maintain optimal membrane fluidity (Hazel and Williams, 1990; Sinensky, 1974). Membrane function is dependent on maintaining fluidity and preventing hyperfluid or rigidity from occurring (Sperfield and Wacker, 2010; Mikami and Murata, 2003). To prevent hyper-fluid or rigid membranes, different FA are incorporated at varying temperatures, based on the characteristics of the FA (Guschina and Harwood, 2009). Melting points of FA are influenced by the degree of unsaturation and chain length (Marsh, 2010). PUFA have lower melting points, making them dominant in cell membranes at lower temperatures, while saturated fatty acids (SFA) have higher melting points, making them dominant at higher temperatures (Gladyshev et al., 2015; Usui et al., 2012; Murray et al., 2010). Due to the melting points of FA, short saturated FA are incorporated into membranes at higher temperatures in order to maintain membrane fluidity and function (Marsh, 2010).

Climate warming is accelerating due to anthropogenic emissions and natural pressures (Root and Schneider, 2006; Crowley, 2000). Temperature increases have been seen in surface air and water temperatures (Woodward et al., 2010; Prowse et al., 2006). Surface water temperatures in some instances have increased by $2.9^{\circ} \mathrm{C}$ from 1979 to 2006 (Austin et al., 2007). Increased water temperatures are expected to have impacts on biological activity by disrupting organisms' physiology and biochemistry (Renaud et al., 2002; Davison, 1991). Since PUFA are found in lower proportions at higher temperatures due to membrane fluidity maintenance (Gladyshev et al., 2015; McMeans et al., 2015), there is a potential for an overall decrease in PUFA availability as a result of climate change.

In this experiment, I examined the effects that temporally fluctuating water temperatures, as would be observed in a natural shallow freshwater pond, have on FA content in the freshwater diatom, Navicula pelliculosa. The freshwater diatom, N. pelliculosa, is a common and widely 
distributed species, is easy to maintain a culture, and produces the LC-PUFA of interest: EPA and DHA. Although previous studies on algal species examined the effects that temperature has on growth and FA content, there is a critical gap in knowledge of understanding the rate at which FA content changes in response to temperature changes and to the effects of different temperature environments (e.g. simulated short and long heat waves). Examining the effects of time on FA content changes, allowed me to determine, a) the rate at which FA content changes in response to temperature; and, b) whether FA content eventually reaches a plateau. For the purpose of this experiment, I examined the effects of temperature and time on the sum of saturated fatty acids (SFA), monounsaturated fatty acids (MUFA) and polyunsaturated fatty acids (PUFA). Specifically, I also examined two MUFA: palmitoleic acid (16:1n-7), a MUFA that dominates diatom FA composition (Fahl and Kattner, 1993), and oleic acid (18:1n-9), a FA that can be used as a taxonomic biomarker in algal species (Sahu et al., 2013). I also examined two PUFA groups, EPA and DHA, due to their important role as a dietary resource in the health of other organisms.

The objective of this experiment was to determine the rate at which $N$. pelliculosa adjusts its FA content in response to temperature changes. Preliminary research, using a green alga, has shown that FA content changes temporally in response to temperature changes (Fushino, 2010). In general, once a peak temperature is reached, the adjustment of FA content over time may not occur at equivalent rates before and after the temperature change, creating an asymmetrical distribution in FA content over time and temperature. Alternatively, there is also the possibility that FA content changes at equivalent rates before and after a temperature change, resulting in a symmetrical distribution over time and temperature. Previous research has shown the relationship between elevated temperatures and increased SFA proportions and decreased PUFA 
proportions, but has not examined the effect that time has on the rate at which FA proportions change, or the effect that an increase in temperature followed by a subsequent decrease in temperature has on the net FA content. I hypothesized that in response to exposure to a 10-day regime of temperature changes, there would be: a) a net loss in LC-PUFA (EPA and DHA); b) a net gain in SFA as a response to thermal stress; and c) a shift in FA content within the first $24 \mathrm{~h}$.

\section{Methods}

In order to assess the effect that temperature change has on FA composition in algae, a temperature treatment was designed based on environmental temperature variation in the Spring/Summer of 2015 in the surface waters of a freshwater pond at Koffler Scientific Reserve (King City, Ontario, 44.029590, -79.531553). A common freshwater diatom, N. pelliculosa, was used in temperature treatments in order to determine the temporal response and net FA content (i.e.: symmetrical vs. asymmetrical responses) in both increasing and decreasing temperature treatments.

\section{Culturing of Navicula pelliculosa (CPCC 552)}

The diatom, N. pelliculosa (obtained from Canadian Phycological Culturing Centre, CPCC 552) was used in all temperature treatments. Cultures were grown in CHU-10 media (see Appendix 1) on a $24 \mathrm{~h}$ light cycle (average light intensity of $184 \mu \mathrm{mol}$ photons $\mathrm{m}^{-2} \mathrm{~s}^{-1}$ ) in a VWR Signature Diurnal Growth Chamber (Model 2015). A $24 \mathrm{~h}$ light cycle was used for culturing conditions in order to minimize the influence of light on FA composition (Sicko-Goad et al., 1991). The diatom, $N$. pelliculosa was cultured in batches of $250 \mathrm{~mL}$ in glass Erlenmeyer flasks with cellulose stoppers and were stirred once every $48 \mathrm{~h}$. Cultures were grown at ideal conditions of $22^{\circ} \mathrm{C}$ (see Appendix 1) prior to exposure to temperature treatments. A population 
growth curve using optical density (OD) readings was generated with a spectrophotometer for $N$. pelliculosa under these conditions in order to ensure that cultures were in exponential phase during collection periods. Growth curves were constructed using average OD readings at $685 \mathrm{~nm}$ (chlorophyll absorbance range) and age of the culture. OD readings at $685 \mathrm{~nm}$ were plotted against the age of the culture from inoculation date in days.

\section{Temperature Ramp Design}

Temperature ramps were designed to simulate spring/summer temperature variation seen in shallow freshwater bodies. Temperature data was collected hourly using a HOBO TidBit v2 Water Temperature Data logger (model UTBI-001) in the surface waters of a freshwater pond at Koffler Scientific Reserve from June 2015 to September 2015. In order to ensure that temperature patterns seen in the pond at KSR were representative of freshwater bodies in the spring/summer, data from Lakes Environmental Association (L.E.A) on a group of lakes in Maine, United States of America, was compiled into a database representing temperature patterns seen from 2013 to 2015 seasons. Comparison of 2015 KSR data to 2013-2015 L.E.A data (Appendix 2) allowed me to confirm that the temperature treatment pattern we choose was representative for freshwater surface waters. Temperature data collected from the L.E.A database showed an average maximum water temperature of $28^{\circ} \mathrm{C}$ during the summer months.

While mid- to late-summer temperatures showed the most extreme temperature points and patterns (with a maximum of $32.6^{\circ} \mathrm{C}$ being reached at the end of July at the KSR pond, surface waters $\sim 20 \mathrm{~cm}$ depth and a minimum of $18.6^{\circ} \mathrm{C}$ being reached in June and at the beginning of September), treatment temperatures were based on those observed in early-mid June. Temperature data collected from the L.E.A database showed an average maximum water temperature of $28^{\circ} \mathrm{C}$ during the summer months. While this is lower than the maximum 
temperatures observed in the pond at KSR, the lakes and ponds part of the L.E.A database were often much larger in size and deeper resulting in differences in water temperature potentials. This was done because diatoms typically bloom in spring and fall due to silica and high light availability, and it would be unrealistic to expose a diatom to temperatures experienced in late July. In order to create a more environmentally-realistic temperature treatment regime, temperatures values recorded in June were chosen to account for seasonality of diatoms and also to not expose $N$. pelliculosa to unreasonable conditions. The temperature treatments were designed to represent a simplified pattern of what is seen with increasing and decreasing temperatures. Our simplified temperature ramp has $48 \mathrm{~h}$ periods of holding designated temperatures constant. After the holding periods, temperatures were increased and decreased in $3^{\circ} \mathrm{C}$ increments from 22 to 25 to $28^{\circ} \mathrm{C}$, or from 28 to 25 to $22^{\circ} \mathrm{C}$ (Fig. 2.1). During each $48 \mathrm{~h}$ holding period, sample collection occurred. The control condition was designated to be $22^{\circ} \mathrm{C}$ due to the optimal growth seen at this temperature (Appendix 1). 


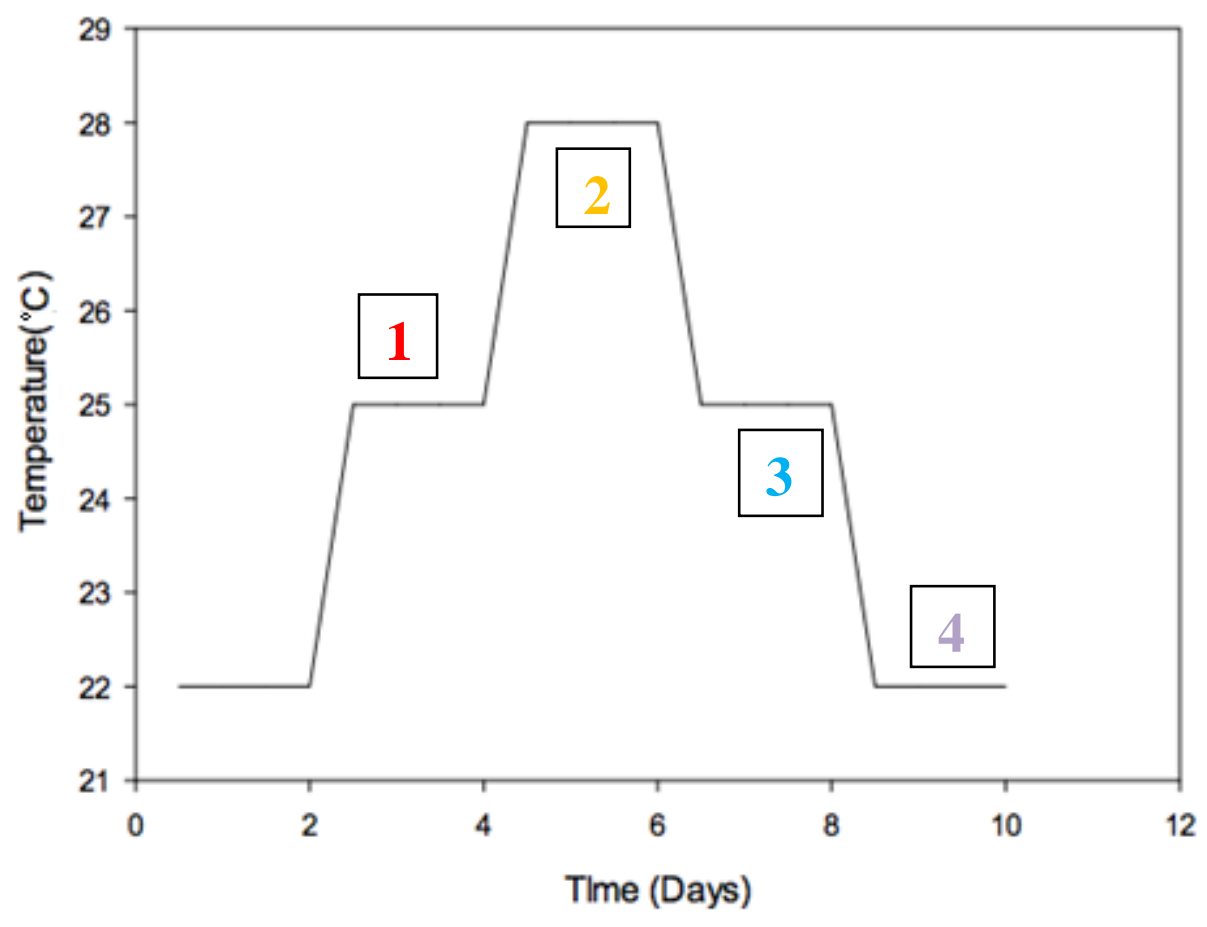

Figure 2.1: Short-term temperature ramp including temperature holding periods of 48 hours. The temperature treatments are broken into two increasing temperature steps: \#1 $\left(22-25^{\circ} \mathrm{C}\right)$ and \#2 $\left(25-28^{\circ} \mathrm{C}\right)$, followed by two decreasing temperature steps: \#3 $\left(28-25^{\circ} \mathrm{C}\right)$ and $\# 4\left(25-22^{\circ} \mathrm{C}\right)$

\section{Sample Collection}

Samples were collected at designated time points at each temperature change. Each time the temperature was increased/decreased, samples were collected at 2, 4, 6, 12, 24 and $48 \mathrm{~h}$. In order to ensure that sample collection was occurring at the desired water temperature and to account for the lag period between changes in air temperature and water temperature, water temperature was measured until the desired temperature point was reached. When culture temperatures reached the necessary temperature, the timer for sample collection was set in order to ensure that cultures were exposed to the new temperature for the necessary time. Due to my prediction that the majority of FA content changes will occur within the first $24 \mathrm{~h}$, more sampling points are concentrated at the beginning of the temperature ramp in order to observe 
the time it takes for a response to be seen. Preliminary research using a green algae species showed sums of FA groups reaching a plateau within $24 \mathrm{~h}$ (Fuschino, 2010). However, this preliminary research involved a more drastic temperature change. Since my temperature treatments are moderate, it would be expected that the changes could reach a plateau earlier than was shown in the preliminary work found in Fuschino (2010). Other research (Rousch et al., 2003) had shown that little change was seen in FA content after two hours of exposure to a temperature change. Due to this it was expected that the most significant changes in FA composition would occur in-between 6 and $12 \mathrm{~h}$ into the temperature change. Once water temperatures were held for respective time based on temperature step and time sampling point, three culture replicate flasks were removed. Cultures were centrifuged in $15 \mathrm{~mL}$ Kimax tubes at $2000 \mathrm{rpm}$ to concentrate algal cells into a pellet. Before centrifugation, a sample $(3 \mathrm{~mL})$ of each culture is used for a spectrophotometer (Perkin Elmer Lambda 20, absorbance readings at 800 $500 \mathrm{~nm}$ ) reading in order to obtain the OD for cell counts. Algal cell pellets were then transferred to cryovials and samples were freeze dried in preparation for total lipid and FA analysis.

\section{Lipid and Fatty Acid Analysis}

Freeze dried cells were placed into $15 \mathrm{~mL}$ Kimax tubes and dry weights were recorded. Total lipids were extracted using a modified Folch et al. (1957) method. Samples were extracted using $4 \mathrm{~mL}$ of 2:1 (v/v) chloroform-methanol and polar impurities were removed by adding 800 $\mu \mathrm{L}$ of $\mathrm{KCl}(0.88 \%$ in water). Samples were then centrifuged for $5 \mathrm{~min}$ at $2000 \mathrm{rpm}$ and the lower phase was transferred to a new tube. $3 \mathrm{~mL}$ of the theoretical lower phase $(86: 14: 1$ chloroformmethanol-water) was added to the original tube and samples were vortexed and centrifuged a second time for $5 \mathrm{~min}$ at $2000 \mathrm{rpm}$. The lower phase was transferred to the other tube, combining 
with the previous volume collected. An internal standard, unmethylated C23:0 (tricosylic acid) was added in order to determine methylation efficiency during transesterification of the FA.

Samples were evaporated under nitrogen gas and then $1 \mathrm{~mL}$ of hexane and $2 \mathrm{~mL}$ of $1 \%$ $\mathrm{H}_{2} \mathrm{SO}_{4}$ was added. Tubes were capped under $\mathrm{N}_{2}$ stream and then heated in the heat block for 90 min at $90^{\circ} \mathrm{C}$. After heating, $1.5 \mathrm{~mL}$ of milliQ water and $4 \mathrm{~mL}$ of hexane was added and tubes were centrifuged for $3 \mathrm{~min}$ at $2000 \mathrm{rpm}$. The upper phase was then transferred to a new tube. Fatty acid methyl esters (FAME) were extracted for the second time by adding $4 \mathrm{~mL}$ of hexane and centrifuging again. The upper phase was then transferred to the other tube, combining with the previous volume collected. Samples were evaporated to near dryness under $\mathrm{N}_{2}$ and $300 \mu \mathrm{L}$ of hexane was added. Samples were then transferred to GC vials and FAME were separated using a Shimadzu gas chromatograph (GC)-2010 Plus with a Supelco SP2560 column. Identification of was performed by comparing peak retention times with those of the FAME37-standard. Quantification of FAME was done using an external standard curve.

\section{Statistical Analysis}

\section{MANOVA}

To assess the effects that time and temperature and FA group/type had on FA composition for all FA groups (i.e. there were multiple dependent measures), a multivariate analysis of variance (MANOVA) was used. Time was set as a categorical predictor with six time categories representing the six sampling points $(t=2, t=4, t=6, t=12, t=24, t=48)$. Temperature treatments were used as a categorical variable as well with the four temperature treatments representing each temperature change that occurred $\left(22-25^{\circ} \mathrm{C}, 25-28^{\circ} \mathrm{C}, 28-25^{\circ} \mathrm{C}, 25-\right.$ $22^{\circ} \mathrm{C}$ ). Data were transformed using a $\log 10$ transformation to normalize the data. The MANOVA allowed us to examine the effects that temperature treatment and time had on FA 
group sums (SFA, MUFA, and PUFA), and also to examine the effects that temperature treatment and time had on select FA of interest (18:0, 16:1n-7, 18:1n-9, EPA and DHA). Two MANOVA was performed using SPSS 24. The first MANOVA used FA group as a categorical predictor using the sum FA groups (SFA, MUFA, and PUFA). The second MANOVA used FA type as a categorical predictor for the individual fatty acids $(18: 0,16: 1 \mathrm{n}-7,18: 1 \mathrm{n}-9$, EPA and DHA). The follow up univariate analyses (ANOVA) and Tukey post-hoc tests allowed me to examine the effects that temperature treatment and time had on FA group sums (SFA, MUFA and PUFA) and also on select fatty acids of interest (18:0, 16:1n-7, 18:1n-9, EPA and DHA).

\section{Repeated Measures ANOVA}

A repeated measures ANOVA was used to take into consideration how the FA of interest responded through time and temperature treatment. FA content was measured repeatedly through the temperature treatments across six different time points. FA content across the six sampling times was defined as the within-subjects variable. Temperature treatment and FA group/type were used as categorical variables for between subject factors. Data was transformed using a $\log 10$ transformation in order to normalize the data. This allowed me to analyze the effects that temperature treatment and time had on FA group sums (SFA, MUFA, PUFA) and select FA of interest (18:0, 16:1n-7, 18:1n-9, EPA and DHA). The repeated measures ANOVA was performed using SPSS 24. The repeated measures ANOVA also examined the interactions between time and temperature, time and FA group/FA type and between time, temperature and FA group/type. Two repeated measures ANOVA were performed. The first repeated measures ANOVA used FA group as a categorical variable for between-subject factors. The second repeated measures ANOVA used FA type as a categorical variable for between-subject factors. 
By controlling for time, an overall effect of temperature, FA group/type and a combination of temperature and FA group/type was calculated.

\section{Initial and Final Fatty Acid Content Comparison}

To assess the effect that the entire temperature regime had on overall FA composition, $\mathrm{t}$ tests for each group/FA was performed between a pooled sample of the first three time points at step \#1 of the temperature ramp $(t=0, t=2$ and $t=4)$ and a pooled sample of the last three time points at the end of the ramp $(\mathrm{t}=12, \mathrm{t}=24, \mathrm{t}=48$ at step \#4) using SPSS Statistics 24 . For MUFA, since no distinctive pattern in response to temperature has been witnessed in past research, a twotailed t-test was performed. From previous research, SFA content increases and PUFA content decreases as temperature increases (Pasquet et al., 2014). For SFA and PUFA, since a distinctive relationship with temperature is known, a one-tailed t-test was performed.

\section{Skewness}

Skewness calculations were performed using the Microsoft Excel SKEW function in order to determine the symmetry of the distribution of FA and sums of FA groups (SFA, MUFA, PUFA) over time and temperature independently. Skew calculations were performed using the average values for specific FA (16:1n-7, 18:1n-9, EPA and DHA) and sums of FA (SFA, MUFA, PUFA) and were performed for time independence and temperature independence. Time-independent skew calculations used the same time point (i.e. $\mathrm{t}=2$ ) across all the temperature treatments. Temperature-independent skew calculations used the same temperature step across all the time sampling points. Negative skew values were designated as asymmetrically left-skewed. Positive skew values were designated as asymmetrically right- 
skewed. Values falling with between -0.5 to 0.5 were designated as symmetrical. Values exceeding -1 or 1 were designated as highly asymmetrical.

\section{Curve Fitting}

Using the Dynamic Fit Wizard function in SigmaPlot, cubic polynomial curves were fitted to temperature and time independent FAME content values. A cubic polynomial distribution was chosen due to the high $\mathrm{R}^{2}$ values and the overall shape of the distribution across time or temperature. In situations where the p-value was determined to be significant, average FAME content values were used to determine $\mathrm{R}^{2}$ values for the curve.

\section{Results}

\section{MANOVA}

Temperature treatment, time, and a combination of time and temperature all had significant effects on the sum groups of FA (Table 2.1). This shows that individually time $(\mathrm{p}<0.001)$ and temperature $(\mathrm{p}<0.001)$ affect fatty acid content and that as a combined effect they interact to influence fatty acid content $(\mathrm{p}=0.005)$. When examining the individual FA of interest (EPA, DHA, 16:1n-7, 18:1n-9 and 18:0) time $(\mathrm{p}<0.001)$, temperature treatment $(\mathrm{p}<0.001)$ and time and temperature combined $(\mathrm{p}<0.001)$ were all found to significantly influence fatty acid content (Table 2.2). It was found that temperature and time combined results in the overall trend of increased SFA content and decreased PUFA and MUFA content with increasing temperatures often resulting in net losses for MUFA and PUFA.

A univariate analysis showed that SFA ( $\mathrm{p}=0.094$ ) was not significantly influenced by temperature indicating that SFA content has no significant net difference in temperature treatments (Table 2.3). Although SFA as a group were not found to have a significant change as a result of temperature independently, 18:0 $(\mathrm{p}=0.010)$ showed a significant change as a result of 
temperature change, showing increases in 18:0 content with temperature increases and decreased content with temperature decreases. However, MUFA $(\mathrm{p}=0.002)$ and PUFA $(\mathrm{p}=0.002)$ were significantly affected by temperature. This indicates that MUFA and PUFA are more susceptible to alteration as a result of temperature. MUFA showed increases in content as a result of temperature decreasing steps $\left(28-25^{\circ} \mathrm{C}, 25-22^{\circ} \mathrm{C}\right)$ and decreases in content as a result of temperature increasing steps $\left(22-25^{\circ} \mathrm{C}, 25-28^{\circ} \mathrm{C}\right)$. PUFA also showed decreases in content with temperature increases, resulting in up to $67.4 \%$ decreases in PUFA content after the temperature increasing steps. PUFA content was found to increase with temperature decreasing steps, however still resulted in a 55\% net loss from initial conditions. Post-hoc tests further confirmed this showing that temperature treatments in PUFA elicited a significant difference in PUFA content potentially influencing the overall effect of differences observed. Differences found between temperature treatment $1\left(22-25^{\circ} \mathrm{C}\right)$ and temperature treatment $4\left(25-22^{\circ} \mathrm{C}\right)$ showed significant differences $(\mathrm{p}=0.076)$ in SFA further supporting the significance seen in differences between initial and final conditions resulting in a net $2.3 \%$ increase from initial conditions. MUFA also showed significant differences between temperature treatment 1 (22 $\left.25^{\circ} \mathrm{C}\right)$ and treatment $3\left(28-25^{\circ} \mathrm{C}\right)(\mathrm{p}=0.002)$ resulting in an $11.8 \%$ increase in MUFA content from initial conditions and treatment $4\left(25-22^{\circ} \mathrm{C}\right)(\mathrm{p}=0.014)$ resulting in a $39.4 \%$ decrease in comparison to initial conditions. This also supports the asymmetrical response resulting in net losses of MUFA after temperature treatment. PUFA were found to have significant differences when comparing temperature treatment $1\left(22-25^{\circ} \mathrm{C}\right)$ to treatment $2\left(25-28^{\circ} \mathrm{C}\right)(\mathrm{p}=0.009)$ resulting in a $13.5 \%$ decrease, treatment $3\left(28-25^{\circ} \mathrm{C}\right)(\mathrm{p}=0.003)$ resulting in a $79.1 \%$ decrease and treatment $4\left(25-22^{\circ} \mathrm{C}\right)(\mathrm{p}=0.033)$ resulting in a $55 \%$ decrease and an overall net loss in PUFA. This further supports the net loss and asymmetrical response that is seen in PUFA across 
all temperature treatments. Specifically, EPA $(\mathrm{p}=0.005)$ and DHA $(\mathrm{p}=0.001)$ were found to be significantly different as a result of temperature independently. EPA content was found to decrease in both temperature increasing steps and still experience net losses during temperature decreases. DHA was also found to experience decreases in content with temperature increases. However, DHA experienced a higher recovery rate than EPA and did not result in as large of a net loss. 16:1n-7 ( $\mathrm{p}=0.031)$ and 18:1n-9 $(\mathrm{p}<0.001)$ were also found to change significantly as a result of temperature changes exhibiting the same trends seen in total MUFA.

A univariate analysis on the effects of time on FA content (Table 2.4) revealed significant results only for MUFA $(\mathrm{p}=0.006)$ and SFA $(\mathrm{p}=0.015)$. SFA showed a $2.3 \%$ net increases in content with time and MUFA resulted in a 39.4\% net decrease with time. 18:0 ( $p=0.01), 16: 1 n-7$ $(\mathrm{p}=0.031)$ and $18: 1 \mathrm{n}-9(\mathrm{p}<0.001)$ were all found to have significant decreases in content as a result of time independently, further supporting the changes seen in their respective summary groups. This indicates that time independently does not significantly alter PUFA $(\mathrm{p}=0.066)$ content resulting in similar content values across time indicating that temperature has a larger effect on PUFA content than time. EPA $(p=0.005)$ and DHA $(p=0.001)$ both showed significant decreases as a result of time producing a net loss in EPA and DHA content. This indicates that certain FA may have different response rates and that other PUFA may not be as strongly influenced. Post-hoc analysis further confirmed this, producing non-significant results between the majorities of time treatments across FA groups. This indicates that time independently does not have a large effect on FA content differences.

Further examination of Tukey post-hoc analysis for the effects of time showed significant differences at $\mathrm{t}=6$. SFA showed a significant difference between $\mathrm{t}=6$ and $\mathrm{t}=4(\mathrm{p}=0.011)$ resulting in SFA content decreases and $\mathrm{t}=6$ and $\mathrm{t}=12(\mathrm{p}=0.03)$ resulting in SFA content increases. This in 
combination with the post-hoc analysis on temperature treatment suggests that $t=6$ is the critical time point required for FA content to adjust to new temperature conditions. MUFA also showed a significant decrease between $\mathrm{t}=2$ and $\mathrm{t}=6(\mathrm{p}=0.043)$, and $\mathrm{t}=4$ and $\mathrm{t}=6(\mathrm{p}=0.002)$. The trend is further seen with PUFA between $\mathrm{t}=6$ and $\mathrm{t}=4(\mathrm{p}=0.047)$ resulting in PUFA content decreases between the two time points. The differences observed in FA content in the initial time points and $t=6$ suggests that after approximately 6 hours, the majority of FA content change has occurred and that the content value has begun to plateau. DHA only showed a significant decrease in content between $\mathrm{t}=6$ and $\mathrm{t}=2(\mathrm{p}=0.001)$ which further supports the theory that DHA content is constantly conserved for physiological needs.

\section{Repeated-Measures ANOVA}

Out of the potential effectors and combinations of different effectors, time $(\mathrm{p}<0.001)$ and a combination of time and temperature $(\mathrm{p}=0.022)$ produced significant changes in FA content (Table 2.5). PUFA content was seen to decrease with time and also experience a net loss in PUFA content as a result of temperature and time. At the first temperature increase, PUFA showed an $11.1 \%$ decrease in content. PUFA resulted in a $48.5 \%$ decrease at the second temperature increase between $\mathrm{t}=2$ and $\mathrm{t}=48$. During the first temperature decrease, PUFA resulted in a $42.1 \%$ increase from $t=2$ to $t=48$, followed by a $30 \%$ decrease from $t=2$ to $t=48$ at the second temperature decrease. SFA content was found to increase with temperature and also showed an overall net increase in SFA content. SFA at $\mathrm{t}=2$ and at $\mathrm{t}=48$ at $22-25^{\circ} \mathrm{C}$ showed a $15.6 \%$ increase in content. SFA at $\mathrm{t}=2$ and $\mathrm{t}=12$ at $25-28^{\circ} \mathrm{C}$ further showed a $14.6 \%$ increase in content. Proceeding to the third temperature treatment of $28-25^{\circ} \mathrm{C}$ at $\mathrm{t}=2$ and $\mathrm{t}=48$, a $17.7 \%$ increase in SFA content was observed. During the final temperature treatment, $25-22^{\circ} \mathrm{C}$ no net change was observed between $\mathrm{t}=2$ and $\mathrm{t}=48$ resulting in an overall net increase in SFA content. 
MUFA also experienced an overall net decrease in content as a function of temperature and time. During the first temperature treatment from $\mathrm{t}=2$ to $\mathrm{t}=48$, MUFA showed a $2.9 \%$ increase. However, following a second temperature increase at $\mathrm{t}=2$ and $\mathrm{t}=48$, MUFA showed a $66.3 \%$ decrease in content. Following the first temperature decrease from $t=2$ to $t=48$, MUFA showed a further increase of $40.4 \%$. The final temperature decrease resulted in a $13.4 \%$ decrease in MUFA content resulting in a total net loss in MUFA. This is likely due to the strong effect that time has on FA content and due to this, in combination with temperature it still results in significant changes. The large changes seen across time during each treatment contributes to the significant changes observed in FA content. However, the lack of significance seen in FA groups affecting FA content results in non-significant changes in FA content when combined with time $(\mathrm{p}=0.298)$ and as a combination of time, temperature and FA group ( $\mathrm{p}=0.906)$.

Temperature $(\mathrm{p}=0.618)$ and a combination of temperature and FA group $(\mathrm{p}=0.997)$ were found to be non-significant as an overall effect. SFA, MUFA and PUFA content at different temperatures when time is controlled did not show a significant net loss or net gain. This further supports the hypothesis that time contributes significantly to FA content (Table 2.6). Due to the non-significant changes produced by temperature independently this suggests that the significant change seen as a combined effect of temperature and time is largely driven by time. FA groups were also found to be significant $(\mathrm{p}<0.001)$ in affecting FA content. The significance of FA groups was expected due to the large difference seen in the FA profile of $N$. pelliculosa. The FA profile of $N$. pelliculosa is largely dominated by MUFA contributing to the significance of FA group.

When examining the potential effect of variables on specific FA (Table 2.7), significant differences were seen for every combination. As before, time $(\mathrm{p}<0.001)$ produced significant 
differences in FA content as well as when in combination with temperature $(\mathrm{p}<0.001)$. As a response to time, EPA and DHA content were seen to decrease resulting in net losses. From $\mathrm{t}=2$ to $\mathrm{t}=48$ at $22-25^{\circ} \mathrm{C}$, EPA content decreased by $20.4 \%$ and DHA content decreased by $79.4 \%$. Across time at $25-28^{\circ} \mathrm{C}$, EPA decreased by $75.8 \%$ and DHA content decreased by $56 \%$. During temperature decreases, EPA content increased by $50 \%$ followed by a $34.8 \%$ decrease resulting in a net decrease in EPA over time and temperature. DHA content increased by $33 \%$ at the first temperature decrease $\left(28-25^{\circ} \mathrm{C}\right)$ followed by a $38.6 \%$ decrease at the second temperature decrease $\left(25-22^{\circ} \mathrm{C}\right)$ resulting in an overall net decrease in DHA content. 16:1n-7 experienced a $34.8 \%$ net loss and 18:1n-9 experienced a $23.7 \%$ net loss as a result of temperature and time. 18:0 experienced a net increase by $96.3 \%$ as a result of temperature and time. Due to the importance of FA type in this analysis, there was a stronger significance seen when examining the effect that time and FA type $(\mathrm{p}<0.001)$ and time, temperature and FA type $(\mathrm{p}<0.001)$ has on changes in FA content. As with FA group, FA type contributes greatly to FA content due to the differences seen in the FA profile. Individual fatty acid changes have more significant changes over temperature treatments when examined individually, instead of as a group. For individual fatty acid types (Table 2.8), the overall effect of temperature was found to be significant $(\mathrm{p}=0.007)$. This suggests that individual FA have different abilities to respond to temperature changes and respond at different rates as seen with the variable differences in content changes presented above. As a response to temperature, SFA content experienced a net increase, MUFA content experienced a net decrease and PUFA content also experienced a net decrease.

\section{Initial and Final Fatty Acid Content Comparisons}

By comparing the first three time points $\left(\mathrm{t}=0, \mathrm{t}=2\right.$ and $\mathrm{t}=4$ at $\left.22-25^{\circ} \mathrm{C}\right)$ and the final three time points $\left(\mathrm{t}=12, \mathrm{t}=24, \mathrm{t}=48\right.$ at $\left.25-22^{\circ} \mathrm{C}\right)$, an overall effect of the 10 day temperature 
ramp on FA content can be determined (Table 2.9, Figs. 2.2 to 2.4). After performing a paired ttest, both PUFA $(\mathrm{p}=0.0105)$ and EPA $(\mathrm{p}=0.002)$ content showed a significant difference between initial and final content values indicating a decrease in PUFA content by 55\% and EPA content after the experimental period. MUFA ( $\mathrm{p}=0.009)$ content also showed a significant difference between initial and final content, and a decrease of $39.4 \%$ from initial content values.

Specifically, $16: 1 \mathrm{n}-7(\mathrm{p}=0.013)$ and $18: 1 \mathrm{n}-9(\mathrm{p}<0.001)$ both show significant differences between initial and final content and a decrease in 16:1n-7 and 18:1n-9 content after the experimental period. SFA content $(\mathrm{p}=0.0175)$ showed a significant difference between initial and final content indicating a net difference between initial values and final values. However, the saturated fatty acid, 18:0, did not show any significant difference $(\mathrm{p}=0.466)$ between initial and final content, indicating that other SFA may be experiencing a large change between initial and final content values. In comparison to initial conditions, there was a $2.3 \%$ increase in SFA content found at the end of all temperature treatments indicating an asymmetrical response and further supporting the significant change observed in the paired t-test. There was no significant difference in DHA content $(\mathrm{p}=0.436)$ between initial and final content values.

\section{Skewness}

The right skewed distribution at $\mathrm{t}=2, \mathrm{t}=6$ and $\mathrm{t}=48$ for SFA indicates a dominance of SFA during the first two steps of increasing temperatures during the temperature ramp (Table 2.10). The left-skewed asymmetrical distribution for SFA at $t=12$ and $t=24$ is indicative of higher SFA content values during the final two temperature decreasing ramp steps. The highly asymmetrical right-skewed distribution for MUFA seen at $\mathrm{t}=6, \mathrm{t}=12$, and $\mathrm{t}=24$ indicates a decrease in MUFA content during the final two decreasing temperature steps of the temperature ramps. Across $t=6$ (Fig. 2.5 for distributions at $\mathrm{t}=6$ ) for SFA, MUFA, PUFA, EPA, and DHA, there is a highly 
asymmetrical distribution. The right skewedness of PUFA and EPA is indicative of a decrease in content and availability as the temperature ramp steps proceed. The left skewedness of DHA at $\mathrm{t}=6$ (Fig. 2.6) indicates an increase in DHA content during the decreasing temperature steps of the ramp. The left skewedness of EPA at $t=24$ and $t=48$ indicates an increase in EPA content during the final two temperature decreases. The right skewedness of EPA at $t=4$ and $t=6$ (Fig. 2.6 for distribution at $\mathrm{t}=6$ ) is indicative of higher EPA content during the first two temperature increasing steps in the temperature ramp. The dominance of asymmetrical right skewed distributions during $\mathrm{t}=2, \mathrm{t}=4$ and $\mathrm{t}=6$ in PUFA, EPA and DHA shows the transition period required for FA composition to respond to temperature changes. The left skewedness seen at $\mathrm{t}=12$ in PUFA and $\mathrm{t}=24$ and $\mathrm{t}=48$ in EPA shows the time responses that are required for PUFA and EPA recovery to occur after temperature changes.

When examining the independent effect of temperature changes on the distribution of FA it was found that the majority of individual FA exhibited an asymmetrical right skew distribution during temperature increases (Table 2.11). This indicates that during temperature increases, there are higher FA contents at earlier time points and a decrease in FA content after longer time exposure to elevated temperatures. Under increasing temperature conditions, DHA was found to be highly asymmetrical, indicating a large decrease in DHA content. Under increasing temperature conditions $\left(22-25^{\circ} \mathrm{C}\right.$ and $\left.25-28^{\circ} \mathrm{C}\right)$, EPA did not exhibit the same patterns seen across the other FA. At $22-25^{\circ} \mathrm{C}$, the distribution of EPA was found to be symmetrical indicating that the EPA content was equivalent. At $25-28^{\circ} \mathrm{C}, \mathrm{EPA}$ was found to have a minor asymmetrical left-skew distribution. At $25-28^{\circ} \mathrm{C}$, PUFA also exhibited an asymmetrical distribution indicating greater content of PUFA at later time points than initial time points. 
Under decreasing temperature conditions, the majority of distributions were designated as symmetrical (Table 2.11). The symmetrical distribution seen across SFA, MUFA and DHA indicates an equal distribution of FA content at initial time conditions and final time conditions. The symmetrical distribution indicates no net change from starting times to end times at each temperature change. At $28-25^{\circ} \mathrm{C}$, EPA exhibited a highly asymmetrical right-skewed distribution and an asymmetrical right-skew distribution at $25-22^{\circ} \mathrm{C}$. This indicates that EPA content experiences a decrease as a function of time.

\section{Curve Fitting}

FA content across time and temperature treatments were fitted to cubic polynomial curves and plotted. At $\mathrm{t}=6$, SFA, MUFA, PUFA and EPA all exhibited $\mathrm{p}<0.05$ and a $\mathrm{R}^{2}$ value of 1, indicating a significant and exact fit to the cubic polynomial curve. At increasing temperatures, EPA and DHA at $22-25^{\circ} \mathrm{C}$, and $25-28^{\circ} \mathrm{C}$, respectively, both showed significant values when matched with their respective cubic polynomial curves (Table 2.12 and Table 2.13, Figs. 2.8 to 2.15$)$. 
Table 2.1: Multivariate analysis results for the overall effects of predictors (time, temperature, combined time and temperature) on fatty acid content across all groups (saturated fatty acids, monounsaturated fatty acids, polyunsaturated fatty acids).

\begin{tabular}{|l|l|l|l|l|l|}
\hline Effect & Value & Hypothesis d.f. & Error d.f. & F-Stat & P-Value \\
\hline Temperature Treatment & 0.433 & 9 & 112 & 5.11 & $<\mathbf{0 . 0 0 1}$ \\
\hline Time & 0.366 & 15 & 127 & 3.73 & $<\mathbf{0 . 0 0 1}$ \\
\hline Time and Temperature & 0.253 & 45 & 137 & 1.80 & $\mathbf{0 . 0 0 5}$ \\
\hline
\end{tabular}

Table 2.2: Multivariate analysis results for the overall effects of predictors (time, temperature, combined time and temperature) on individual fatty acid content (EPA, DHA, 16:1n-7, 18:1n-9, and 18:0).

\begin{tabular}{|l|l|l|l|l|l|}
\hline Effect & Value & Hypothesis d.f. & Error d.f. & F-Stat & P-Value \\
\hline $\begin{array}{l}\text { Temperature } \\
\text { Treatment }\end{array}$ & 0.154 & 25 & 150 & 5.18 & $<\mathbf{0 . 0 0 1}$ \\
\hline Time & 0.230 & 15 & 111 & 3.92 & $<\mathbf{0 . 0 0 1}$ \\
\hline Time and Temperature & 0.060 & 75 & 196 & 2.09 & $<\mathbf{0 . 0 0 1}$ \\
\hline
\end{tabular}

Table 2.3: Univariate analysis results for the effect of temperature treatment on each major fatty acid group (saturated fatty acids, monounsaturated fatty acids and polyunsaturated fatty acids; d.f=3) and individual fatty acids (EPA, DHA, 16:1n-7, 18:1n-9, and 18:0; d.f=3) used in order to determine the individual effect that temperature has on fatty acid content within major fatty acid groups.

\begin{tabular}{|l|l|l|}
\hline Fatty Acid Group & F-Stat & P-Value \\
\hline $18: 0$ & 4.29 & $\mathbf{0 . 0 1 0}$ \\
\hline $16: 1 n-7$ & 3.25 & $\mathbf{0 . 0 3 1}$ \\
\hline $18: 1 n-9$ & 8.33 & $<\mathbf{0 . 0 0 1}$ \\
\hline $20: 5 n-3$ (EPA) & 4.87 & $\mathbf{0 . 0 0 5}$ \\
\hline $22: 6 n-3$ (DHA) & 7.17 & $\mathbf{0 . 0 0 1}$ \\
\hline SFA & 2.25 & 0.094 \\
\hline MUFA & 5.53 & $\mathbf{0 . 0 0 2}$ \\
\hline PUFA & 5.71 & $\mathbf{0 . 0 0 2}$ \\
\hline
\end{tabular}


Table 2.4: Univariate analysis results for the effect that of time on each major fatty acid group (saturated fatty acids, monounsaturated fatty acids and polyunsaturated fatty acids; $d . f=5$ ) and individual fatty acids (EPA, DHA, 16:1n-7, 18:1n-9, and 18:0; d.f=5) used in order to determine the individual effect that time has on fatty acid content within major fatty acid groups.

\begin{tabular}{|l|l|l|}
\hline Fatty Acid Group & F-Stat & P-value \\
\hline $18: 0$ & 5.27 & $\mathbf{0 . 0 0 1}$ \\
\hline $16: 1 \mathrm{n}-7$ & 2.37 & 0.054 \\
\hline $18: 1 \mathrm{n}-9$ & 4.05 & $\mathbf{0 . 0 0 4}$ \\
\hline $20: 5 \mathrm{n}-3$ (EPA) & 2.54 & $\mathbf{0 . 0 4 2}$ \\
\hline $22: 6 n-3$ (DHA) & 3.85 & $\mathbf{0 . 0 0 6}$ \\
\hline SFA & 3.19 & $\mathbf{0 . 0 1 5}$ \\
\hline MUFA & 3.76 & $\mathbf{0 . 0 0 6}$ \\
\hline PUFA & 2.23 & 0.066 \\
\hline
\end{tabular}

Table 2.5: Repeated measures multivariate analysis for different effectors on fatty acid content in fatty acid groups (saturated fatty acids, monounsaturated fatty acids and polyunsaturated fatty acids) to determine the overall effect that time, temperature, fatty acid group and a combination of these variables has on fatty acid content changes.

\begin{tabular}{|l|l|l|l|l|l|}
\hline Effect & Value & Hypothesis d.f. & Error d.f. & F-Stat & P-Value \\
\hline Time & 0.470 & 5 & 41 & 9.23 & $<\mathbf{0 . 0 0 1}$ \\
\hline $\begin{array}{l}\text { Time and } \\
\text { Temperature }\end{array}$ & 0.525 & 15 & 113 & 1.99 & $\mathbf{0 . 0 2 2}$ \\
\hline $\begin{array}{l}\text { Time and FA } \\
\text { Group }\end{array}$ & 0.759 & 10 & 82 & 1.21 & 0.298 \\
\hline $\begin{array}{l}\text { Time, } \\
\text { Temperature } \\
\text { and FA Group }\end{array}$ & 0.635 & 30 & 166 & 0.665 & 0.906 \\
\hline
\end{tabular}

Table 2.6: Overall effects of temperature treatment and FA type while time is controlled to determine the individual and combined overall effects on fatty acid content in fatty acid groups (saturated fatty acids, monounsaturated fatty acids and polyunsaturated fatty acids).

\begin{tabular}{|l|l|l|l|l|}
\hline Effect & Mean Square & d.f. & F-Stat & P-Value \\
\hline Temperature & 1.02 & 3 & 0.601 & 0.618 \\
\hline FA Groups & 41.8 & 2 & 24.7 & $<\mathbf{0 . 0 0 1}$ \\
\hline $\begin{array}{l}\text { Temperature and } \\
\text { FA Type }\end{array}$ & 0.148 & 6 & 0.088 & 0.997 \\
\hline
\end{tabular}


Table 2.7: Repeated measures ANOVA for different effectors on fatty acid content in specific fatty acids (EPA, DHA, 16:1n-7, 18:1n-9 and 18:0) to determine the overall effect that time, temperature, fatty acid group and a combination of these variables has on fatty acid content changes.

\begin{tabular}{|l|l|l|l|l|l|}
\hline Effect & Value & $\begin{array}{l}\text { Hypothesis } \\
\text { d.f. }\end{array}$ & Error d.f. & F-Stat & P-Value \\
\hline Time & 0.334 & 5 & 33 & 13.2 & $<\mathbf{0 . 0 0 1}$ \\
\hline $\begin{array}{l}\text { Time and } \\
\text { Temperature }\end{array}$ & 0.254 & 15 & 91. & 3.92 & $<\mathbf{0 . 0 0 1}$ \\
\hline $\begin{array}{l}\text { Time and FA } \\
\text { Type }\end{array}$ & 0.243 & 20 & 110 & 2.94 & $<\mathbf{0 . 0 0 1}$ \\
\hline $\begin{array}{l}\text { Time, } \\
\text { Temperature } \\
\text { and FA Type }\end{array}$ & 0.065 & 60 & 158 & 2.10 & $<\mathbf{0 . 0 0 1}$ \\
\hline
\end{tabular}

Table 2.8: Overall effects of temperature treatment and fatty acid type while time is controlled to determine the individual and combined overall effects on fatty acid content in specific fatty acids (EPA, DHA, 16:1n-7, and 18:1n-9).

\begin{tabular}{|l|l|l|l|l|}
\hline Effect & Mean Square & d.f. & F-Stat & P-Value \\
\hline Temperature & 0.224 & 3 & 4.70 & $\mathbf{0 . 0 0 7}$ \\
\hline FA Type & 47.1 & 4 & 988 & $<\mathbf{0 . 0 0 1}$ \\
\hline $\begin{array}{l}\text { Temperature and } \\
\text { FA Type }\end{array}$ & 0.402 & 12 & 8.44 & $<\mathbf{0 . 0 0 1}$ \\
\hline
\end{tabular}

Table 2.9: Paired t-test performed between initial three time points $\left(t=0, t=2, t=4\right.$ at $\left.22-25^{\circ} \mathrm{C}\right)$ and final three time points $\left(\mathrm{t}=12, \mathrm{t}=24, \mathrm{t}=48\right.$ at $\left.25-22^{\circ} \mathrm{C}\right)$. For saturated fatty acids (SFA), polyunsaturated fatty acids (PUFA), 18:0, EPA and DHA, a one-tailed t-test (d.f.=8) was used due to the known response to changing temperatures. Monounsaturated fatty acids (MUFA), 16:1n-7 and 18:1n-9 used a two-tailed t-test (d.f.=8).

\begin{tabular}{|l|l|l|}
\hline & T-Stat & P-Value \\
\hline $16: 1 n-7$ & 3.19 & $\mathbf{0 . 0 1 3}$ \\
\hline $18: 1 n-9$ & 5.97 & $<\mathbf{0 . 0 0 1}$ \\
\hline 20:5n-3 (EPA) & 4.08 & $\mathbf{0 . 0 0 2}$ \\
\hline 22:6n-3 (DHA) & 0.166 & 0.436 \\
\hline SFA & 2.53 & $\mathbf{0 . 0 1 7 5}$ \\
\hline MUFA & 3.44 & $\mathbf{0 . 0 0 9}$ \\
\hline PUFA & 2.88 & $\mathbf{0 . 0 1 0 5}$ \\
\hline
\end{tabular}




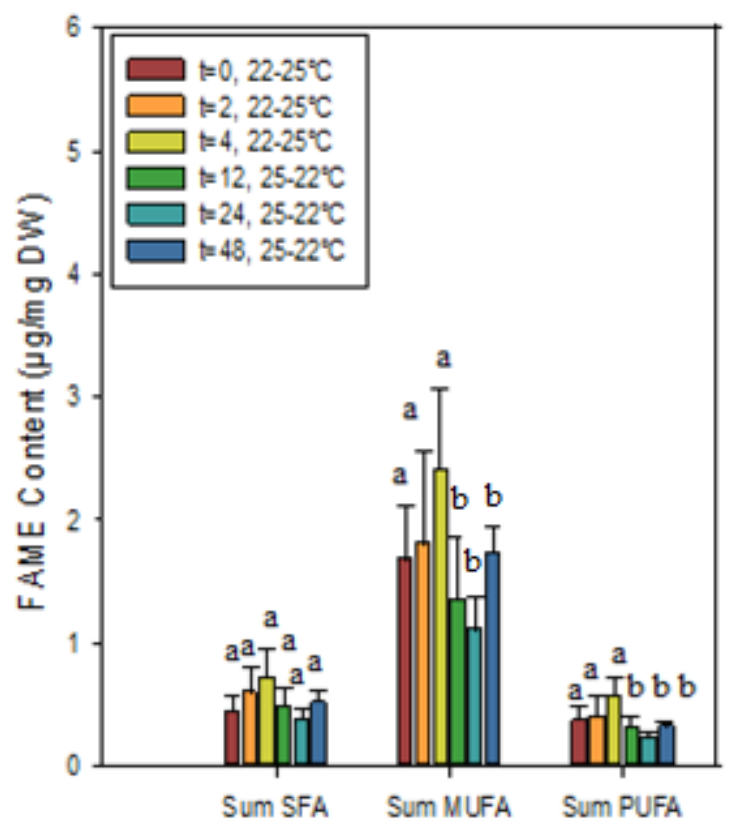

Figure 2.2: Average fatty acid methyl ester (FAME) content values for the initial three and final three sampling times across fatty acid groups. Error bars denote the standard deviation.

Groups marked with the same letter (capital for temperature, lower case for time) are significantly different from each other (Tukey post-hoc).

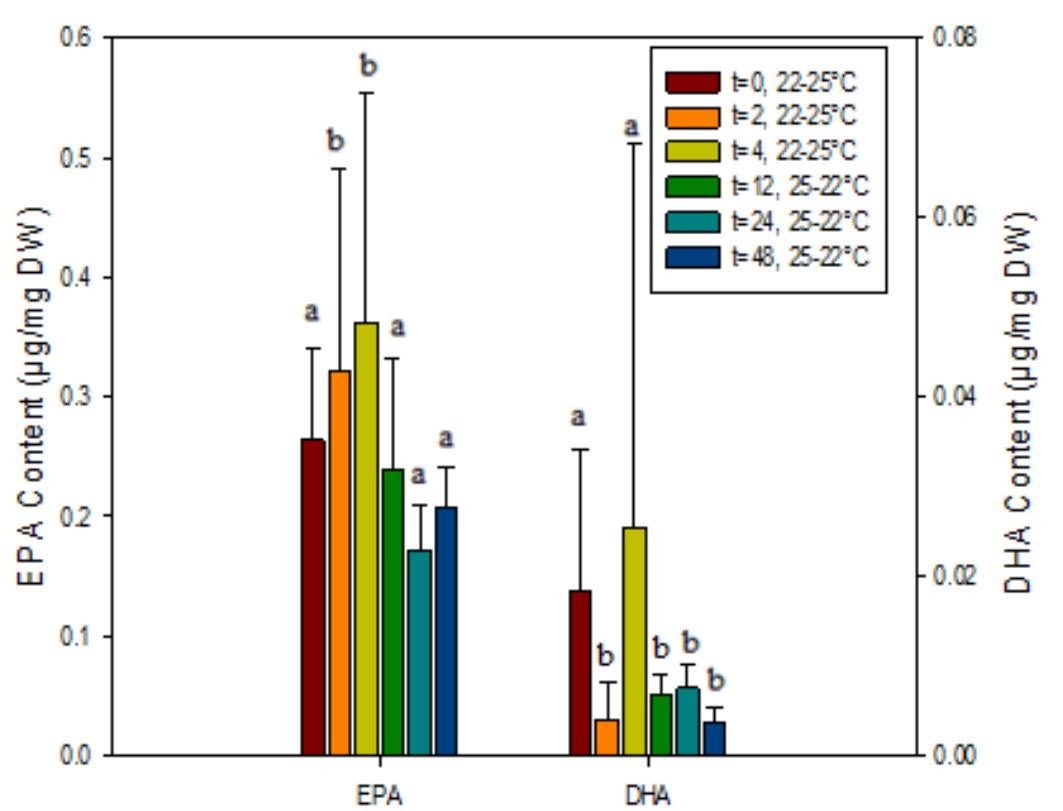

Figure 2.3: Average fatty acid methyl ester (FAME) content values for the initial three and final three sampling times across EPA and DHA. Error bars denote the standard deviation.

Groups marked with the same letter (capital for temperature, lower case for time) are significantly different from each other (Tukey post-hoc). 


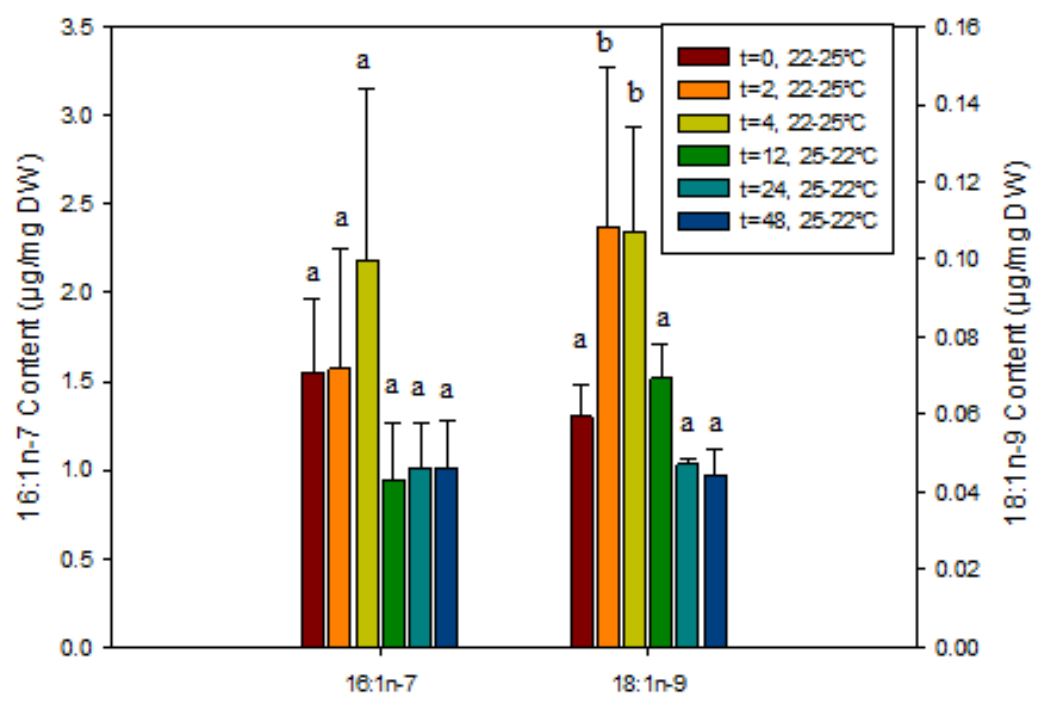

Figure 2.4: Average fatty acid methyl ester (FAME) content values for the initial three and final three sampling times for 16:1n-7 and 18:1n-9. Error bars denote the standard deviation. Groups marked with the same letter (capital for temperature, lower case for time) are significantly different from each other (Tukey HSD). 
Table 2.10: Time independence skewness across temperatures. Positive values indicate right skewness, while negative values indicate left skewness. Highly skewed is represented by values exceeding 1 for right-skewed, and values lower than -1 for left-skewed. Symmetrical distributions are represented by values falling between -0.5 to 0.5 . Bolded values indicate distributions found to be highly skewed

\begin{tabular}{|l|l|l|l|l|l|l|}
\hline & $\mathrm{T}=2$ & $\mathrm{~T}=4$ & $\mathrm{~T}=6$ & $\mathrm{~T}=12$ & $\mathrm{~T}=24$ & $\mathrm{~T}=48$ \\
\hline $20: 5 \mathrm{n}-3$ & 0.457 & 0.805 & $\mathbf{1 . 7 8}$ & -0.0338 & -0.983 & $\mathbf{- 1 . 4 0}$ \\
\hline $22: 6 n-3$ & $\mathbf{1 . 5 7}$ & $\mathbf{1 . 8 7}$ & $\mathbf{- 1 . 6 9}$ & 0.119 & $\mathbf{1 . 9 0}$ & $\mathbf{0 . 8 9 0}$ \\
\hline SFA & 0.832 & -0.161 & $\mathbf{1 . 8 9}$ & -0.609 & -0.656 & 0.815 \\
\hline MUFA & 0.687 & -0.653 & $\mathbf{1 . 9 5}$ & $\mathbf{1 . 2 1}$ & $\mathbf{1 . 8 0}$ & -0.0979 \\
\hline PUFA & -0.339 & $\mathbf{1 . 1 8}$ & $\mathbf{1 . 6 6}$ & -0.888 & 0.921 & 0.0728 \\
\hline
\end{tabular}

Table 2.11: Temperature independence skewness across time. Right skewness is represented by positive values. Left skewness is represented by negative values. Highly skewed is represented by values exceeding 1 for right-skewed, and values lower than -1 for left-skewed. Symmetrical distributions are represented by values falling between -0.5 to 0.5 . Bolded values indicate distributions found to be highly skewed

\begin{tabular}{|l|l|l|l|l|}
\hline & $22-25^{\circ} \mathrm{C}$ & $25-28^{\circ} \mathrm{C}$ & $28-25^{\circ} \mathrm{C}$ & $25-22^{\circ} \mathrm{C}$ \\
\hline $20: 5 n-3$ & 0.216 & -0.661 & $\mathbf{2 . 0 4}$ & 0.786 \\
\hline $22: 6 n-3$ & $\mathbf{1 . 1 1}$ & $\mathbf{2 . 0 7}$ & 0.552 & 0.0777 \\
\hline SFA & 0.629 & 0.676 & 0.312 & 0.0612 \\
\hline MUFA & 0.633 & 0.794 & 0.521 & 0.232 \\
\hline PUFA & $\mathbf{1 . 0 9}$ & -0.793 & 0.729 & 0.379 \\
\hline
\end{tabular}


Table 2.12: Curve fitting results using raw replicate data for time independence. Significant values indicate that the probability of the data distribution fitting to the curve was not due to random sampling and that data distributions follow the respective cubic polynomial function.

\begin{tabular}{|c|c|c|c|c|c|c|c|c|c|c|c|c|}
\hline & \multicolumn{2}{|l|}{$\mathrm{T}=2$} & \multicolumn{2}{|l|}{$\mathrm{T}=4$} & \multicolumn{2}{|l|}{$\mathrm{T}=6$} & \multicolumn{2}{|l|}{$\mathrm{T}=12$} & \multicolumn{2}{|l|}{$\mathrm{T}=24$} & \multicolumn{2}{|l|}{$\mathrm{T}=48$} \\
\hline & F-Stat & $\mathrm{P}$-value & F-Stat & P-Value & F-Stat & P-Value & F-Stat & P-Value & F-Stat & P-Value & F-Stat & P-Value \\
\hline $20: 5 n-3$ & 1.10 & 0.404 & 1.22 & 0.363 & 16.5 & 0.0009 & 3.87 & 0.0559 & 0.337 & 0.800 & 0.202 & 0.892 \\
\hline $22: 6 n-3$ & 1.83 & 0.230 & 0.677 & 0.590 & 2.77 & 0.111 & 0.224 & 0.877 & 1.57 & 0.271 & 0.864 & 0.498 \\
\hline SFA & 0.642 & 0.610 & 0.963 & 0.456 & 5.09 & 0.0293 & 0.390 & 0.763 & 1.12 & 0.358 & 0.204 & 0.890 \\
\hline MUFA & 0.991 & 0.445 & 1.66 & 0.251 & 10.0 & 0.0044 & 1.13 & 0.393 & 1.90 & 0.210 & 0.138 & 0.935 \\
\hline PUFA & 0.652 & 0.604 & 0.981 & 0.449 & 13.2 & 0.0018 & 1.04 & 0.428 & 2.45 & 0.138 & 0.399 & 0.758 \\
\hline
\end{tabular}

Table 2.13: Curve fitting results using raw replicate data for time independence. Significant values indicate that the probability of the data distribution fitting to the curve was not due to random sampling and that data distributions follow the respective cubic polynomial function.

\begin{tabular}{|l|l|l|l|l|l|l|l|l|}
\hline & \multicolumn{2}{|l}{} & \multicolumn{2}{l|}{$25-25^{\circ} \mathrm{C}$} & \multicolumn{2}{l|}{$28-25^{\circ} \mathrm{C}$} & $25-22^{\circ} \mathrm{C}$ \\
\cline { 2 - 10 } & F-Stat & P-Value & F-Stat & P-value & F-Stat & P-Value & F-Stat & P-Value \\
\hline $20: 5 n-3$ & 3.24 & $\mathbf{0 . 0 4 8 1}$ & 1.68 & 0.217 & 0.367 & 0.778 & 1.55 & 0.245 \\
\hline $22: 6 n-3$ & 0.289 & 0.833 & 5.47 & $\mathbf{0 . 0 1 0 7}$ & 0.705 & 0.564 & 1.05 & 0.400 \\
\hline SFA & 4.06 & $\mathbf{0 . 0 2 4}$ & 0.340 & 0.797 & 0.383 & 0.767 & 0.0375 & 0.990 \\
\hline MUFA & 1.66 & 0.213 & 0.907 & 0.462 & 0.544 & 0.660 & 0.244 & 0.864 \\
\hline PUFA & 1.76 & 0.193 & 1.26 & 0.326 & 1.29 & 0.316 & 0.833 & 0.498 \\
\hline
\end{tabular}




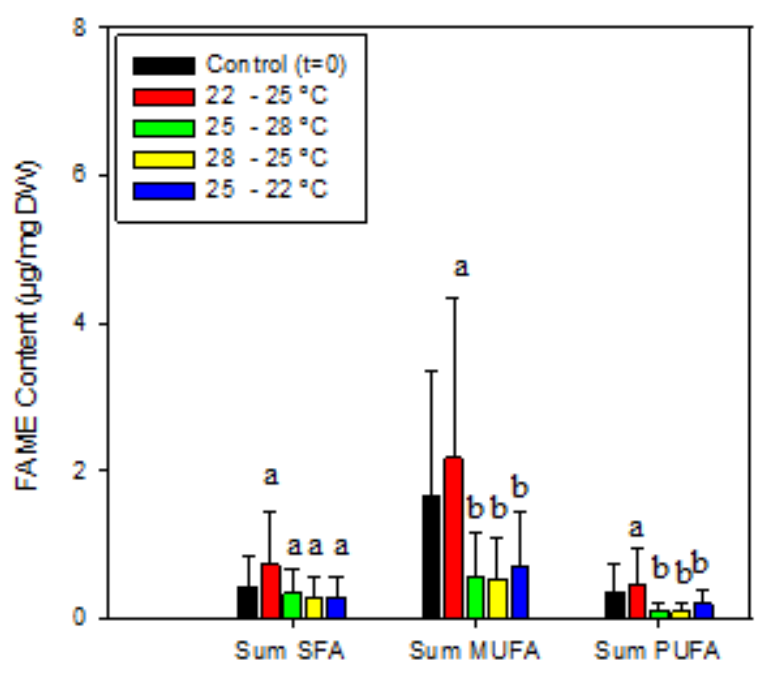

Figure 2.5: Average fatty acid methyl ester (FAME) Content across all temperature treatments at sampling time $\mathrm{t}=6 \mathrm{~h}$. Error bars denote standard deviation. Groups marked with the same letter are significantly different from each other (Tukey HSD).

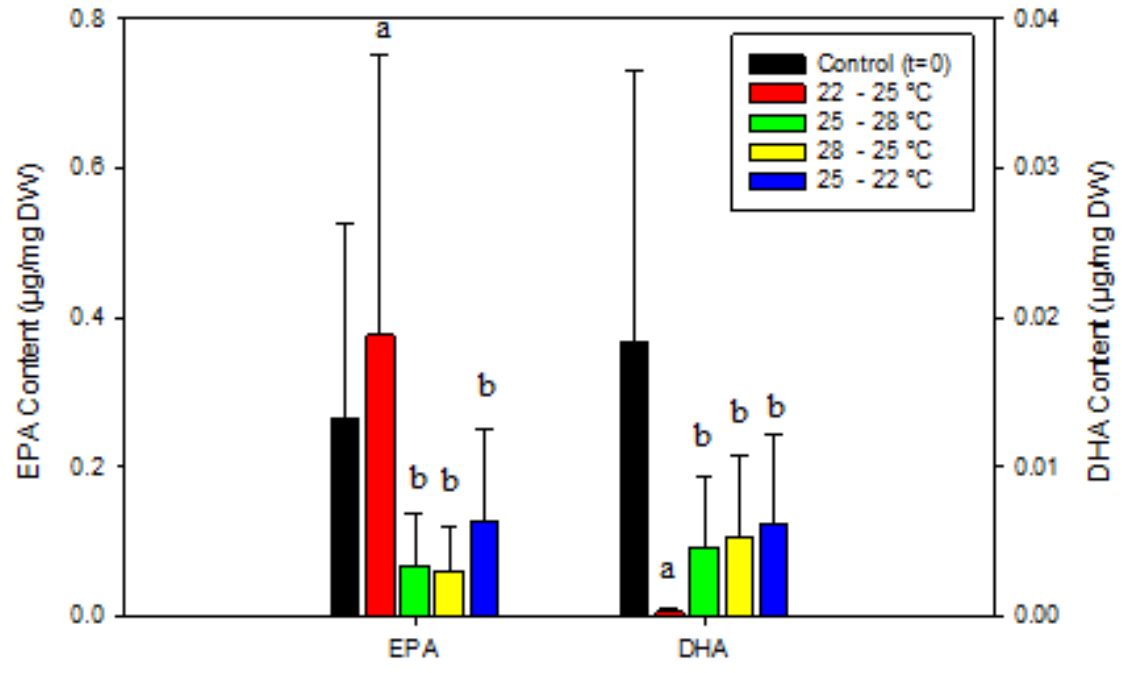

Figure 2.6: Average fatty acid methyl ester (FAME) Content across all temperature treatments at sampling time $\mathrm{t}=6 \mathrm{~h}$ for EPA (left-hand axis) and DHA (right-hand axis). Error bars denote standard deviation values. Groups marked with the same letter are significantly different from each other (Tukey HSD). 


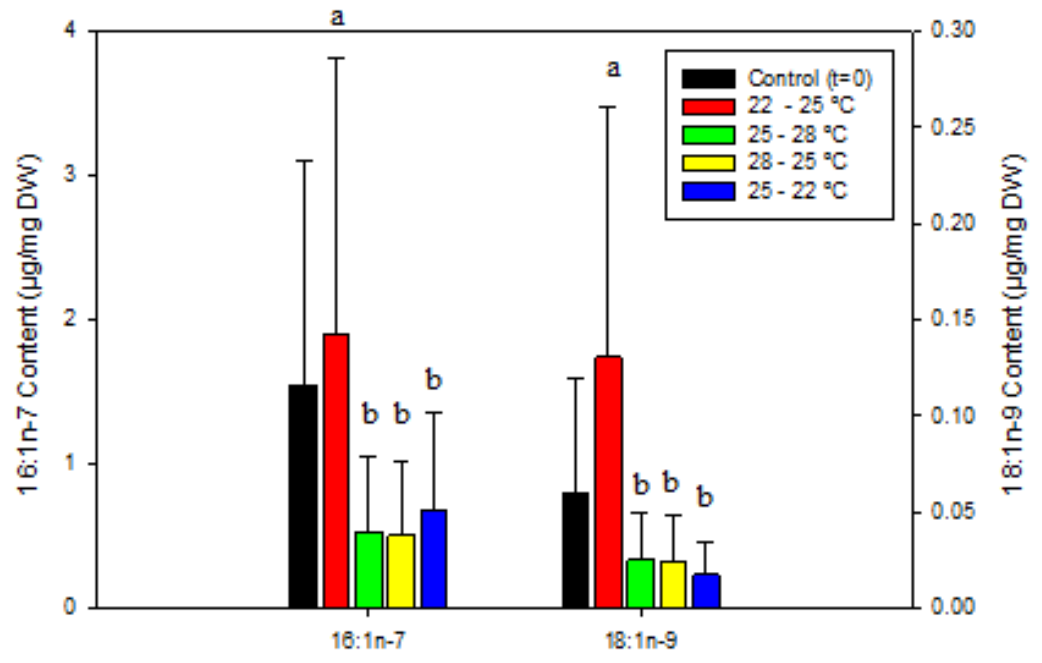

Figure 2.7: Average fatty acid methyl ester (FAME) Content across all temperature treatments at sampling time $\mathrm{t}=6 \mathrm{~h}$ for 16:1n-7 (left-hand axis) and 18:1n-9 (right-hand axis). Error bars denote standard deviation values. Groups marked with the same letter are significantly different from each other (Tukey HSD). 


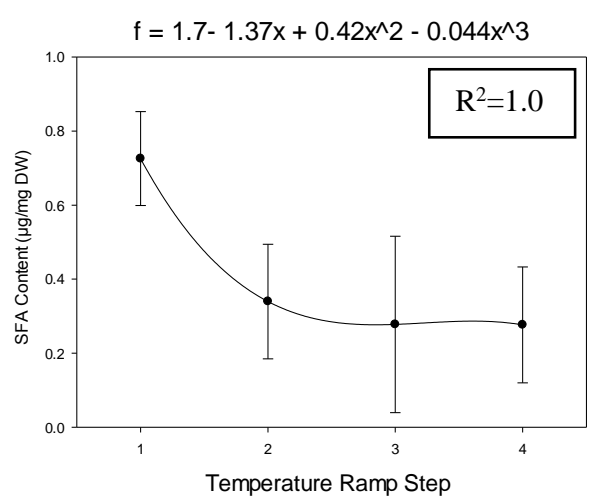

Figure 2.8: Cubic polynomial curve fitted to the average saturated fatty acid (SFA) Content (three replicates for each temperature treatment step) at $\mathrm{t}=6 \mathrm{~h}$ across temperature treatments. Error bars denote the standard deviation values.

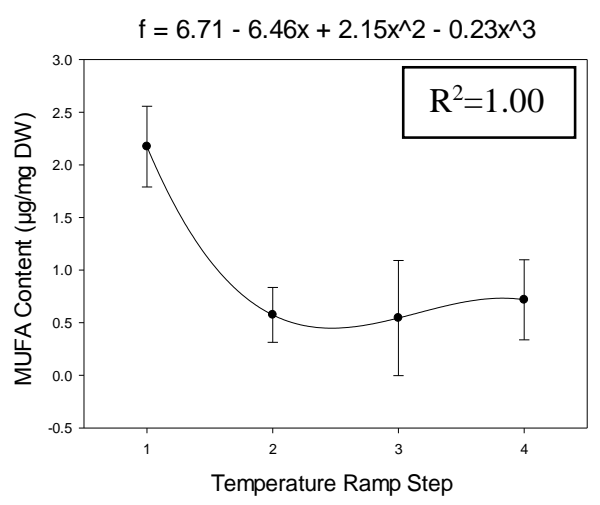

Figure 2.9: Cubic polynomial curve fitted to the average monounsaturated fatty acid (MUFA) (three replicates for each temperature treatment step) at $\mathrm{t}=6 \mathrm{~h}$ across temperature treatments. Error bars denote the standard deviation values.

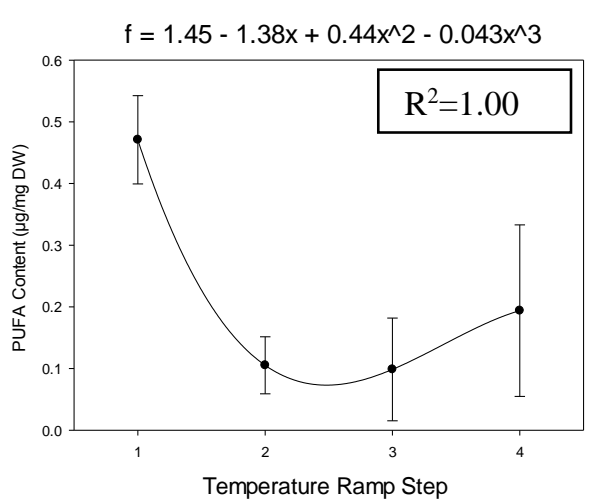

Figure 2.10: Cubic polynomial curve fitted to the average polyunsaturated (PUFA) (three replicates for each temperature treatment step) at $\mathrm{t}=6 \mathrm{~h}$ across temperature treatments. Error bars denote the standard deviation values.

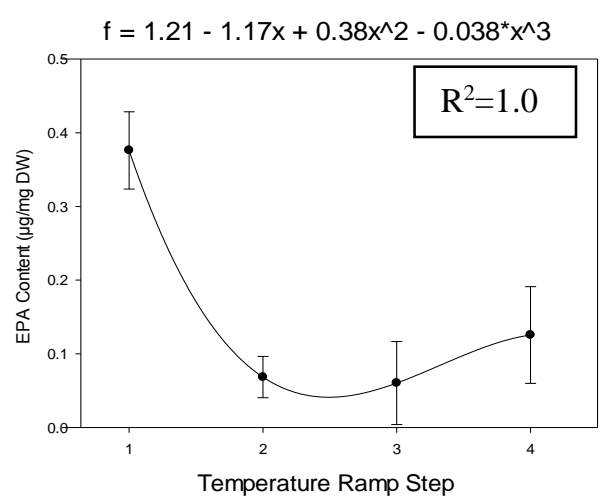

Figure 2.11: Cubic polynomial curve fitted to the average EPA (three replicates for each temperature treatment step) at $\mathrm{t}=6$ across temperature treatments. Error bars denote the standard deviation values. 


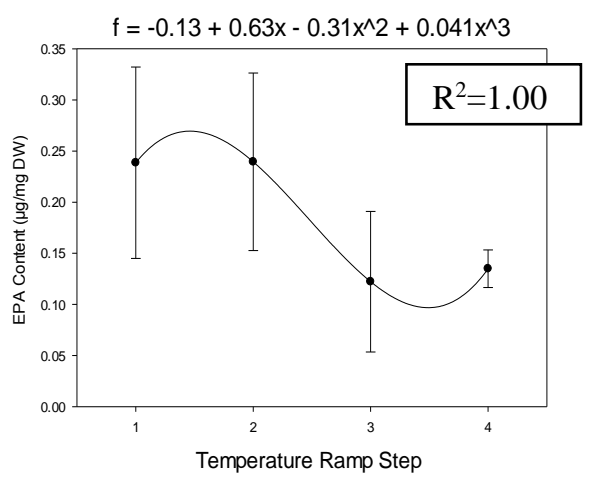

Figure 2.12: Cubic polynomial curve fitted to the average DHA (three replicates for each temperature treatment step) at $\mathrm{t}=6 \mathrm{~h}$ across temperature treatments. Error bars denote the standard deviation values.

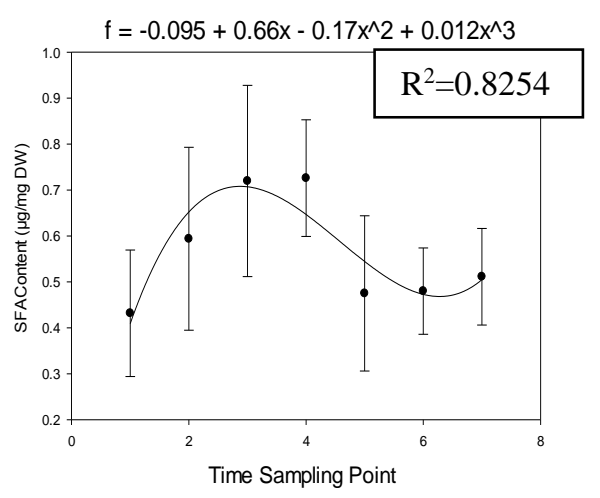

Figure 2.13: Cubic polynomial curve fitted to the average saturated fatty acid (SFA) content for $22-25^{\circ} \mathrm{C}$ (three replicates for each time point) across seven sampling times $(t=0, t=2, t=4, t=6, t=12, t=24, t=48 h)$. Error bars denote the standard deviation values.

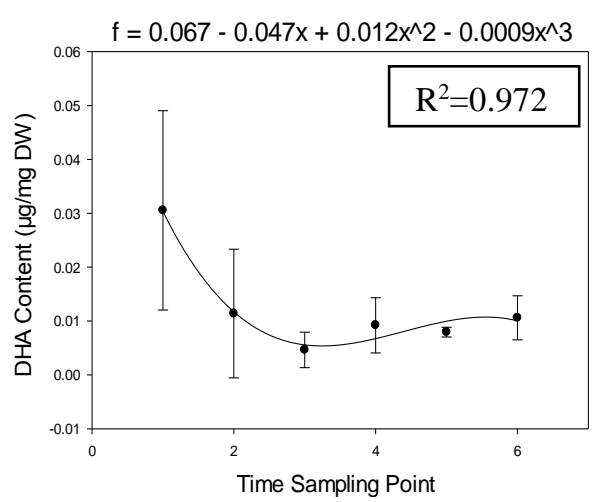

Figure 2.14: Cubic polynomial curve fitted to the average DHA content for $22-25^{\circ} \mathrm{C}$ across (three replicates for each time point) across six sampling times $(\mathrm{t}=2, \mathrm{t}=4, \mathrm{t}=6, \mathrm{t}=12$, $\mathrm{t}=24, \mathrm{t}=48 \mathrm{~h}$ ). Error bars denote the standard deviation values.

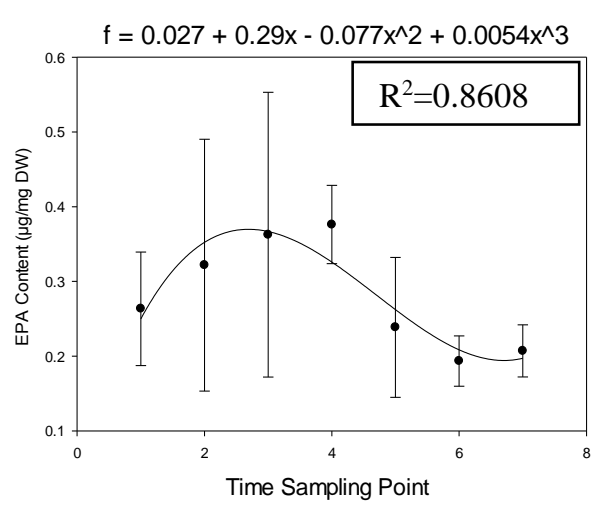

Figure 2.15: Cubic polynomial curve fitted to the average EPA Content for $22-25^{\circ} \mathrm{C}$ (three replicates for each time point) across seven sampling times $(\mathrm{t}=0, \mathrm{t}=2, \mathrm{t}=4, \mathrm{t}=6, \mathrm{t}=12, \mathrm{t}=24$, $\mathrm{t}=48 \mathrm{~h}$ ). Error bars denote the standard deviation values 


\section{Discussion}

As a result of anthropogenic pressures, climate change has caused accelerated increases in water temperature (Crowley, 2000). As seen during the summer months of 2015, surface water temperatures in a shallow freshwater pond in Ontario reached a maximum temperature of $32.8^{\circ} \mathrm{C}$. Water temperatures that exceed optimal growth temperatures (generally ranging from $25^{\circ} \mathrm{C}$ to $30^{\circ} \mathrm{C}$ for temperate algae, Ji et al., 2016) of algal populations are expected to result in decreased growth and mortality (Renaud, 2002). From the temperature treatments imposed on cultures over a 10-day period, there was a significant difference between initial FA content and the final FA content in algal samples, suggesting that cultures do not experience a symmetrical and full recovery of total FA content, summary FA group content, and the four specific FA that I examined (16:1n-7, 18:1n-9, EPA and DHA).

The control conditions (constant growth temperature of $22^{\circ} \mathrm{C}$, see Appendix 1) showed similar FA profiles found in a marine strain of $N$. pelliculosa (Appendix 1, Ying et al., 2000). The strain of $N$. pelliculosa used in this study was found to have a higher composition of MUFA and lower composition of PUFA in comparison to the marine strain seen in Ying et al., 2000. The differences seen in FA profiles between my experimental strain and published marine strain results are expected because of the differences found between freshwater and marine algae FA composition (Patil et al., 2007). Under optimal growth conditions, FA proportional composition in N. pelliculosa is dominated by MUFA ( 60\%) and in particular 16:1n-7. Diatoms also characteristically produce high amounts of omega-3 LC-PUFA (Burns et al., 2011). Under optimal conditions, $N$. pelliculosa is also seen to have a greater amount of EPA $(\sim 13 \%)$ than DHA ( 1\%). Due to the similarities found between published literature values and control 
conditions, the control condition used in this experiment is seen to be an appropriate baseline for FA changes across time and temperature.

Previous studies on the effects of temperature (heat treatments up to $28^{\circ} \mathrm{C}$. ) on FA composition in a green alga have shown that PUFA content tends to decrease, and SFA content tends to increase, with increasing temperature (Fuschino et al., 2011). Correspondingly, other studies have shown that lower temperatures cause an increase PUFA and a decrease in SFA in order to maintain membrane fluidity (Guschina and Harwood 2009). Total FA content is also known to be influenced by growth conditions (Solovchenko et al., 2008; Hu and Gao, 2006; Yongmanitchai and Ward, 1991). As expected, the increase in SFA as a result of temperature increases is indicative of the favored shift towards elevated SFA content in order to maintain membrane fluidity at higher temperatures. However, the decrease in SFA content found between $\mathrm{t}=48$ at 22 and $25^{\circ} \mathrm{C}$ and $\mathrm{t}=48$ at 25 and $28^{\circ} \mathrm{C}$ suggests a potential decrease in total $\mathrm{FA}$ content when exposed to very high temperatures. During temperature decreases, SFA content was also found to be reduced which could be a result of, a) an overall increase in total FA content as a response to temperatures returning to optimal conditions or, b) a thermal stress response. MUFA showed a similar response and is indicative of FA content recovery and a recovery of total FA content. The decrease in PUFA content found with the two temperature increasing steps is expected due to the higher incorporation of SFA at higher temperatures in order to maintain membrane fluidity. The increase in PUFA content shows partial recovery when temperatures decrease and begin to return to ideal conditions.

The FA content of algae exposed to warming temperatures may show three possible responses: a) no net gain or loss in PUFA/SFA, b) net gain in SFA and net loss in PUFA, or c) net loss in SFA and net gain in PUFA. As hypothesized, FA content did not respond 
symmetrically after exposure to the ten-day temperature regime. Fluctuating temperatures outside of optimal conditions results in thermal stress and alters the physiological capacity of cultures (Kreslavski et al., 2007; Davison, 1991). Due to the exposure of N. pelliculosa to nonoptimal growth conditions, a net loss in PUFA and total FA was observed. During the temperature increasing steps of the temperature ramps, PUFA content was seen to decrease and SFA content was seen to decrease. Furthermore, with increasing temperature a decrease in total FA content was observed. During the decreasing steps of the temperature ramps, PUFA content was seen to increase but it did not return to original content values, resulting in a net loss of total PUFA, EPA and DHA. Elevated temperature exposure can contribute to cellular damage and genetic damage (Kreslavski et al., 2007). The damage caused by elevated temperature is potentially what contributes to the asymmetrical response and the net loss in PUFA, EPA and DHA. The asymmetrical response seen during the short-term temperature ramp would be expected to be seen under situations of long-term heat exposure but with potential for more detrimental losses and damages (see Chapter 3).

Previous studies have not done an in-depth of examination of the temporal responses of FA content in diatoms or algae to temperature changes (Fuschino, 2010; Rousch et al., 2003). As expected, as a result of time, FA content reaches a plateau after extended exposure to temperature changes and FA content does not continue to change. The plateau seen in FA content is likely due to acclimation to the novel environmental change. Acclimation allows organisms to adjust to gradual environmental changes, such as a change in temperature, in order to maintain physiological performance to a degree under a variety of environmental conditions (Thompson, 1991). Previous work suggests that as response to a change in temperature, or the induction of thermal stress, there is often a delay in molecular and biochemical responses within 
algae (Bajguz, 2009; Rousch et al., 2004; Rousch et al., 2003). Time also showed that there was a critical point of change occurring at $\mathrm{t}=6 \mathrm{~h}$ where FA content appear to change drastically in response to temperature. In Rousch et al., 2004, it was found that small heat shock proteins were not present until $t=8$ hours into elevated temperature exposure, but Bajguz (2009) showed that protein content did not show significant differences after 3 hours of temperature exposure. While this is not directly applicable to FA, it indicates that there is a lag period in an organism's ability to physiologically respond to temperature changes. Specific for FA, Rousch et al. (2003) showed minimal changes in FA content changes across temperature for $\mathrm{t}=2 \mathrm{~h}$ time points in two marine diatom species. This further contributes to the idea that responses to elevated temperatures do not occur instantaneously, but rather have a lag period before physiological and biochemical changes are implemented. This suggests that in order to acclimate to changing temperatures, $6 \mathrm{~h}$ is the critical time point for N. pelliculosa, where change occurs from initial conditions. After the $6 \mathrm{~h}$ point (i.e. $\mathrm{t}=12 \mathrm{~h}$ onwards), content reaches a plateau and stabilizes. From the previous molecular responses to temperature on a temporal scale, this supports that the changes in FA content takes longer than 2 to $4 \mathrm{~h}$, with the majority of significant changes occurring within the first $12 \mathrm{~h}$.

Other diatoms have shown thermo-tolerant characteristics and the ability to grow and survive when exposed to temperatures up to $40^{\circ} \mathrm{C}$ (Rousch et al., 2003). In thermo-tolerant species, FA content did not show significant differences under heat stress (Rousch et al., 2003). In both thermo-tolerant and non-thermo-tolerant species, a similar temporal response was seen with minimal changes in FA content occurring after being exposed to elevated temperatures for only $\mathrm{t}=2 \mathrm{~h}$ (Rousch et al., 2003). This is similar to what was found in my results, suggesting that multiple algal species experience a lag period between a temperature change and the FA response. The strain of $N$. pelliculosa obtained from CPCC was originally isolated from a "hot, 
dusty" environment in California, United States. While the original strain was isolated prior to 1975, the strain of $N$. pelliculosa used in my experiments could possess a stronger evolutionary potential as a result of originating from a "hot dusty" environment in California. This could potentially give the strain of $N$. pelliculosa a genetic benefit to being able to survive in warmer conditions, which allows it to not experience such detrimental cellular damage when exposed to elevated temperatures.

Algae are the main producers of omega-3 LC-PUFA and provide necessary nutritional requirements to aquatic organisms (invertebrates and fish), and also facilitate the dietary demands of EFA in terrestrial organisms through trophic transfer (Burns et al., 2011). The decrease in PUFA, including EPA and DHA, seen after temperature fluctuations suggests that during the summer, indicates that there is a net loss and a decrease in availability of these essential compounds. The net loss in PUFA in algae may result in decreased nutritional quality and EFA availability to other organisms (Hixson and Arts, 2016; Werbrouck et al., 2016). Decreases in PUFA content in algae, and in particular in diatoms (a dominant producer of EPA and DHA), may result in cascading effects on health, growth and reproduction in aquatic organisms and terrestrial organisms. Decreased PUFA content in algae reduces the availability to zooplankton and higher trophic organisms, such as fish and humans.

These results suggest that under elevated temperature during heat waves or during short periods of hot temperatures, the nutritional quality of algae may be reduced due to the deceased PUFA content found at higher temperatures. Further research on the temporal response of FA content to temperature changes in different algae taxa will help determine whether the responses shown in N. pelliculosa are unique to the species or seen broadly across algae taxa. It would also be of interest to consider different stressors outside of temperature that climate change and 
anthropogenic emissions is causing in aquatic ecosystems, such as $\mathrm{pH}$. Due to the many physical and chemical changes that aquatic ecosystems are facing as a result of anthropogenic pressures, it is imperative to have a full understanding how the novel suite of stressors will influence the physiological and biochemical pathways of globally important organisms, such as algae. Furthermore, the potential for developing a biological mathematical model to predict fatty acid content in algal species should be devised. Due to the strong pattern of following polynomial cubic curves for multiple groups and FA represented above, this suggests the possibility for being able to create a model in order to predict fatty acid availability in algal populations during climate warming scenarios, in order to understand the potential decreased availability that might occur. 


\title{
Chapter 3
}

\section{The Effects of Long Term Heat Exposure on Fatty Acid Content}

\author{
Recovery in Navicula pelliculosa
}

\section{Introduction}

Climate change has become a growing concern with global temperatures increasing each decade, and is predicted to further increase in the future (Meehl et al., 2007; Trenberth et al., 2007). During the summer months, extreme heat days (temperatures $>30^{\circ} \mathrm{C}$ ) are predicted to rise in frequency and duration (Kharin et al., 2007; Meehl et al., 2007). Warming surface air temperatures lead to subsequent warming in surface water temperatures, creating warmer environments for aquatic ecosystems (Woodward et al., 2010; Bindoff et al., 2007).

Warming water temperatures impose physiological stress on aquatic organisms, including algae (Davison, 1991). Temperate algal species generally have an optimal growth temperature ranging between 25 to $30^{\circ} \mathrm{C}$, and exceeding the optimal growth temperature contributes to heat stress in algae (Ji et al., 2016; Allakhverdiev et al., 2008). Heat exposure can cause permanent cellular damage and genetic damage under certain circumstances (Kreslavski et al., 2007). Heat stress limits biomass production and photosynthetic efficiency (Ji et al., 2016; Allakhverdiev et al., 2008). High heat has the potential to permanently damage the photosystem II in the chloroplasts, affecting photosynthetic capacity (Ji et al., 2016; Allakhverdiev et al., 2008). The severity of heat stress is dependent on the ability of an organism to tolerate temperature changes, and in extreme cases, can lead to mortality (Ji et al., 2016; Allakhverdiev et al., 2008). Algae can 
potentially acclimate to elevated temperatures within a given range, depending on species (Ji et al., 2016).

In response to temperature changes, algae can change the fatty acid (FA) content in their cell membranes in order to maintain membrane fluidity; a process known as homeoviscous adaptation (Gladyshev et al., 2011; Sinensky, 1974). The incorporation of different FA in membranes allows for rapid adaptations of poikilothermic organisms to fluctuating temperatures (Oger and Cario, 2013). FA are incorporated into membranes based upon the melting points to prevent membrane rigidity or membrane hyper-fluidity (Sperfield and Wacker, 2010; Mikami and Murata, 2003; Murata and Los, 1997). Higher temperatures favor the incorporation of saturated fatty acids (SFA) into membranes due to the lower melting point (Usui et al., 2012; Murray et al., 2010). Lower temperatures favor the incorporation of polyunsaturated fatty acids (PUFA) (Usui et al., 2012; Murray et al., 2010). The trend in FA incorporation in response to increasing temperature results in decreased PUFA content and increased SFA content (Gladyshev et al., 2015; McMeans et al., 2015).

I examined the effects that long term heat exposure (as would be seen in a natural shallow freshwater pond during a heat wave) and time have on FA composition in the freshwater diatom, Navicula pelliculosa. Long-chain polyunsaturated fatty acids (LC-PUFA), such as eicosapentaenoic acid (EPA; 20:5n-3) and docosahexaenoic acid (DHA; 22:6n-3), were of interest in this experiment due to their critical physiological role to other organisms. EPA and DHA are physiologically important to vertebrates, contributing to healthy growth, reproduction and development (Gladyshev et al., 2015; Masclaux et al., 2014). However, vertebrates do not have the necessary enzymatic activity to synthesize EPA and DHA at sufficient rates for their physiological needs, forcing vertebrates to rely on dietary sources (Honeyfield and Maloney, 
2015; Gladyshev et al., 2011). N. pelliculosa was chosen for this experiment due to its cosmopolitan distribution, ease of maintaining cultures, and the presence of essential FA of interest, EPA and DHA. Although previous growth studies have been conducted on algal species examining the effect that temperature has on FA composition, there is a critical gap in knowledge of understanding the recovery potential of FA composition after being exposed to high temperatures for a prolonged period before return to optimal conditions.

The objective of this experiment was to determine the effect that long term heat exposure has on fatty acid composition in N. pelliculosa. Previous research, with a green alga, has indicated that in warming water conditions, SFA proportions increase and PUFA proportions decrease (Fuschino et al., 2011). I hypothesized that in response to a 14-day exposure to high heat $\left(28^{\circ} \mathrm{C}\right)$, there will be a net loss in PUFA (including EPA and DHA) and a net gain in SFA. In comparison to the recovery rate seen during the short-term temperature regime (see Chapter 2), I hypothesized that the long-term temperature regime will exhibit a slower recovery rate in PUFA, which will contribute to the net loss in PUFA. I also hypothesized that FA content will not recover to original content due to irreversible physiological and cellular damage caused by the heat stress imposed during the temperature regime and the recovery period given.

\section{Methods}

To assess the effect that long term heat exposure has on FA composition and FA recovery in algae, a temperature treatment regime was designed based on environmental temperature variation in the Spring/Summer of 2015 in the surface waters of a freshwater pond at Koffler Scientific reserve (Newmarket, Ontario). A common freshwater diatom, N. pelliculosa, was used to determine the recovery potential of PUFA after being heat stressed for a two week period. 


\section{Culturing of Navicula pelliculosa (CPCC 552)}

The diatom, N. pelliculosa (obtained from Canadian Phycological Culturing Centre, CPCC 552) was used in all temperature treatments. Cultures were grown in CHU-10 media (see Appendix 1) on a $24 \mathrm{~h}$ light cycle (average light intensity of $184 \mu \mathrm{mol}$ photons $\mathrm{m}^{-2} \mathrm{~s}^{-1}$ ) in a VWR Signature Diurnal Growth Chamber (Model 2015). A $24 \mathrm{~h}$ light cycle was used for culturing conditions in order to minimize the influence of light on FA composition (Sicko-Goad et al., 1991). The diatom, $N$. pelliculosa was cultured in batches of $250 \mathrm{~mL}$ in glass Erlenmeyer flasks with cellulose stoppers and were stirred once every $48 \mathrm{~h}$. Cultures were grown at ideal conditions of $22^{\circ} \mathrm{C}$ (see Appendix 1) prior to exposure to temperature treatments. A population growth curve using optical density (OD) readings was generated with a spectrophotometer for $N$. pelliculosa under these conditions was constructed in order to ensure that cultures were in exponential phase during collection periods. Growth curves were constructed using average OD readings at $685 \mathrm{~nm}$ and age of the culture (see Appendix 1).

\section{Temperature Ramp Design}

Temperature ramps were designed to simulate spring/summer temperature variation seen in shallow freshwater bodies. Temperature data was collected hourly using a HOBO TidBit v2 Water Temperature Data logger UTBI-001 in the surface waters of a freshwater pond at Koffler Scientific Reserve (KSR; King City, Ontario; 44.029590 N, -79.531553 W) from June 2015 to September 2015. In order to ensure that temperature patterns seen in the pond at KSR were representative of freshwater bodies in the spring/summer, data from Lakes Environmental Association (L.E.A) on a group of lakes in Maine, United States of America, was compiled into a database representing temperature patterns seen from 2013 to 2015 seasons. Comparison of 2015 KSR data to 2013-2015 L.E.A data (see Appendix 2) allowed for us to confirm that the 
temperature treatment pattern we choose was accurate and representative for freshwater surface waters typical of a small pond.

While mid- to late-summer temperatures showed the most extreme temperature points and patterns (with a maximum of $32.6^{\circ} \mathrm{C}$ being reached at the end of July at the KSR pond), our treatments focus on the temperatures seen in early-mid June. Due to phytoplankton population succession, diatoms occur during the spring and fall due to silica and nutrient ( $\mathrm{N}$ and $\mathrm{P}$ ) availability. By basing our temperature treatments on temperatures of June, this takes the seasonality of diatoms into account, and will not expose $N$. pelliculosa to overly harsh and unnatural environmental conditions. The temperature treatments were designed to represent a simplified pattern of a heat wave (Fig. 3.1). While in the environment, heat waves would be unlikely to follow a very consistent temperature for a 2 week period straight, this temperature ramp was designed to mimic a simplified outline of water temperature as would be seen during a heat wave and did not take into account daily water temperature fluctuations. To acclimate, the temperature was increased by $3^{\circ} \mathrm{C}$ increments from 22 to $25^{\circ} \mathrm{C}$ for $48 \mathrm{~h}$ and 25 to $28^{\circ} \mathrm{C}$. The maximum temperature of $28^{\circ} \mathrm{C}$ was then held for a two week period. Temperatures were then decreased in $3^{\circ} \mathrm{C}$ increments from 28 to $25^{\circ} \mathrm{C}$ for $48 \mathrm{~h}$ and 25 to $22^{\circ} \mathrm{C}$ for $72 \mathrm{~h}$. 


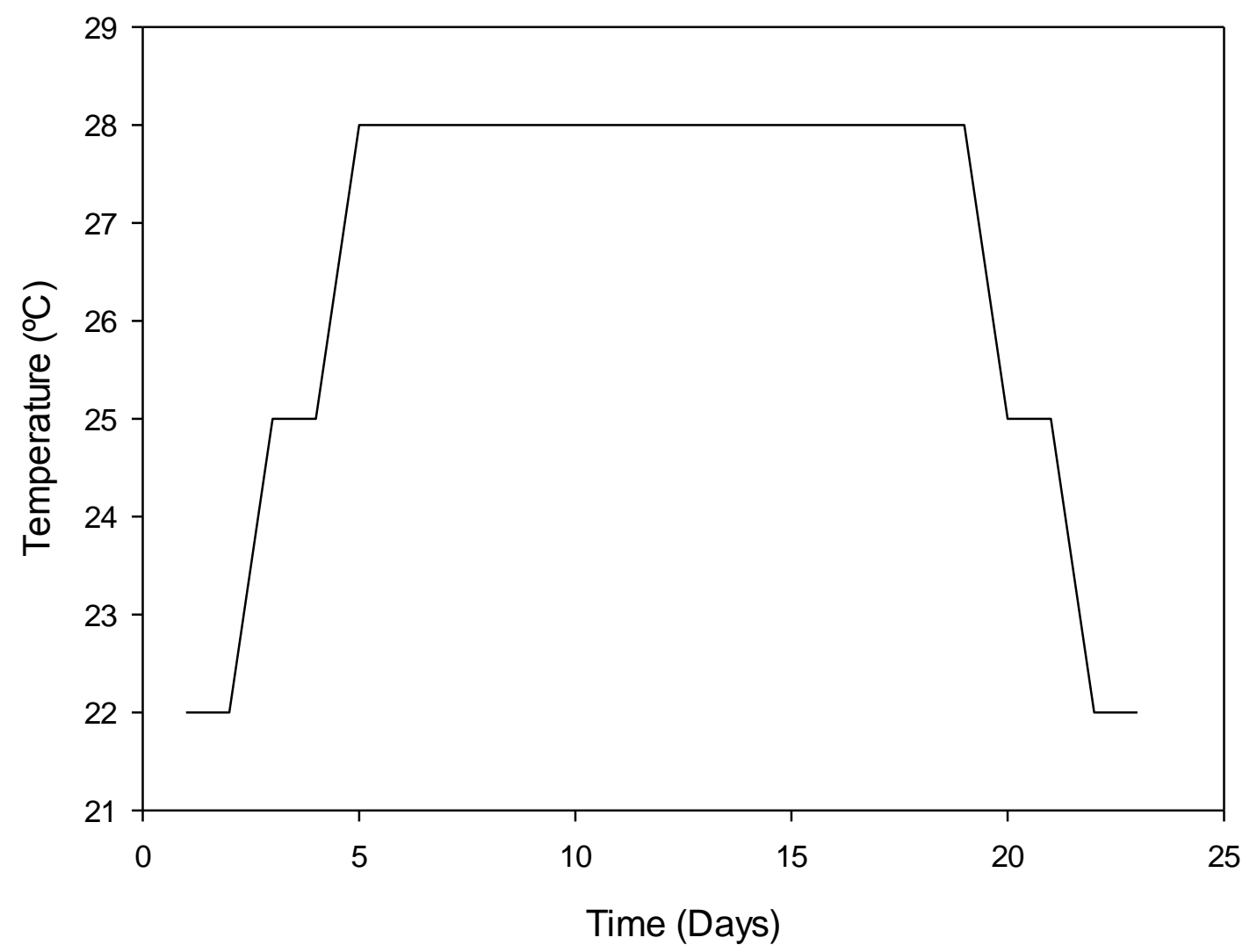

Figure 3.1: Long term heat exposure temperature ramp including a two week holding period at $28^{\circ} \mathrm{C}$. Prior to reaching the maximum temperature of $28^{\circ} \mathrm{C}$, cultures were exposed to an incremental temperature increase. Following the two week exposure to $28^{\circ} \mathrm{C}$, temperatures were deceased to $25^{\circ} \mathrm{C}$ for $48 \mathrm{~h}$, and then to $22^{\circ} \mathrm{C}$ for $72 \mathrm{~h}$.

\section{Sample Collection}

Samples were collected at designated time points into each decreasing temperature change after the two week holding period. It was assumed that FA composition would show the same trends as shown in the increasing temperature step portion of Ramp \#1 (see Chapter 2); therefore, samples were collected during and after the prolonged heat exposure only. Samples were collected every $72 \mathrm{~h}$ throughout the two-week holding time to establish the conditions prior to decreasing temperature steps. At the $28-25^{\circ} \mathrm{C}$ step, samples were collected at 24 and $48 \mathrm{~h}$. At 
$25-22^{\circ} \mathrm{C}$ decrease, samples were collected at 24,48 and $72 \mathrm{~h}$. The 72 -h time point was included during the final step in order to determine whether a longer period is required for FA content to return to original content values. In order to ensure that sample collection was occurring at the desired water temperature and to account for the lag period between changes in air temperature and water temperature, water temperature was measured until the desired temperature point was reached. When culture temperatures reached the necessary temperature, the timer for sample collection was set in order to ensure that cultures were exposed to the new temperature for the necessary time. Once water temperatures were held for respective time based on temperature step and time sampling point, three culture replicate flasks were removed. Cultures were centrifuged in $15 \mathrm{~mL}$ Kimax tubes at $2000 \mathrm{rpm}$ to concentrate algal cells into a pellet. Before centrifugation, a sample ( $3 \mathrm{~mL}$ ) of each culture is used for a spectrophotometer (Perkin Elmer Lambda 20, absorbance readings at $800-500 \mathrm{~nm}$ ) reading in order to obtain the OD for cell counts. Algal cell pellets were then transferred to cryovials and samples were freeze dried in preparation for total lipid and FA analysis.

\section{Lipid and Fatty Acid Analysis}

Fatty acid analysis was performed using the same methodology outlined in Chapter 2.

\section{Statistical Analysis}

\section{MANOVA}

To assess the effects that time and temperature and FA group/type had on FA composition for all FA groups (i.e. there were multiple dependent measures), a MANOVA was used. Time was set as a categorical predictor with time categories representing sampling points $(\mathrm{t}=0, \mathrm{t}=24, \mathrm{t}=48)$. Temperature treatments were used as a categorical variable as well with the four temperature treatments representing each temperature change that occurred $\left(28-25^{\circ} \mathrm{C}, 25-\right.$ 
$22^{\circ} \mathrm{C}$ ). Data was transformed using a $\log 10$ transformation to normalize the data. The MANOVA allowed us to examine the effects that temperature treatment and time had on FA group sums (SFA, MUFA, and PUFA), and also to examine the effects that temperature treatment and time had on select FA of interest (18:0, 16:1n-7, 18:1n-9, EPA and DHA). Two MANOVA was performed using SPSS 24. The first MANOVA used FA group as a categorical predictor using the sum FA groups (SFA, MUFA, and PUFA). The second MANOVA used FA type as a categorical predictor for the individual fatty acids (18:0, 16:1n-7, 18:1n-9, EPA and DHA). The follow up univariate analyses (ANOVA) and Tukey post-hoc tests allowed me to examine the effects that temperature treatment and time had on FA group sums (SFA, MUFA and PUFA) and also on select fatty acids of interest (18:0, 16:1n-7, 18:1n-9, EPA and DHA).

\section{Repeated Measures ANOVA}

A repeated measures ANOVA was used to take into consideration how the FA of interest responded through time and temperature treatment. FA content was measured repeatedly through the temperature treatments across six different time points. FA content across the sampling times was defined as the within-subjects variable. Temperature treatment and FA group/type were used as categorical variables for between subject factors. Data was transformed using a log10 transformation in order to normalize the data. This allowed me to analyze the effects that temperature treatment and time had on FA group sums (SFA, MUFA, PUFA) and select FA of interest (18:0, 16:1n-7, 18:1n-9, EPA and DHA). The repeated measures ANOVA was performed using SPSS 24. The repeated measures ANOVA also examined the interactions between time and temperature, time and FA group/FA type and between time, temperature and FA group/type. Two repeated measures ANOVA were performed. The first repeated measures ANOVA used FA group as a categorical variable for between-subject factors. The second 
repeated measures ANOVA used FA type as a categorical variable for between-subject factors. By controlling for time, an overall effect of temperature, FA group/type and a combination of temperature and FA group/type was calculated.

\section{Initial and Final FA Content Comparison}

A paired t-test was used to compare FA content from the initial control $\left(\mathrm{t}=0,22^{\circ} \mathrm{C}\right)$ to the final sampling of the temperature regime. Paired t-tests were performed to compare FA content between the $\mathrm{t}=48 \mathrm{~h}$ time point at $25-22^{\circ} \mathrm{C}$ and $\mathrm{t}=72 \mathrm{~h}$ at $25-22^{\circ} \mathrm{C}$ to the initial control values. For monounsaturated fatty acids (MUFA; including 16:1n-7 and 18:1n-9), a two-tailed t-test was performed using SPSS since no distinctive pattern in response to temperature has been observed in past research. For SFA and PUFA (including EPA and DHA), a one-tailed t-test was performed using SPSS 24 since a distinctive relationship with temperature has been observed in previous algal research (Fuschino et al., 2011; Pasquet et al., 2014), Tests were performed for SFA, MUFA, PUFA, EPA, DHA, 16:1n-7 and 18:1n-9.

\section{Results}

MANOVA

When examining the overall effects of predictors on FA group content (SFA, MUFA and PUFA) no predictors elicited a significant effect on FA content (Table 3.1). This indicates that as a result of long term heat exposure, FA content is not strongly influenced by temperature, time or a combination of time and temperature. Univariate analyses on temperature (Table 3.3) and time (Table 3.4) also showed no distinctive pattern as observed during the short-term temperature ramp. As a result of temperature, 16:1n-7 $(\mathrm{p}=0.023)$ and MUFA $(\mathrm{p}=0.029)$ showed significant increased as a result of temperature changes. MUFA content was found to increase by $28.3 \%$ and 16:1n-7 increased by $40.6 \%$ as a result of temperature decreases. Time did not have a significant 
effect on FA content. This indicates that there is no significant increase or decrease found as a result of time in FA content under long-term heat conditions. Post-hoc analysis further revealed no significant differences between different temperature treatments for FA group and FA type. This indicates that as a result of temperature, FA content was not significantly influenced. Posthoc analysis also showed no significant differences between time points which further shows that after long-term heat exposure FA content is not as strongly influenced by predictors as observed in the short-term temperature ramp.

\section{Repeated Measures ANOVA}

Out of the potential effectors and combinations of different effectors, under long-term heat exposure it was observed that no effector elicited a significant response in FA content changes (Table 3.5). This indicates that SFA, MUFA and PUFA content did not experience significant net increases or decreases as a response to time, temperature or time and temperature combined. When time samples were pooled to determine the effects of temperature and FA group on FA content, temperature $(\mathrm{p}=0.005)$, FA group $(\mathrm{p}<0.001)$ and a combination of temperature and FA group $(\mathrm{p}=0.039)$ all were found to have significant effects on FA content (Table 3.6). This indicates that temperature has a strong influence on FA content. SFA content was found to experience a significant increase by $10.2 \%$ over temperature treatments. MUFA content was also found to significantly increase $27.8 \%$ over the temperature decreases. PUFA content was also found to significantly increase by $9.5 \%$ over the temperature treatments. FA group also showed significant differences due to the large differences seen between SFA ( $30 \%$ content), MUFA ( $\sim 60 \%$ content) and PUFA ( $10 \%$ content).

When examining the potential effect of variables on specific FA (Table 3.7), no significant difference for FA content was observed. This shows that the individual FA analyzed 
were not influenced by these variables. This further was supported when time was pooled to observe the overall effect of temperature and FA type (Table 3.8). Temperature did not have an influence on the individual fatty acid (EPA, DHA, 16:1n-9, 18:1n-7) content.

\section{Initial and Final FA Content Comparison}

FA content before and after long term heat exposure $\left(\mathrm{t}=48 \mathrm{~h}\right.$ at $\left.25-22^{\circ} \mathrm{C}\right)$ was found to only be significantly different for PUFA $(p=0.03)$, DHA $(p=0.026)$ and 16:1n-7 $(p=0.043)$ (Table 3.9, Figs. 3.2 and 3.3). PUFA content decreased by $31.2 \%$ from initial conditions indicating a significant net loss in PUFA content. DHA content also experienced a significant decrease by $29.7 \%$ from initial conditions. This is indicative that there was a net loss in FA content in PUFA and DHA. While not significantly different, the negative T-value for SFA content indicates that there is a trend for a higher concentration of SFA after being exposure to high heat than in the original conditions. SFA content was shown to increase by $11.6 \%$ from initial conditions. At $\mathrm{t}=72 \mathrm{~h}$ during the recovery period $\left(25-22^{\circ} \mathrm{C}\right)$, no significant differences in FA content were seen (Table 3.10, Figs. 3.4 to 3.6), indicating that after 72 hours, FA content has the potential to return to initial values.

\section{Long-Term Temperature F.A Content and Short-Term Temperature F.A Content}

\section{Comparison}

To determine whether there is a difference in FA content during the $3^{\circ} \mathrm{C}$ temperature decrease from $28-25^{\circ} \mathrm{C}$, the two time points $(\mathrm{t}=24 \mathrm{~h}$ and $\mathrm{t}=48 \mathrm{~h})$ were compared using a $\mathrm{t}$-test (Table 3.11); however, no significant differences were detected. There were no differences in FA content comparing $\mathrm{t}=24$ and $\mathrm{t}=48 \mathrm{~h}$ during the temperature decrease from $25-22^{\circ} \mathrm{C}$ (Table 3.12). 
Table 3.1: Multivariate analysis results for the overall effects of predictors (time, temperature, combined time and temperature) for fatty acid content across (saturated fatty acids, monounsaturated fatty acids, polyunsaturated fatty acids).

\begin{tabular}{|l|l|l|l|l|l|}
\hline Effect & Value & Hypothesis d.f. & Error d.f. & F-Stat & P-Value \\
\hline Temperature Treatment & 0.654 & 3 & 10 & 1.76 & 0.217 \\
\hline Time & 0.235 & 9 & 24 & 2.22 & 0.057 \\
\hline Time and Temperature & 0.593 & 3 & 10 & 2.29 & 0.141 \\
\hline
\end{tabular}

Table 3.2: Multivariate analysis results for the overall effects of predictors (time, temperature, combined time and temperature) for individual fatty acid content (EPA, DHA, 16:1n-7, 18:1n-9, and 18:0).

\begin{tabular}{|l|l|l|l|l|l|}
\hline Effect & Value & Hypothesis d.f. & Error d.f. & F-Stat & P-Value \\
\hline $\begin{array}{l}\text { Temperature } \\
\text { Treatment }\end{array}$ & 0.596 & 5 & 8 & 1.08 & 0.437 \\
\hline Time & 0.282 & 15 & 22 & 0.872 & 0.600 \\
\hline Time and Temperature & 0.594 & 5. & 8 & 1.09 & 0.433 \\
\hline
\end{tabular}

Table 3.3: Univariate analysis results for the effect of temperature treatment on each major fatty acid group (saturated fatty acids, monounsaturated fatty acids and polyunsaturated fatty acids; d.f.=1) and individual fatty acids (EPA, DHA, 16:1n-7, 18:1n-9, and 18:0; d.f=3) used in order to determine the individual effect that temperature has on fatty acid content within major fatty acid groups.

\begin{tabular}{|l|l|l|}
\hline Fatty Acid Group & F-Stat & P-Value \\
\hline $18: 0$ & 0.071 & 0.794 \\
\hline $16: 1 n-7$ & 6.74 & $\mathbf{0 . 0 2 3}$ \\
\hline $18: 1 n-9$ & 0.523 & 0.484 \\
\hline $20: 5 n-3($ EPA) & 4.38 & 0.058 \\
\hline $22: 6 n-3$ (DHA) & 0.001 & 0.98 \\
\hline SFA & 4.12 & 0.065 \\
\hline MUFA & 6.14 & $\mathbf{0 . 0 2 9}$ \\
\hline PUFA & 3.52 & 0.085 \\
\hline
\end{tabular}


Table 3.4: Univariate analysis results for the effect of time had on major fatty acid group (saturated fatty acids, monounsaturated fatty acids and polyunsaturated fatty acids; d.f $=1$ ) and individual fatty acids (EPA, DHA, 16:1n-7, 18:1n-9, and 18:0; d.f=3) used in order to determine the individual effect that time has on fatty acid content within major fatty acid groups.

\begin{tabular}{|l|l|l|}
\hline Fatty Acid Group & F-Stat & P-value \\
\hline $18: 0$ & 2.48 & 0.111 \\
\hline $16: 1 \mathrm{n}-7$ & 1.10 & 0.387 \\
\hline $18: 1 \mathrm{n}-9$ & 0.912 & 0.464 \\
\hline $20: 5 \mathrm{n}-3$ (EPA) & 0.493 & 0.694 \\
\hline $22: 6 \mathrm{n}-3$ (DHA) & 0.562 & 0.006 \\
\hline SFA & 0.282 & 0.837 \\
\hline MUFA & 0.953 & 0.446 \\
\hline PUFA & 0.162 & 0.920 \\
\hline
\end{tabular}

Table 3.5: Repeated measures multivariate analysis for different effectors on fatty acid content in fatty acid groups (saturated, monounsaturated and polyunsaturated) to determine the overall effect that time, temperature, fatty acid group and a combination of these variables has on fatty acid content changes.

\begin{tabular}{|l|l|l|l|l|l|}
\hline Effect & Value & Hypothesis d.f & Error d.f & F-Stat & P-Value \\
\hline Time & 0.884 & 2 & 11 & 0.718 & 0.509 \\
\hline $\begin{array}{l}\text { Time and } \\
\text { Temperature }\end{array}$ & 0.717 & 2 & 11 & 2.16 & 0.161 \\
\hline $\begin{array}{l}\text { Time and FA } \\
\text { Group }\end{array}$ & 0.032 & 4 & 22 & 0.090 & 0.985 \\
\hline $\begin{array}{l}\text { Time, } \\
\text { Temperature and } \\
\text { FA Group }\end{array}$ & 0.87 & 4 & 20 & 0.395 & 0.810 \\
\hline
\end{tabular}

Table 3.6: Overall effects of temperature treatment and fatty acid group while time is controlled to determine the individual and combined overall effects on fatty acid content in fatty acid groups (saturated fatty acids, monounsaturated fatty acids and polyunsaturated fatty acids).

\begin{tabular}{|l|l|l|l|l|}
\hline Effect & Mean Square & d.f. & F-Stat & P-Value \\
\hline Temperature & 0.451 & 1 & 12.0 & $\mathbf{0 . 0 0 5}$ \\
\hline FA Group & 3.143 & 2 & 83.6 & $<\mathbf{0 . 0 0 1}$ \\
\hline $\begin{array}{l}\text { Temperature and } \\
\text { Group }\end{array}$ & 0.162 & 2 & 4.30 & $\mathbf{0 . 0 3 9}$ \\
\hline
\end{tabular}


Table 3.7: Repeated measures multivariate analysis for different effectors on fatty acid content in specific fatty acids (EPA, DHA, 16:1n-7, 18:1n-9 and 18:0) to determine the overall effect that time, temperature, fatty acid group and a combination of these variables has on fatty acid content changes.

\begin{tabular}{|l|l|l|l|l|l|}
\hline Effect & Value & Hypothesis d.f. & Error d.f. & F-Stat & P-value \\
\hline Time & 0.994 & 2 & 19 & 0.061 & 0.941 \\
\hline $\begin{array}{l}\text { Time and } \\
\text { Temperature }\end{array}$ & 0.839 & 2 & 19 & 1.82 & 0.190 \\
\hline $\begin{array}{l}\text { Time and FA } \\
\text { Type }\end{array}$ & 0.996 & 2 & 19 & 0.041 & 0.960 \\
\hline $\begin{array}{l}\text { Time, } \\
\text { Temperature and } \\
\text { FA Type }\end{array}$ & 0.847 & 2 & 19 & 1.71 & 0.207 \\
\hline
\end{tabular}

Table 3.8: Overall effects of temperature treatment and FA type while time is controlled to determine the individual and combined overall effects on fatty acid content in specific fatty acids (EPA, DHA, 16:1n-7, and 18:1n-9).

\begin{tabular}{|l|l|l|l|l|}
\hline Effect & Mean Square & d.f. & F-Stat & P-Value \\
\hline Temperature & 0.242 & 1 & 0.585 & 0.453 \\
\hline FA Type & 3.29 & 1 & 7.956 & $\mathbf{0 . 0 1 1}$ \\
\hline $\begin{array}{l}\text { Temperature and } \\
\text { FA Type }\end{array}$ & 0.191 & 1 & 0.462 & 0.504 \\
\hline
\end{tabular}

Table 3.9: $T$-test results for comparison of initial control conditions to $t=48 \mathrm{~h}$ at $25-22^{\circ} \mathrm{C}$. Control conditions consisted of cultures grown at $22^{\circ} \mathrm{C}$. A one tailed t-test was used for saturated fatty acids (SFA), polyunsaturated fatty acids (PUFA), EPA and DHA due to the directional response expected. A two-tailed t-test was used for monounsaturated fatty acids (MUFA), 16:1n7 and 18:1n-9. The comparison on the initial control fatty acid content to the $t=48 \mathrm{~h}$ shows whether fatty acid content experiences a full recovery after long-term temperature exposure.

\begin{tabular}{|l|l|l|}
\hline & T-Stat & P-Value \\
\hline $16: 1 \mathrm{n}-7$ & -4.68 & $\mathbf{0 . 0 4 3}$ \\
\hline $18: 1 \mathrm{n}-9$ & 0.507 & 0.662 \\
\hline $20: 5 \mathrm{n}-3$ & -1.47 & 0.14 \\
\hline $22: 6 \mathrm{n}-3$ & -0.774 & $\mathbf{0 . 0 2 6}$ \\
\hline SFA & -2.47 & 0.066 \\
\hline MUFA & -3.72 & 0.065 \\
\hline PUFA & -3.92 & $\mathbf{0 . 0 3}$ \\
\hline
\end{tabular}


Table 3.10: $T$-test results for comparison of initial control conditions to $t=72 \mathrm{~h}$ at $25-22^{\circ} \mathrm{C}$. Control conditions consisted of cultures grown at $22^{\circ} \mathrm{C}$. A one tailed t-test was used for saturated fatty acids (SFA), polyunsaturated fatty acids (PUFA), EPA and DHA due to the directional response expected. A two-tailed t-test was used for monounsaturated fatty acids (MUFA), 16:1n7 and 18:1n-9. The comparison on the initial control fatty acid content to the $t=72 \mathrm{~h}$ shows whether fatty acid content experiences a full recovery after long-term temperature exposure.

\begin{tabular}{|l|l|l|}
\hline & T-Stat & P-Value \\
\hline $16: 1 \mathrm{n}-7$ & -1.13 & 0.376 \\
\hline $18-1 \mathrm{n}-9$ & 0.685 & 0.564 \\
\hline $20: 5 \mathrm{n}-3$ & -0.645 & 0.293 \\
\hline $22: 6 \mathrm{n}-3$ & 0.990 & 0.214 \\
\hline SFA & -0.331 & 0.386 \\
\hline MUFA & -0.997 & 0.212 \\
\hline PUFA & 0.302 & 0.395 \\
\hline
\end{tabular}

Table 3.11: Long-term versus short-term conditions at $28-25^{\circ} \mathrm{C}$. Fatty acid content values at $\mathrm{t}=24 \mathrm{~h}$ and $\mathrm{t}=48 \mathrm{~h}$ at $28-25^{\circ} \mathrm{C}$ during the short-term temperature ramp were compared to FA content values at $\mathrm{t}=24 \mathrm{~h}$ and $\mathrm{t}=48 \mathrm{~h}$ at $28-25^{\circ} \mathrm{C}$. The comparison of long term-conditions to short-term conditions determines whether there is a difference in the rate of fatty acid recovery.

\begin{tabular}{|c|c|c|c|c|}
\hline & \multicolumn{2}{|l|}{ T-Stat } & \multicolumn{2}{|c|}{ P-Value } \\
\hline & $\mathrm{T}=24$ & $\mathrm{~T}=48$ & $\mathrm{~T}=24$ & $\mathrm{~T}=48$ \\
\hline $16: 1 n-7$ & 1.85 & 0.884 & 0.206 & 0.470 \\
\hline $18: 1 n-9$ & 6.21 & 0.757 & 0.025 & 0.528 \\
\hline $20: 5 n-3$ & 1.00 & 1.19 & 0.211 & 0.178 \\
\hline $22: 6 n-3$ & 0.927 & 0.573 & 0.226 & 0.313 \\
\hline SFA & 2.40 & 0.980 & 0.069 & 0.215 \\
\hline MUFA & 2.21 & 0.871 & 0.157 & 0.476 \\
\hline PUFA & 2.11 & 1.96 & 0.085 & 0.313 \\
\hline
\end{tabular}

Table 3.12: Long-term versus short-term conditions at $25-22^{\circ} \mathrm{C}$. Fatty acid content values at $\mathrm{t}=24 \mathrm{~h}$ and $\mathrm{t}=48 \mathrm{~h}$ at $25-22^{\circ} \mathrm{C}$ during the short-term temperature ramp were compared to fatty acid content values at $\mathrm{t}=24 \mathrm{~h}$ and $\mathrm{t}=48 \mathrm{~h}$ at $25-22^{\circ} \mathrm{C}$. The comparison of long term-conditions to short-term conditions determines whether there is a difference in the rate of fatty acid recovery.

\begin{tabular}{|c|c|c|c|c|}
\hline & \multicolumn{2}{|c|}{ T-Stat } & \multicolumn{2}{c|}{ P-Value } \\
\hline $16: 1 \mathrm{n}-7$ & -0.846 & -0.267 & 0.487 & 0.814 \\
\hline $18: 1 \mathrm{n}-9$ & 11.5 & -1.15 & $\mathbf{0 . 0 0 7}$ & 0.368 \\
\hline $20: 5 \mathrm{n}-3$ & 2.65 & 0.979 & 0.056 & 0.202 \\
\hline $22: 6 \mathrm{n}-3$ & -1.00 & -3.58 & 0.212 & 0.407 \\
\hline SFA & -1.24 & -0.665 & 0.17 & 0.184 \\
\hline MUFA & -0.555 & -0.167 & 0.635 & 0.883 \\
\hline PUFA & 1.61 & -1.02 & 0.124 & 0.202 \\
\hline
\end{tabular}




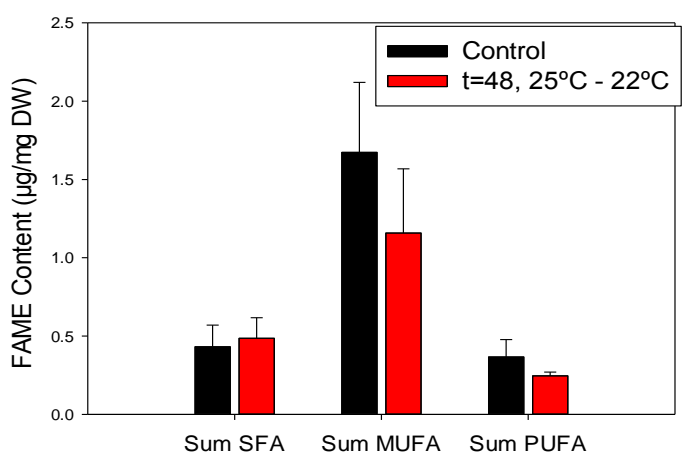

Figure 3.2: Average fatty acid methyl ester (FAME) concentration values for the control condition and $t=48 \mathrm{~h}$ sampling time for saturated fatty acids, monounsaturated fatty acids and polyunsaturated fatty acids. Error bars denote standard deviations.

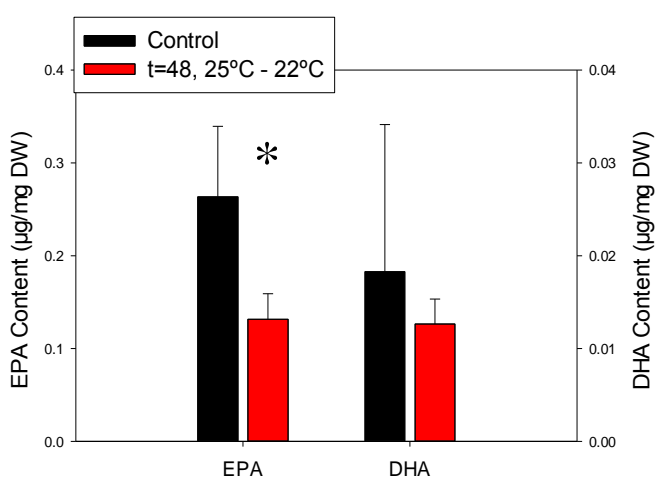

Figure 3.3: Average fatty acid methyl ester (FAME) concentration values for the control condition and $t=48 \mathrm{~h}$ sampling time for EPA and DHA. Error bars denote standard deviations. Groups marked with a * were significantly different at $\mathrm{P}<0.05$

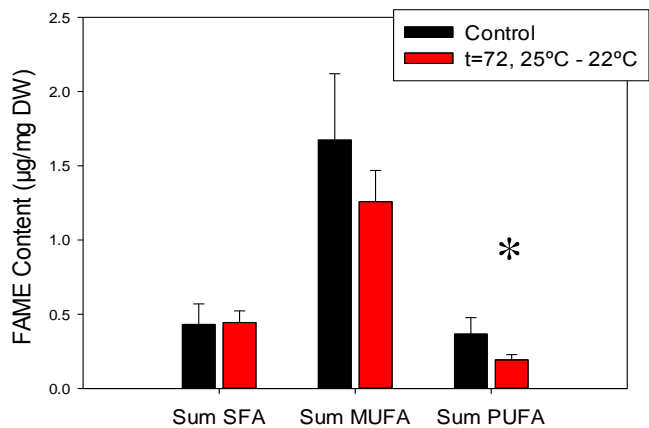

Figure 3.4: Average fatty acid methyl ester (FAME)

concentration values for the control condition and $t=72 \mathrm{~h}$ sampling time for saturated fatty acids, monounsaturated fatty acids and polyunsaturated fatty acids.. Error bars denote standard deviations. Groups marked with a * were significantly different at $\mathrm{P}<0.05$

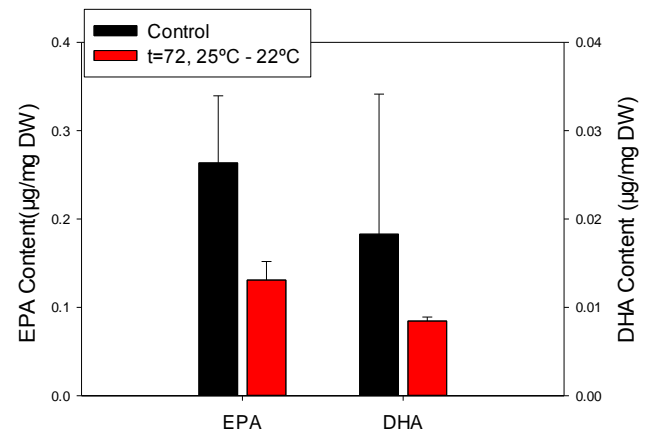

Figure 3.5: Average fatty acid methyl ester (FAME) concentration values for the control condition and $\mathrm{t}=72 \mathrm{~h}$ sampling time for EPA (left-axis) and DHA (right-axis). Error bars denote standard deviations. Groups marked with a * were significantly different at $\mathrm{P}<0.05$. 


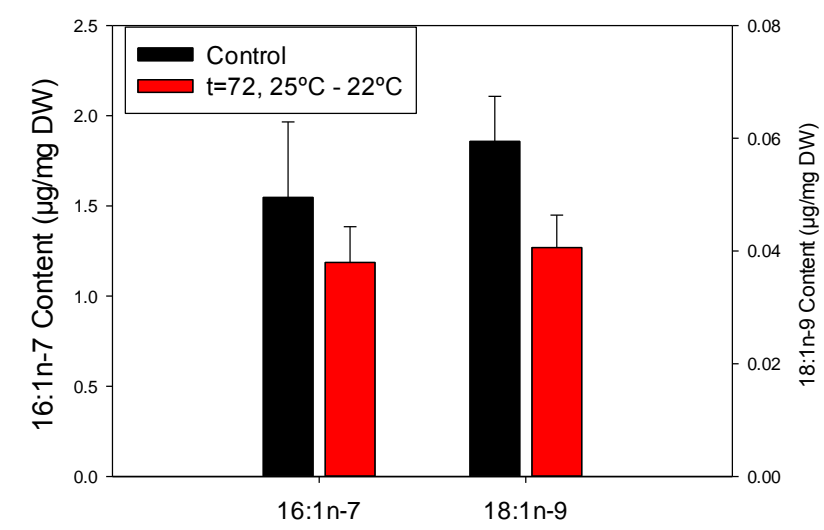

Figure 3.6: Average fatty acid methyl ester (FAME) content values for the control condition and $\mathrm{t}=72 \mathrm{~h}$ sampling time for 16:1n-7 (left-axis) and 18:1n-9 (right-axis). Error bars denote standard deviations. Groups marked with a * indicate a significant difference. 


\section{Discussion}

After two weeks of exposure to $28^{\circ} \mathrm{C}$, and the temperature restored to $22^{\circ} \mathrm{C}$ for $48 \mathrm{~h}$, there was no difference in SFA, MUFA, PUFA, DHA, 16:1n-7 and 18:1n-9 amounts when comparing pre- and post- long term heat exposure. This indicates that after two weeks of exposure to suboptimal high heat conditions, the FA content of $N$. pelliculosa, returned to original values found at optimal conditions, prior to heat exposure (with the exception of EPA). Long term heat exposure of up to $14 \mathrm{~d}$ resulted in a net loss of EPA after the temperature was lowered to the optimal growth temperature $\left(22^{\circ} \mathrm{C}\right)$. This was observed after 48 hours of exposure at $22^{\circ} \mathrm{C}$, and the same result was observed after $72 \mathrm{~h}$ of exposure. This suggests that EPA was not capable of recovering to original pre-heat content values after experiencing heat stress in this experiment.

An increase in water temperature has been found to result in a decrease in PUFA content in varying algal species (including EPA and DHA; Pasquet et al. 2014; Fuschino et al., 2011). However, an examination of the effects of length of exposure and a subsequent decrease in temperature was not performed in these studies. The net loss in EPA after heat exposure in the present study suggests that EPA may either: a) not have the potential to recover to original values; or, b) $>72 \mathrm{~h}$ is required for EPA to recover. Multiple environmental conditions influence FA composition such that growth conditions other than water temperature may have influenced FA content and the recovery of PUFA during temperature treatments. The difference observed in EPA at $\mathrm{t}=48$ and $\mathrm{t}=72$, and PUFA at $\mathrm{t}=72$ post-long term exposure compared to the control values (pre-long term exposure), but not with DHA could be due to the trace amounts of DHA found in samples. DHA accounts for a very small amount of FA in this strain of N. pelliculosa $(\sim 1 \%)$, and is also seen in trace amounts in literature values (Ying et al., 2000). This may also suggest a greater physiological demand for maintenance of DHA content. If DHA has a greater 
physiological role in $N$. pelliculosa, the conversion of EPA to DHA might be favored contributing to the observed decrease in EPA.

It is possible that the increased light conditions (24-h light cycle) may have caused photooxidative damage to cells. High light exposure has been shown to increase total FA content (Solovchenko et al., 2008). Excessive light can result in photooxidative damage to algae and photosynthetic apparatus, photosystem II (PSII) (Solovchenko et al., 2008; Gombos et al., 1997). During temperature treatments, cultures were grown under $24 \mathrm{~h}$ light at an average of $184 \mu \mathrm{mol}$ photons $\mathrm{m}^{-2} \mathrm{~s}^{-1}$. In Solovchenko et al., 2008, light intensities of $200 \mu \mathrm{mol}$ photons $\mathrm{m}^{-2} \mathrm{~s}^{-1}$ for a green algae $P$. incisa was found to not be saturating. However, in Synechococcus sp. cultures used in Gombos et al., 1997, light intensities of $70 \mu \mathrm{mol}$ photons $\mathrm{m}^{-2} \mathrm{~s}^{-1}$ were used. This is indicative of different optimal light intensities for different algal species suggesting that the light intensity used during temperature treatments may have been approaching saturating conditions. Under conditions of high saturating light, photoinhibition of photosynthesis may occur by, a) quenching of excitation energy available to PSII resulting in a decrease in photosynthetic rates; or, b) light induced damage to photosynthetic machinery (Gombos et al., 1997). Previous work has shown that under conditions of high light, PUFA content, in particular EPA, has an influence on the ability to tolerate high light conditions via protection pathways, suggesting a role of PUFA in protecting algae from photoinhibition (Klyachko-Gurvich et al., 1999; Gombos et al., 1992). Due to the high light conditions exposed to N. pelliculosa cultures it would be expected that there is the chance for photoinhibition and photooxidative damage to occur. However, PUFA content, including EPA and DHA, may be conserved even under exposure to high temperatures, to protect cells from experiencing damage to the photosynthetic machinery and protect from detrimental losses in photosynthetic rates. Due to the non-significant difference 
found in DHA content, it is possible that DHA has a stronger role in being able to tolerate high light conditions and DHA content is conserved under high light exposure. However, since high temperatures result in the decline of PUFA content, DHA content is potentially conserved at the expense of EPA content under both high temperature and high light exposure conditions.

Exposure to elevated temperature for extended periods can lead to cellular damage and genetic damage depending on the extent of heat stress and the length of exposure (Kreslavski et al., 2007). Under moderate levels of stress, organisms have the potential to recover fully but damage becomes irreversible when the stress period is extended (Kreslavski et al., 2007). The omega-3 LC-PUFA, EPA and DHA, are produced in algae through enzymatic activity of a desaturase and an elongase (Pottel et al., 2014; Masclaux et al., 2012). Desaturases insert a double bond between carbons, and elongases extend the acyl carbon chain of the FA, which synthesize the LC-PUFA from precursor FA (Pottel et al., 2014; Masclaux et al., 2012). Desaturase is encoded for by various desaturase genes and specifically the $\omega 3$-desaturase is encoded for by $\operatorname{des} B$ (Sakamoto and Bryant, 1997; Los et al., 1993). Previous research has shown decreased concentrations of $\operatorname{des} B$ and other desaturase transcripts under elevated temperatures in Synechocystis and Synechococcus (Sakamoto and Bryant, 1997; Los et al., 1993). The temperature dependence of the expression of desaturase genes (Los et al., 1997; Sakamoto and Bryant, 1997) suggests at elevated temperatures that the production of desaturase enzymes is decreased and accounts for the decrease seen in EPA and PUFA content. Along with decreased genetic expression of desaturase genes with temperature increases, temperature has also been connected to enzymatic activity of desaturase and elongase in Pythium irregular and in developing soybean seeds (Cantrell and Walker, 2009; Cheesbrough, 1989). This further can potentially contribute to the loss of EPA and PUFA content. 
Contrary to what was hypothesized, the long-term temperature ramp did not show significant differences in FA content. This suggests that the recovery pathway after $48 \mathrm{~h}$ of high temperature and of two weeks of high temperature is similar. This means that the PUFA content, including EPA and DHA, are higher during the long-term temperature ramp than what was originally hypothesized. Increases in temperature can result in increased metabolic rates as a mechanism to acclimate to temperature changes (Staehr and Birkeland, 2006). If metabolic rates were increased in response to the temperature increases, the nutrient content in the CHU-10 media may have been depleted abnormally quickly in comparison to growth experienced under control conditions. Previous research has shown that conditions of nutrient limitation, in particular nitrogen, result in elevated PUFA content (Rodolfi et al., 2008; Solovchenko et al., 2008). Limiting amounts of trace elements available to algal cultures have also shown the rapid accumulation of neutral lipids (Chen et al., 2011). A decrease in nutrients and trace elements available to $N$. pelliculosa would result in elevated PUFA, EPA, and DHA content in the longterm temperature ramp. The increased PUFA content as a result of nutrient starvation in longterm temperature treatment cultures could cause FA content recovery to mimic the short-term temperature ramp recovery process closer than what would have been seen if other environmental conditions (i.e. nutrient availability, light) did not influence the FA content and recovery process.

The remaining FA groups analyzed exhibited full recovery after the exposure of high heat for an extended period. The recovery suggests that $N$. pelliculosa is perhaps thermo-tolerant and is able to respond to heat stress appropriately. During the high temperature $\left(28^{\circ} \mathrm{C}\right)$, PUFA, EPA, and DHA content decreased as expected. This suggests that multi-day heat waves would result in lower nutritional food sources available to primary consumers. However, during the short-term 
temperature ramp, the decreased PUFA content would only influence nutritional quality for a shorter amount of time. To fully assess whether a long-term heatwave or many short term heat waves would be more damaging to food web dynamics, short-term temperature treatments would have to be examined in depth. While the long-term heat wave scenario would be detrimental to organisms during this period, many short-term heat waves could result in exponential decreases in PUFA content after each temperature increase. From what was observed during the long-term temperature treatment performed during this experiment, it suggests that the aftermath would not provide different PUFA content availability to consumers.

In previous research, $N$. pelliculosa has shown the ability to maintain metabolic rates over a wide range of temperatures (Chalifour and Juneau, 2011). Many species of algae have shown the ability to survive in wide temperature ranges of up to $20^{\circ} \mathrm{C}$ for some species (Staehr and Birkeland, 2006). Alternatively, it may indicate that $14 \mathrm{~d}$ of heat exposure allowed $N$. pelliculosa to acclimate to new growth conditions. Other diatom species (Phaeodactylum tricornutum and Chaetoceros muelleri) have shown thermal-tolerant abilities (Rousch et al., 2003). In thermo-tolerant species, FA content did not show significant differences under heat stress (Rousch et al., 2003). While this research did not examine the effects of a subsequent temperature decrease, the ability for $N$. pelliculosa to recover FA content after long term heat exposure indicates that the heat stress imposed did not influence SFA and MUFA content. Previous research has shown that acclimation to growth conditions can occur within $21 \mathrm{~d}$ of exposure (Gracilariopsis lemaneiformis) (Ji et al., 2016), suggesting the possibility that after 14 $\mathrm{d}$ of elevated temperature exposure, cultures can acclimate and experience recovery. Algae have shown the ability to rapidly adapt to new environmental conditions inside of their temperature growth range (Staehr and Birkeland, 2006). By altering cellular processes (i.e. metabolism, 
photosynthesis) and physiological characteristics algae are able to acclimate and survive in varying temperatures (Staehr and Birkeland, 2006). Certain algae species are capable of increasing optimal growth temperatures when exposed to elevated temperatures for multiple generations (Das et al., 2013). This suggests that algal populations have the potential to evolutionarily respond to growth temperatures when exposed to long-term environmental conditions.

Phenotypic acclimation allows organisms to survive in changing environments (Kubler and Davison, 1995). For example, elevated growth temperatures can result in an increase in photosynthetic pigment content in algae, resulting in increased photosynthetic rates (Kubler and Davison, 1995). These adaptations are often reversible; indicating that after exposure to stressful conditions there is the ability for algae to recover, unless the stress has led to cellular damage (Anderson et al., 1995). Since the short-term temperature ramp and long-term temperature ramps showed similar recovery pathways of FA content, it suggests that the adaptations to elevated temperature are reversible in both scenarios. Due to the similar recovery processes seen in the short-term temperature ramp and long-term temperature ramps, it suggests that the adaptations to changing temperatures are reversible in both situations.

There was no significant difference between FA content under long-term elevated temperature exposure and short-term elevated temperature exposure. This suggests that the content of FA found at $\mathrm{t}=24$ and $\mathrm{t}=48 \mathrm{~h}$ are not influenced whether they are exposed to $28^{\circ} \mathrm{C}$ for $14 \mathrm{~d}$ (as in Temperature ramp \#2) or for $48 \mathrm{~h}$ (as in Temperature ramp \#1, see Chapter 2). This suggests that the recovery potential after long term exposure to $28^{\circ} \mathrm{C}$ is similar to the recovery potential to short term exposures. The similarities observed in recovery potential under long term heat conditions and short term conditions suggests that length of heat exposure does not 
influence the recovery potential in FA content in $N$. pelliculosa. This also suggests that FA composition is not necessarily influenced by length of exposure, and alternatively may respond to: a) the temperature of exposure; and, b) the time of exposure before FA content plateau is maintained. This further supports that FA content in cultures exposed to long term high temperatures respond in a similar fashion as found in cultures grown under short term temperature regime conditions. However, since the short-term temperature ramp showed a similar recovery pathway to the long-term temperature ramp, this indicates that either: a) prolonged heat exposure or light exposure did not result in excessive cellular and genetic damage, or b) the damage from the short-term temperature exposure (and potentially increased light exposure) is equivalent to the damage caused during the long-term temperature ramp. Since only FA content was measured during the two different temperature regimes, the possibility remains that damages in other cellular processes or genetic areas could have been obtained during the long-term temperature ramp. The similar pattern seen in FA content recovery may indicate that the desaturase and elongase enzymes were not damaged at all, or were damaged at the same frequency despite the different temperature treatments. Temperatures exceeding optimal growth temperatures are believed to be more deleterious to algae than temperatures lower than optimal growth temperatures (Das et al., 2013). However, due to the similar recovery pathways, it suggests that $28^{\circ} \mathrm{C}$ does not exceed optimal growth temperatures enough to result in deleterious and permanent effects to fatty acid content.

Spring and early summer temperatures were not found to exceed or approach temperatures of $28^{\circ} \mathrm{C}$ during the years of 2013-2016 (see Appendix 2). Since diatoms, such as $N$. pelliculosa grow in the spring due to nutrient availability, it suggests that the FA content responses witnessed during the temperature treatment are in line with what can be expected with 
future climate warming. Summer surface water temperatures were shown to exceed $32^{\circ} \mathrm{C}$ (see Appendix 2). To assess how these summer surface water temperatures will affect aquatic food web dynamics and FA content, green algae should be examined with the same schematic of temperature/time regime used for $N$. pelliculosa. Under worst case climate change scenarios, temperatures are predicted to increase by up to $9^{\circ} \mathrm{C}$ in certain regions (Bush et al., 2014). While this would prove detrimental if imposed instantaneously, the gradual temperature increases annually give the potential for algal populations to acclimate. The changes that occur in cellular processes, biochemical characteristics, and photosynthetic apparatus, in response to temperature increases can be reversed if damage is not sustained. The recovery seen in the long-term temperature treatment further indicates that damage was not accumulated and that the changes experienced in response were able to be reversed. 


\section{Chapter 4}

\section{Summary and Research Recommendations}

\section{Summary}

Climate change is causing temperature increases and is being accelerated by anthropogenic emissions of $\mathrm{CO}_{2}$ and other greenhouse gases (Bush et al., 2014; Hegerl et al., 2004). As a result of increases in water temperatures, saturated fatty acid (SFA) content incorporation in membranes of algae is predicted to increase, and long-chain polyunsaturated fatty acid (LC-PUFA) content is predicted to decrease (Hixson and Arts, 2016; Sperfield and Wacker, 2012; Fuschino et al., 2011). LC-PUFA play a critical role in maintaining physiological health in organisms, but are predominantly produced by aquatic primary producers (Gladyshev et al., 2015; Gladyshev et al., 2013; von Elert, 2002). High trophic level organisms, including humans, should obtain LC-PUFA from dietary sources in order to meet physiological requirements, due to inefficient production (Hixson et al., 2015; Honeyfield and Maloney, 2015; Gladyshev et al., 2011). As a result of climate change, LC-PUFA could decrease, resulting in decreased availability of these critical compounds to all organisms (Hixson et al., 2015). As the majority of LC-PUFA are derived from algae, it is necessary to understand how elevated temperatures will affect fatty acid (FA) content in these organisms (Gladyshev et al., 2013; von Elert, 2002), and how this may affect the potential for cascading effects through other trophic levels.

Fushino (2010) observed that $\sim 6 \mathrm{~h}$ was required in order to create a significance difference in FA content of a green algae (Scenedesumus obliquus) exposed to elevated water temperatures. They also observed that after $10 \mathrm{~d}$ of being exposed to elevated temperatures MUFA, PUFA, EPA, 16:1n-7, 18:1n-9 and total FA content was found to be significantly 
different than FA content profiles measured prior to temperature treatments. Thus, from their study it appears that FA content may not fully recover to original levels and that therefore there is an asymmetrical distribution of FA (i.e. comparing profiles before and after the temperature shift). This suggests that in response to increasing temperatures as a result of heat waves, there will potentially be a net loss in FA content availability (for some period) in primary producers in freshwater ecosystems. A net loss in FA content, in particular the LC-PUFA, EPA and DHA, could have detrimental effects to high trophic level organisms by reducing the availability of dietary sources of these physiologically required FA.

Contrary to this hypothesis, the recovery of fatty acid content in $N$. pelliculosa under long-term heat exposure was not found to be significantly different in comparison to the shortterm temperature ramp. This suggests that the length of time of high heat exposure (i.e. $48 \mathrm{~h} v s$. 14 days at $28^{\circ} \mathrm{C}$ ) does not influence the recovery potential of fatty acid content in N. pelliculosa. If the recovery potential of FA content in N. pelliculosa is not influenced by total time of exposure to high heat, this means that FA content will not be as detrimentally affected during heat wave conditions as originally hypothesized. However, due to the predicted increase in frequency and severity of extreme heat days as a result of climate change (Kharin et al., 2007; Vincent and Mekis, 2006), LC-PUFA content may experience amplified losses compared to a controlled temperature setting. It also appears that in both long-term and short-term conditions, DHA content is not significantly different as a result of time or temperature, suggesting that DHA is physiologically conserved. The physiological conservation of DHA content observed in N. pelliculosa could be beneficial to primary consumers, since this will not decrease dietary sources of DHA required for healthy growth, reproduction and survival to high trophic level organisms. 
While the elevated long-term heat conditions created during the second temperature regime did not impact DHA content severely in $N$. pelliculosa, responses of DHA content in different freshwater algae and the increased severity/frequency of extreme heat days should be considered before concluding if DHA availability to other organisms will be threatened with climate change. In comparison to initial control conditions, a significant difference in EPA was observed at $\mathrm{t}=48$ and $\mathrm{t}=72 \mathrm{~h}$, and total PUFA at $\mathrm{t}=72 \mathrm{~h}$. Similar to the results found in the shortterm temperature ramp, this suggests that total PUFA and EPA do not have the capability to fully recover, resulting in a net loss in EPA and PUFA content as a result of heat exposure. SFA content, while not significantly different between control conditions and $t=48$ and $t=72 \mathrm{~h}$, showed a net increase in the long-term heat exposure regime. This in combination with the results found for PUFA and EPA suggests that under long-term heat exposure there is a total shift in the composition of fatty acid groups as a result of temperature change.

\section{Research Recommendations}

With the imposing threats of temperature increases as a result of anthropogenic pressures on freshwater ecosystems, the biochemical and physiological response pathways need to be fully understood in order to fully assess potential damage owing to increasing water temperature. Due to the critical role that algae play in global aquatic ecosystems, it is necessary to understand how fluctuating and elevated temperatures will influence physiological and biochemical characteristics in different algal populations.

As algae are an important food source in aquatic ecosystems, future work could examine the suitability of temperature-treated algae as a food source for primary consumers. Consumption of algae grown at different temperature/time treatments by primary producers, such as a common zooplankton Daphnia magna, would show how higher temperature will influence the quality of 
nutrients, and how this will affect growth and survival of primary consumers. This will help to determine the magnitude of a potential cascading effect that temperature may have on higher trophic levels. To further observe the effects of elevated temperatures on FA content across trophic levels, secondary consumers (i.e. fish) can be observed on a diet composed of zooplankton raised on temperature-treated algal food sources. By examining the FA content at multiple trophic levels, this will help to determine the strength of the cascading effect that environmental conditions such as temperature, such as altering food web dynamics. Furthermore, primary consumers such as Daphnia magna could be exposed to the same time/temperature regimes and assessed with the temperature-treated diet in comparison to organisms only fed a non-temperature treated diet in order to determine the strength of the effect that environmental characteristics, diet, or a combination of both environmental characteristics and diet have on the physiological and biochemical characteristics of primary consumers.

Since my experiments only looked at one species of algae, it would be helpful to examine other species subjected to the same temperature regimes. Different algae species can potentially have different temperature thresholds and FA recovery pathways. Due to the seasonality of algal populations, it is also important to assess and understand how different algal species and populations respond in order to fully determine whether climate change will result in a deficit in PUFA availability depending on the species of algae found in a system. Assessing the FA recovery pathway of different algal species and taxa will also help to determine whether the potential for FA recovery after temperature fluctuations is phylogenetically independent, or whether all algal taxa possess the same capability of FA recovery after heat exposure. Along with examining multiple species of algae, multiple temperature regimes should be considered (i.e. altering minimum/maximum temperatures, altering time of exposure to novel temperatures) 
in order to broaden understanding of the effects of different temperature scenarios on FA content in algae.

While my controlled laboratory experiment set out to minimize other environmental factors such as light cycles so as to be able to examine the effect that time and temperature independently have on FA content and recovery, this is not representative of what would be found in a natural environment. To determine whether the responses seen in the controlled laboratory temperature regimes is representative of what would occur in an environmental setting, temperature treatment regimens following the same temporal basis should be carried out in a field setting using mesocosms. In a natural environment, many combined factors (including temperature and time) will influence FA content and recovery. Although having multiple factors influencing FA content in algae could complicate the effects a temperature regime, it will more realistically represent the changes in FA content and recovery expected to be seen with a changing climate.

Finally, to expand the breadth of knowledge on the effects of heat exposure on algae, an examination on the genetic and evolutionary level can be performed. This will help determine the evolutionary potential that short term or long term heat exposure has on algal populations. Phenotypic plasticity and acclimation had previously been discussed as a method for algae to rapidly adjust to novel environmental changes; however, this often is energetically costly to maintain for long term conditions (Thompson, 1991). Understanding the evolutionary response that algal populations follow when exposed to stress will help determine whether there is potential for algal populations to be able to evolve in order to survive in novel environmental conditions created by climate change. Using a modified Luria-Delbrück fluctuation analysis, the effects of short-term and long-term temperature exposure on survival and mutation rates can be 
determined. A modified Luria-Delbrück fluctuation analysis determines whether mutations in cultures are induced as a result of environmental factors (i.e. elevated temperatures), or whether mutations occur spontaneously (Luria and Delbrück, 1943). Assessing whether mutations occur spontaneously or are induced, will further demonstrate how algal populations respond to thermal stress and what the evolutionary potential of algal populations is during long-term climate change trends. 


\title{
Appendix 1: Common Abbreviations and Fatty Acid Categorization
}

\author{
Abbreviations: \\ FA \\ Fatty acid(s) \\ SFA \\ Saturated fatty acid(s) \\ MUFA \\ Monounsaturated fatty acid(s) \\ PUFA \\ Polyunsaturated fatty acid(s) \\ LC-PUFA \\ Long-chain polyunsaturated fatty acid(s) \\ Eicosapentaenoic acid \\ EPA (20:5n-3) \\ Docosahexaenoic acid \\ DHA (22:6n-3) \\ FAME \\ Fatty acid methyl esters
}

\section{Fatty Acid Categorization:}

18:0

$16: 1 n-7$

$18: 1 n-9$

20:5n-3 (EPA)

22:6n-3 (DHA)
Saturated fatty acid

Monounsaturated fatty acid

Monounsaturated fatty acid

Polyunsaturated fatty acid

Polyunsaturated fatty acid 


\section{Appendix 2: Navicula pelliculosa Growth Conditions}

\section{$\underline{\text { CHU10 Media Recipe }}$}

Modified by J. Acreman, Canadian Phycological Culturing Centre.

\begin{tabular}{|l|l|l|}
\hline Stock & Stock Solution & $\mathrm{mL} / \mathrm{Litre}$ \\
\hline $\mathrm{Na}_{2} \mathrm{SiO}_{3} * 9 \mathrm{H}_{2} \mathrm{O}$ & $5 \mathrm{~g} / \mathrm{L}$ & $10 \mathrm{~mL}$ \\
\hline $\mathrm{Ca}\left(\mathrm{NO}_{3}\right)_{2} * 4 \mathrm{H}_{2} \mathrm{O}$ & $57.56 \mathrm{~g} / \mathrm{L}$ & $1 \mathrm{~mL}$ \\
\hline $\mathrm{K}_{2} \mathrm{HPO}_{4}$ & $10 \mathrm{~g} / \mathrm{L}$ & $1 \mathrm{~mL}$ \\
\hline $\mathrm{MgSO}_{4} * 7 \mathrm{H}_{2} \mathrm{O}$ & $25 \mathrm{~g} / \mathrm{L}$ & $1 \mathrm{~mL}$ \\
\hline $\mathrm{Na}_{2} \mathrm{CO}_{3}$ & $20 \mathrm{~g} / \mathrm{L}$ & $1 \mathrm{~mL}$ \\
\hline $\mathrm{F} / 2 \mathrm{Vitamins}$ & $*$ see below & $1 \mathrm{~mL}$ \\
\hline $\mathrm{Na}_{2} \mathrm{EDTA}^{*} 2 \mathrm{H}_{2} \mathrm{O}$ & $1 \mathrm{~g} / \mathrm{L}$ & $1 \mathrm{~mL}$ \\
\hline Trace Metal Mix & $*$ see below & $1 \mathrm{~mL}$ \\
\hline Ferric citrate and citric acid & $6.00 \mathrm{~g} / \mathrm{L}$ & $1 \mathrm{~mL}$ \\
\hline $\mathrm{H}_{2} \mathrm{SeO}_{3}$ & $0.163 \mathrm{~g} / \mathrm{L}$ & $0.5 \mathrm{~mL}$ \\
\hline
\end{tabular}

\begin{tabular}{|l|l|}
\hline Trace Metal Mix & \\
\hline Substance & g/Litre \\
\hline $\mathrm{H}_{3} \mathrm{BO}_{3}$ & $2.86 \mathrm{~g}$ \\
\hline $\mathrm{MnCl}_{2} * 4 \mathrm{H}_{2} \mathrm{O}$ & $1.81 \mathrm{~g}$ \\
\hline $\mathrm{ZnSO}_{4} * 7 \mathrm{H}_{2} \mathrm{O}$ & $0.222 \mathrm{~g}$ \\
\hline $\mathrm{Na}_{2} \mathrm{MoO}_{4} * 2 \mathrm{H}_{2} \mathrm{O}$ & $0.390 \mathrm{~g}$ \\
\hline $\mathrm{CuSO}_{4} * 5 \mathrm{H}_{2} \mathrm{O}$ & $0.079 \mathrm{~g}$ \\
\hline $\mathrm{Co}\left(\mathrm{NO}_{3}\right)_{2} * 6 \mathrm{H}_{2} \mathrm{O}$ & $0.0494 \mathrm{~g}$ \\
\hline
\end{tabular}

\begin{tabular}{|l|l|}
\hline F/2 Vitamin Solution & \\
\hline Stock & Stock Solution \\
\hline Vitamin B12 (Cyanocobalamin) & $5 \mathrm{mg} / 5 \mathrm{~mL}$ \\
\hline Biotin & $1 \mathrm{mg} / 10 \mathrm{~mL}$ \\
\hline
\end{tabular}

\begin{tabular}{|l|l|}
\hline Working Vitamin Solution & \\
\hline Vitamin B12 & $0.1 \mathrm{~mL}$ \\
\hline Biotin & $1.0 \mathrm{~mL}$ \\
\hline Thiamine $\mathrm{HCl}$ & $20 \mathrm{mg}$ \\
\hline
\end{tabular}

Media was adjusted to a $\mathrm{pH}$ of 6.4 using concentrated solutions of $\mathrm{HCl}$ (to decrease $\mathrm{pH}$ ) or $\mathrm{NaOH}$ (to increase $\mathrm{pH}$ ). 


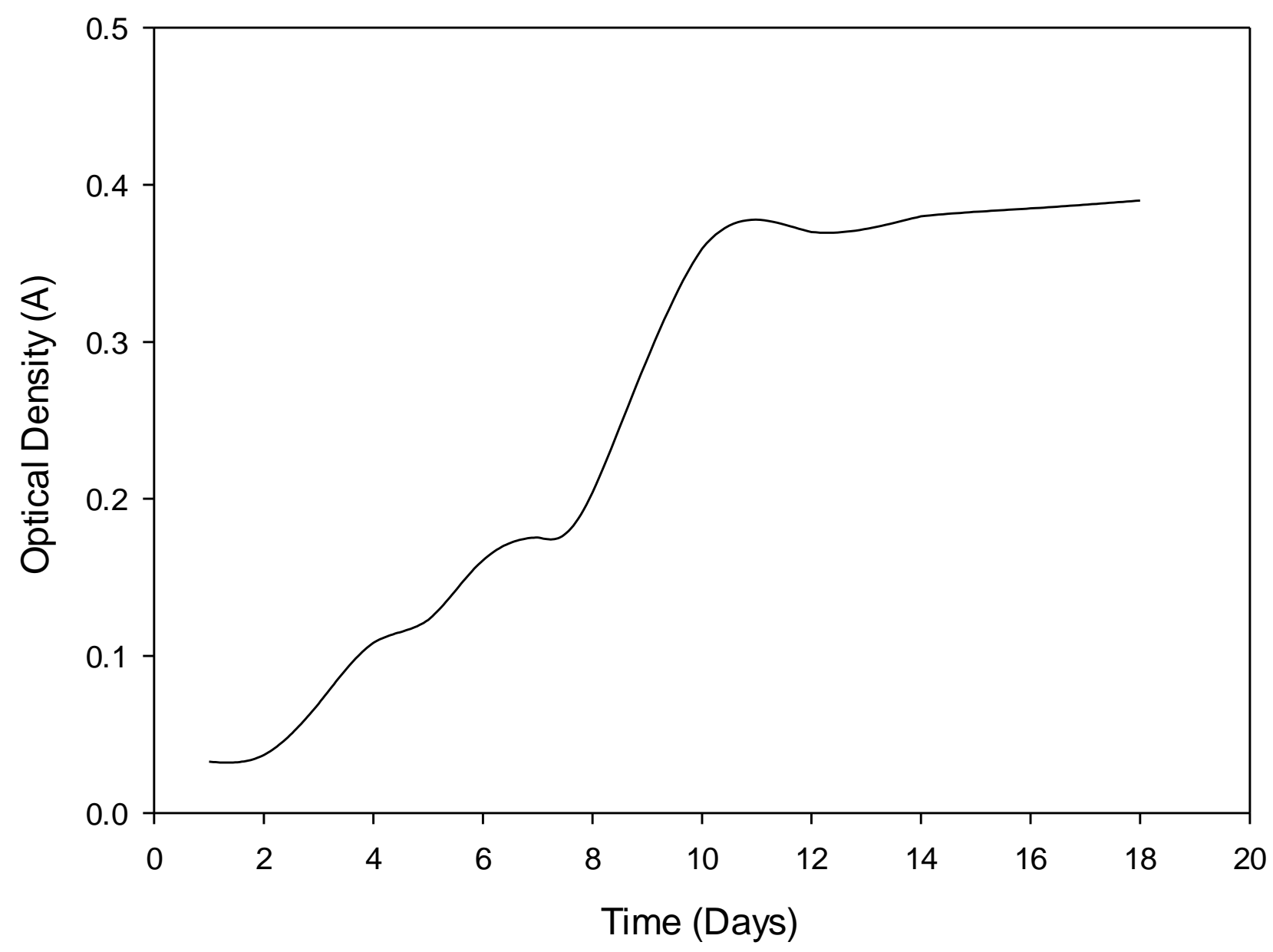

Figure 1: Growth curve of $N$. pelliculosa culture grown at $22^{\circ} \mathrm{C}$ over a three work period. Optical density was measured across the range $500-800 \mathrm{~nm}$. The construction of the growth curve used average $(\mathrm{n}=3)$ absorbance readings at $685 \mathrm{~nm}$. 


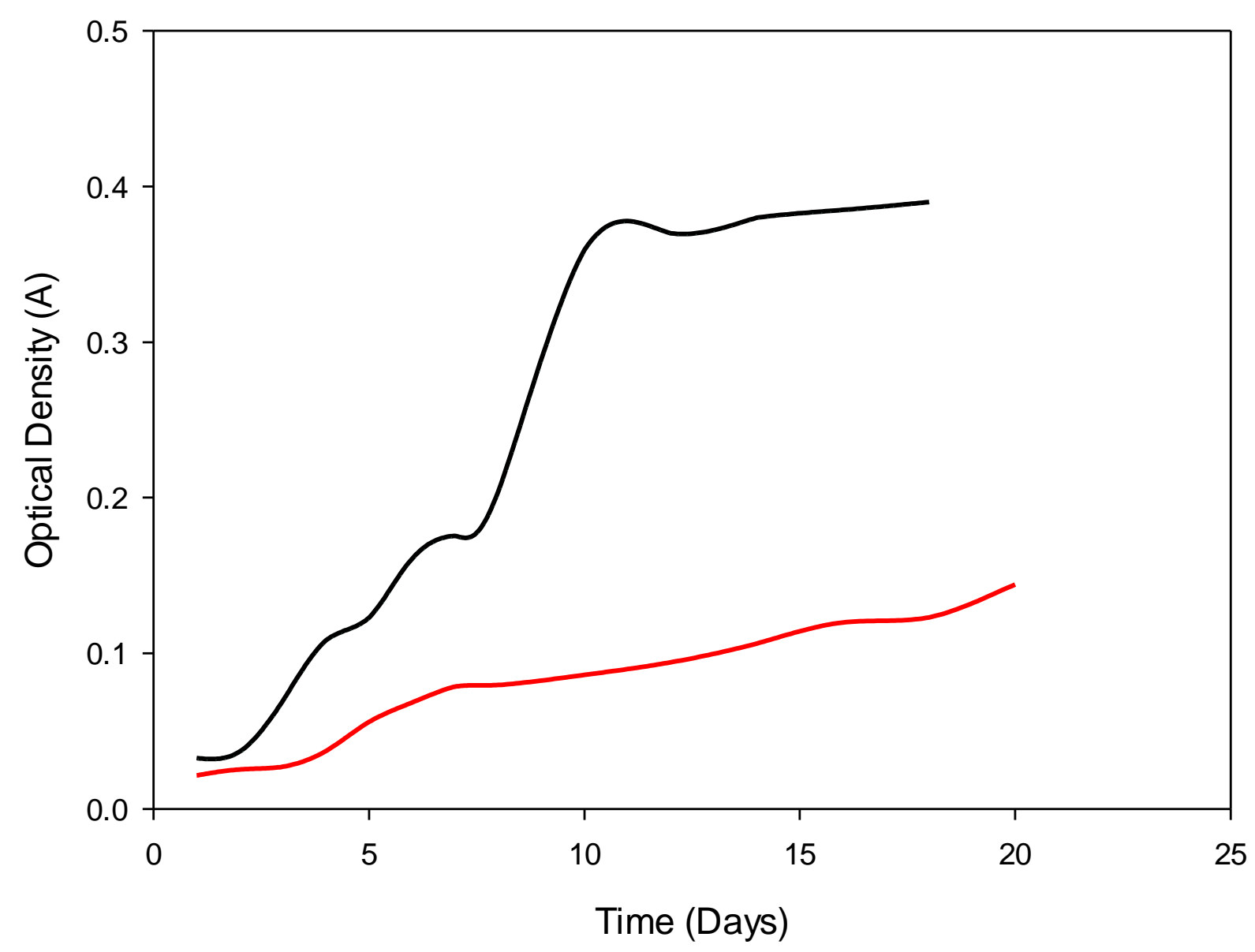

Figure 2: Growth curve of $N$. pelliculosa cultures grown at optimal conditions $\left(22^{\circ} \mathrm{C}\right)$ and at elevated heat $\left(28^{\circ} \mathrm{C}\right)$ represented in red, over a three week period. Growth at the different temperatures was assessed to determine the optimal growth conditions of N. pelliculosa. Optical density was measured across the range $500-800 \mathrm{~nm}$. The growth curve used average absorbance $(\mathrm{n}=3)$ at $685 \mathrm{~nm}$. 


\section{Appendix 3: 2015 Pond Temperatures in Ontario}

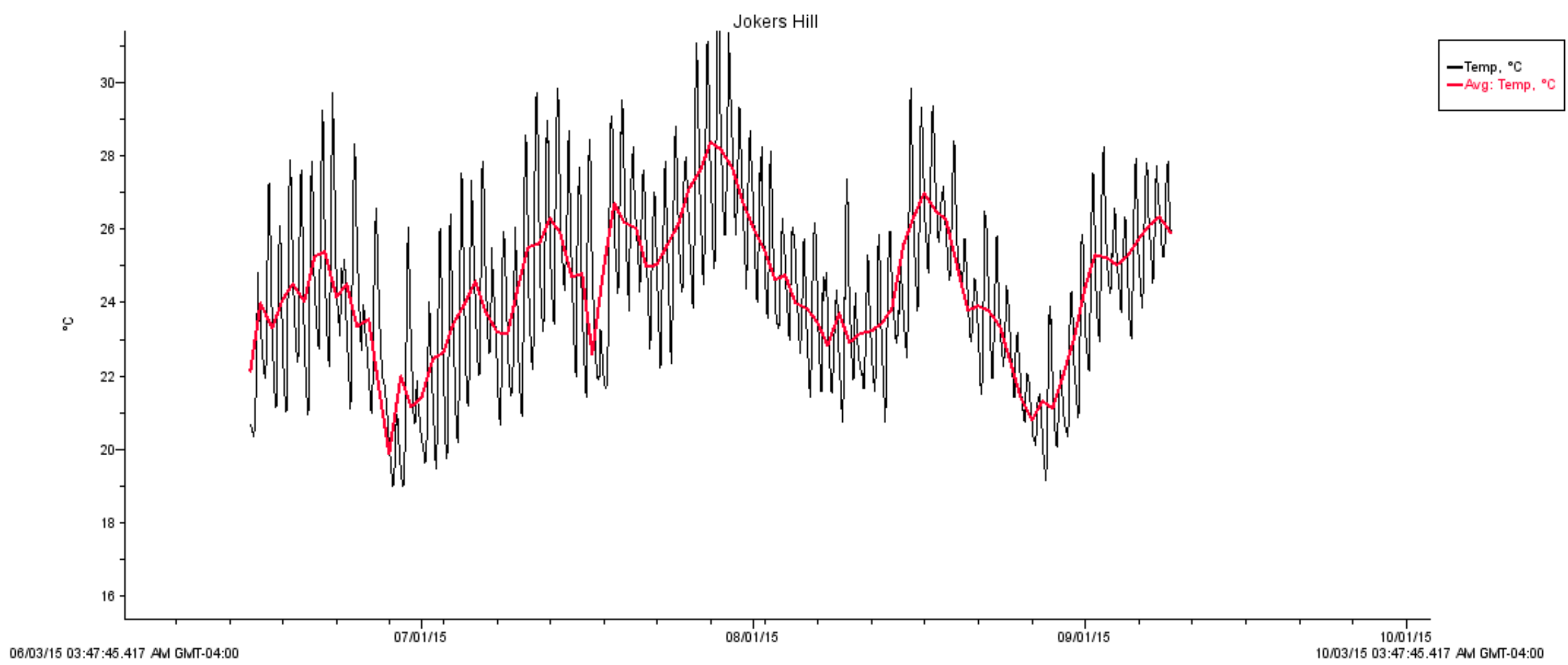

Figure 1: Surface water temperatures $(\sim 15 \mathrm{~cm}$ depth) and daily average temperatures of freshwater pond located at Koffler Scientific Reserve (King City, Ontario, 44.029590, -79.531553). Temperatures were recorded from mid-June until the end of August in the year 2015. Maximum water temperature occurred at the end of July (July 28-29) with a temperature recorded as $32.8^{\circ} \mathrm{C}$. 


\section{Appendix 4: Complete Fatty Acid Profiles- Short Term Temperature Ramp}

(Temperature Ramp \#1, Chapter 2)

Table 1: Control Temperature $\left(22^{\circ} \mathrm{C}\right)$ Fatty Acid Profile

\begin{tabular}{|c|c|c|}
\hline & \% Composition & $\begin{array}{l}\text { FAME Concentration } \\
(\mu \mathrm{g} / \mathrm{mg} \text { D.W })\end{array}$ \\
\hline Saturated & $17.62 \pm 0.99$ & $0.4318 \pm 0.14$ \\
\hline 14:0 & $1.612 \pm 0.11$ & $0.04314 \pm 0.0098$ \\
\hline $15: 0$ & $0.2471 \pm 0.01$ & $0.006625 \pm 0.0017$ \\
\hline 16:0 & $14.28 \pm 0.71$ & $0.3455 \pm 0.1109$ \\
\hline $17: 0$ & $0.1417 \pm 0.034$ & $0.003324 \pm 2.8 \mathrm{e}^{-5}$ \\
\hline 18:0 & $0.6411 \pm 0.066$ & $0.01555 \pm 0.0034$ \\
\hline $20: 0$ & $0.8738 \pm 0.0055$ & $0.02211 \pm 0.0063$ \\
\hline $22: 0$ & $0.0646 \pm 0.0056$ & $0.001725 \pm 0.00049$ \\
\hline $24: 0$ & $0.05275 \pm 0.0095$ & $0.001047 \pm 0.00017$ \\
\hline Monounsaturated & $67.93 \pm 1.6$ & $1.673 \pm 0.44$ \\
\hline $15: 1$ & $0.5056 \pm 0.045$ & $0.0166 \pm 0.0061$ \\
\hline $16: 1 n-7$ & $62.76 \pm 1.3$ & $1.547 \pm 0.42$ \\
\hline $17: 1 n-7$ & $1.30 \pm 0.2$ & $0.03172 \pm 0.0090$ \\
\hline $18: 1 \mathrm{n}-9 \mathrm{c}$ & $2.566 \pm 0.34$ & $0.05945 \pm 0.0080$ \\
\hline $22: 1 n-9$ & $0.09921 \pm 0.0024$ & $0.002657 \pm 0.00078$ \\
\hline $24: 1 n-9$ & $0.541 \pm 0.017$ & $0.0111 \pm 0.0033$ \\
\hline Polyunsaturated & $14.42 \pm 0.64$ & $0.3664 \pm 0.11$ \\
\hline $18: 2 n-6 c$ & $1.543 \pm 0.11$ & $0.04308 \pm 0.014$ \\
\hline $18: 3 n-6$ & $0.1715 \pm 0.0059$ & $0.004746 \pm 0.0013$ \\
\hline $20: 2 n-6$ & $0.1430 \pm 0.013$ & $0.003528 \pm 0.00076$ \\
\hline
\end{tabular}




\begin{tabular}{|l|l|l|}
\hline $20: 3 n-6$ & $0.06857 \pm 0.0016$ & $0.001861 \pm 0.000511$ \\
\hline $20: 3 n-3$ & $0.1138 \pm 0.0061$ & $0.003134 \pm 0.001082$ \\
\hline $22: 2 n-6$ & $0.2842 \pm 0.021$ & $0.2043 \pm 0.03$ \\
\hline $20: 5 n-3$ & $10.42 \pm 0.16$ & $0.2634 \pm 0.076$ \\
\hline $22: 5 n-3$ & $0.7426 \pm 0.19$ & $0.01942 \pm 0.004041$ \\
\hline $22: 6 n-3$ & $0.6323 \pm 0.53$ & $0.01828 \pm 0.01585$ \\
\hline
\end{tabular}


Table 2: Average fatty acid profiles across time for $22-25^{\circ} \mathrm{C}$ presented in FAME content ( $\left.\mu \mathrm{g} / \mathrm{mg} \mathrm{DW}\right)$. In samples where all three replicates did not have specific fatty acids detected, the standard deviation was not listed for consistency.

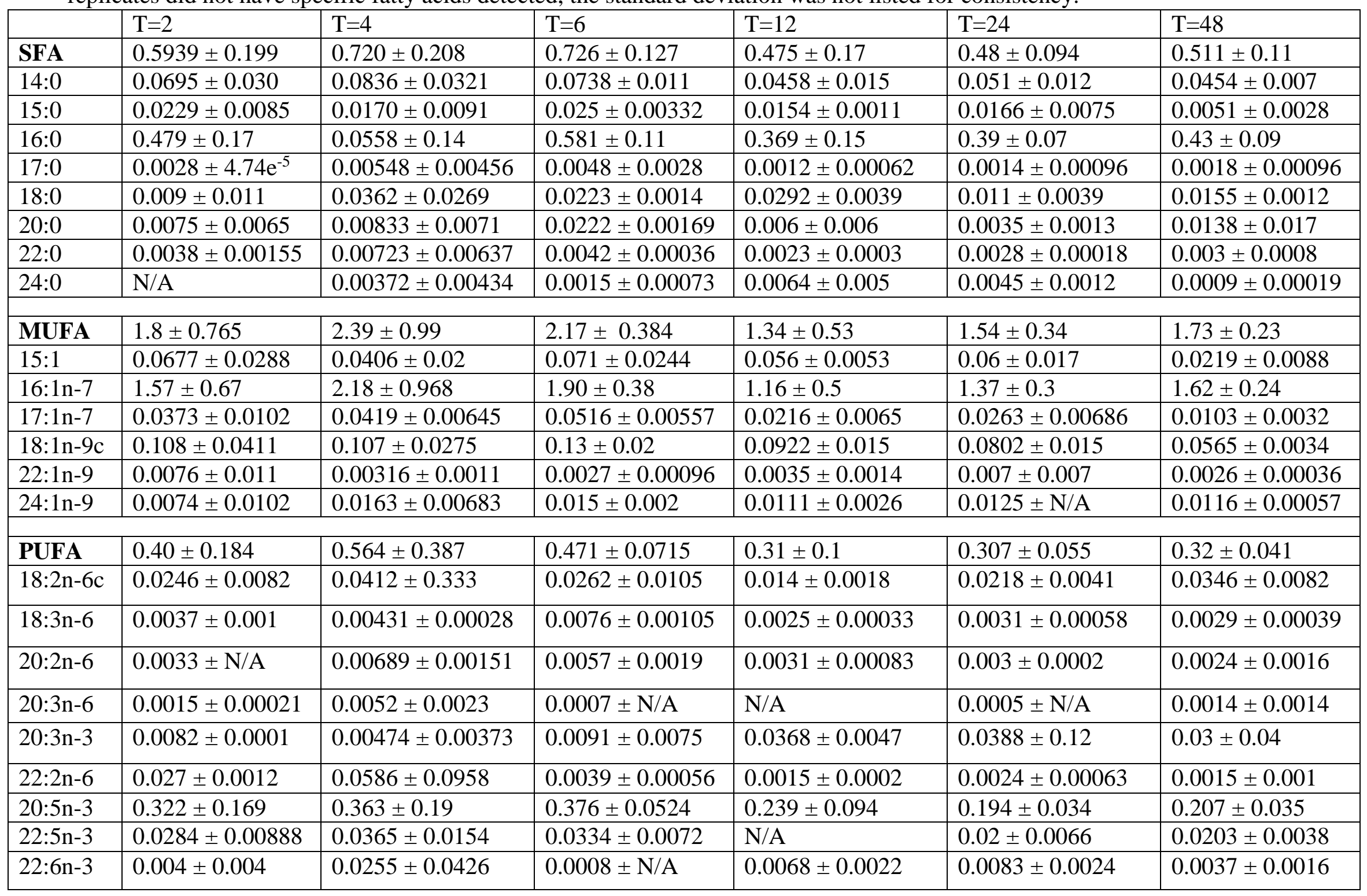


Table 3: Average fatty acid profiles across time at $25-28^{\circ} \mathrm{C}$ presented in FAME content ( $\left.\mu \mathrm{g} / \mathrm{mg} \mathrm{DW}\right)$. In samples where all three replicates did not have specific fatty acids detected, the standard deviation was not listed for consistency.

\begin{tabular}{|c|c|c|c|c|c|c|}
\hline & $\mathrm{T}=2$ & $\mathrm{~T}=4$ & $\mathrm{~T}=6$ & $\mathrm{~T}=12$ & $\mathrm{~T}=24$ & $\mathrm{~T}=48$ \\
\hline $15: 0$ & $0.0077 \pm 0.0039$ & $0.0143 \pm 0.0021$ & $0.0043 \pm 0.0037$ & $0.021 \pm 0.0091$ & $0.0142 \pm 0.0016$ & $0.0056 \pm 0.0045$ \\
\hline $17: 0$ & $0.0033 \pm 0.0016$ & $0.0027 \pm 0.0003$ & $0.0007 \pm 0.0004$ & $0.0017 \pm 0.00078$ & $0.0016 \pm 0.001$ & $0.0028 \pm 0.0013$ \\
\hline 18:0 & $0.0226 \pm 0.01$ & $0.0311 \pm 0.0051$ & $0.0069 \pm 0.0037$ & $0.0405 \pm 0.019$ & $0.0247 \pm 0.0031$ & $0.0113 \pm 0.0021$ \\
\hline $20: 0$ & $0.021 \pm 0.0078$ & $0.0021 \pm \mathrm{N} / \mathrm{A}$ & $0.0218 \pm 0.017$ & $0.0072 \pm 0.0059$ & $0.0146 \pm 0.0017$ & $0.0015 \pm \mathrm{N} / \mathrm{A}$ \\
\hline MUFA & $1.48 \pm 0.54$ & $2.68 \pm 0.67$ & $0.574 \pm 0.26$ & $1.87 \pm 1.1$ & $1.13 \pm 0.25$ & $0.895 \pm 0.29$ \\
\hline $15: 1$ & $0.0231 \pm 0.013$ & $0.0033 \pm 0.0057$ & $0.0127 \pm 0.0048$ & $0.057 \pm 0.013$ & $0.0425 \pm 0.0056$ & $0.0345 \pm 0.022$ \\
\hline $16: 1 n-7$ & $1.32 \pm 0.46$ & $2.52 \pm 0.66$ & $0.528 \pm 0.24$ & $1.67 \pm 1.03$ & $0.994 \pm 0.24$ & $0.82 \pm 0.27$ \\
\hline $17: 1 \mathrm{n}-7$ & $0.0175 \pm 0.0059$ & $0.0258 \pm 0.0026$ & $0.0036 \pm 0.0017$ & $0.0244 \pm 0.012$ & $0.0194 \pm 0.0011$ & $0.0097 \pm 0.0067$ \\
\hline $18: 1 n-9 c$ & $0.0541 \pm 0.017$ & $0.0754 \pm 0.0044$ & $0.0246 \pm 0.0091$ & $0.111 \pm 0.045$ & $0.0688 \pm 0.002$ & $0.0345 \pm 0.029$ \\
\hline $18: 2 n-6 c$ & $0.0462 \pm 0.034$ & $0.0455 \pm 0.0014$ & $0.0176 \pm 0.0091$ & $0.0222 \pm 0.0091$ & $0.021 \pm 0.0041$ & $0.0553 \pm 0.057$ \\
\hline $18: 3 n-6$ & $0.0053 \pm 0.0024$ & $0.0057 \pm 0.0018$ & $0.0014 \pm 0.0007$ & $0.0028 \pm 0.0016$ & $0.0023 \pm 0.00097$ & $0.0018 \pm 0.0011$ \\
\hline $20: 2 n-6$ & $0.0055 \pm 0.0024$ & $0.0059 \pm 0.0014$ & $0.0005 \pm 0.0001$ & $0.0044 \pm 0.0017$ & $0.0033 \pm 0.00088$ & $0.0025 \pm 0.0012$ \\
\hline $20: 3 n-6$ & $0.0032 \pm 0.0011$ & $0.0034 \pm 0.0016$ & $0.0005 \pm \mathrm{N} / \mathrm{A}$ & $0.0008 \pm \mathrm{N} / \mathrm{A}$ & $0.0005 \pm \mathrm{N} / \mathrm{A}$ & $0.0009 \pm 0.0004$ \\
\hline $20: 3 n-3$ & $0.0043 \pm 0.0041$ & $0.0087 \pm 0.011$ & $0.0023 \pm 0.0011$ & $0.0486 \pm 0.016$ & $0.0422 \pm 0.036$ & $0.0158 \pm 0.014$ \\
\hline $22: 2 n-6$ & $0.0035 \pm 0.0018$ & $0.0036 \pm 0.0014$ & N/A & $0.0026 \pm 0.0009$ & $0.0016 \pm \mathrm{N} / \mathrm{A}$ & $0.0018 \pm 0.00056$ \\
\hline $20: 5 n-3$ & $0.195 \pm 0.15$ & $0.206 \pm 0.15$ & $0.0684 \pm 0.028$ & $0.24 \pm 0.087$ & $0.166 \pm 0.058$ & $0.0457 \pm 0.076$ \\
\hline $22: 5 n-3$ & $0.0247 \pm 0.009$ & $0.0326 \pm 0.0025$ & $0.0086 \pm 0.0056$ & N/A & $0.014 \pm 0.0051$ & $0.0195 \pm 0.0079$ \\
\hline $22: 6 n-3$ & $0.0254 \pm 0.018$ & $0.0114 \pm 0.0119$ & $0.0046 \pm 0.0033$ & $0.0092 \pm 0.0051$ & $0.0079 \pm 0.0009$ & $0.0106 \pm 0.0041$ \\
\hline
\end{tabular}


Table 4: Average fatty acid profiles across time at $28-25^{\circ} \mathrm{C}$ presented in FAME content ( $\mu \mathrm{g} / \mathrm{mg}$ DW). In samples where all three replicates did not have specific fatty acids detected, the standard deviation was not listed for consistency.

\begin{tabular}{|c|c|c|c|c|c|c|}
\hline & $\mathrm{T}=2$ & $\mathrm{~T}=4$ & $\mathrm{~T}=6$ & $\mathrm{~T}=12$ & $\mathrm{~T}=24$ & $\mathrm{~T}=48$ \\
\hline SFA & $0.506 \pm 0.24$ & $1.00 \pm 1.04$ & $0.278 \pm 0.24$ & $0.734 \pm 0.14$ & $0.429 \pm 0.12$ & $0.618 \pm 0.42$ \\
\hline 15:0 & $0.0092 \pm 0.0047$ & $0.0077 \pm 0.0044$ & $0.0038 \pm 0.0047$ & $0.0048 \pm 0.0023$ & $0.0136 \pm 0.0029$ & $0.0062 \pm 0.005$ \\
\hline $17: 0$ & $0.001 \pm \mathrm{N} / \mathrm{A}$ & $0.0022 \pm \mathrm{N} / \mathrm{A}$ & N/A & N/A & $0.009 \pm 1.2 \mathrm{e}^{-5}$ & $0.0031 \pm \mathrm{N} / \mathrm{A}$ \\
\hline 18:0 & $0.0084 \pm 0.0059$ & $0.0093 \pm 0.0035$ & $0.0071 \pm 0.0071$ & $0.0208 \pm 0.0088$ & $0.0131 \pm 0.0063$ & $0.0252 \pm 0.02$ \\
\hline $20: 0$ & $0.0288 \pm 0.013$ & $0.02222 \pm 0.017$ & $0.015 \pm 0.011$ & $0.0638 \pm 0.018$ & $0.0124 \pm 0.0069$ & N/A \\
\hline MUFA & $1.12 \pm 0.57$ & $0.776 \pm 0.07$ & $0.544 \pm 0.547$ & $1.29 \pm 0.62$ & $1.19 \pm 0.31$ & $1.88 \pm 1.84$ \\
\hline $15: 1$ & $0.0221 \pm 0.01$ & $0.0244 \pm 0.01$ & $0.01 \pm 0.0088$ & $0.0212 \pm 0.011$ & $0.0377 \pm 0.011$ & $0.0231 \pm 0.013$ \\
\hline $16: 1 n-7$ & $1.04 \pm 0.54$ & $0.891 \pm 0.32$ & $0.506 \pm 0.508$ & $1.21 \pm 0.57$ & $1.08 \pm 0.28$ & $1.78 \pm 1.76$ \\
\hline $17: 1 n-7$ & $0.0073 \pm 0.0026$ & $0.0107 \pm 0.0077$ & $0.0037 \pm 0.0039$ & $0.0073 \pm 0.0016$ & $0.0214 \pm 0.0086$ & $0.0114 \pm 0.014$ \\
\hline $18: 2 n-6 c$ & $0.0294 \pm 0.0066$ & $0.0353 \pm 0.012$ & $0.0145 \pm 0.013$ & $0.0392 \pm 0.013$ & $0.0248 \pm 0.0082$ & $0.0382 \pm 0.02$ \\
\hline $18: 3 n-6$ & $0.0017 \pm \mathrm{N} / \mathrm{A}$ & $0.004 \pm \mathrm{N} / \mathrm{A}$ & N/A & $0.003 \pm \mathrm{N} / \mathrm{A}$ & $0.0039 \pm 0.0018$ & $0.0034 \pm 0.0036$ \\
\hline $20: 2 n-6$ & $0.003 \pm 0.0008$ & $0.0033 \pm 0.0019$ & $0.0021 \pm \mathrm{N} / \mathrm{A}$ & N/A & $0.0039 \pm 0.0018$ & $0.12 \pm 0.16$ \\
\hline $20: 3 n-6$ & $0.0005 \pm \mathrm{N} / \mathrm{A}$ & $0.0027 \pm \mathrm{N} / \mathrm{A}$ & N/A & N/A & N/A & $0.0017 \pm 0.0005$ \\
\hline $20: 3 n-3$ & $0.0076 \pm 0.0066$ & $0.0252 \pm 0.029$ & $0.0024 \pm 0.0004$ & $0.0041 \pm 0.0019$ & $0.0453 \pm 0.034$ & $0.0051 \pm 0.0036$ \\
\hline $22: 2 n-6$ & $0.0018 \pm 0.0012$ & $0.0015 \pm 0.0002$ & N/A & N/A & $0.0016 \pm 0.00067$ & $0.0028 \pm 0.0028$ \\
\hline $20: 5 n-3$ & $0.138 \pm 0.057$ & $0.121 \pm 0.026$ & $0.0604 \pm 0.056$ & $0.122 \pm 0.069$ & $0.0037 \pm 0.0018$ & $0.206 \pm 0.19$ \\
\hline $22: 5 n-3$ & $0.0276 \pm 0.0083$ & $0.0242 \pm 0.0058$ & $0.0139 \pm 0.0084$ & $0.0195 \pm 0.014$ & $0.0217 \pm 0.01$ & $0.026 \pm 0.014$ \\
\hline $22: 6 n-3$ & $0.0115 \pm 0.0045$ & $0.0087 \pm 0.0025$ & $0.0054 \pm 0.0037$ & $0.0086 \pm 0.0033$ & $0.0129 \pm 0.006$ & $0.0175 \pm 0.02$ \\
\hline
\end{tabular}


Table 5: Fatty acid profiles across time at $25-22^{\circ} \mathrm{C}$ presented in FAME content $(\mu \mathrm{g} / \mathrm{mg} \mathrm{DW})$

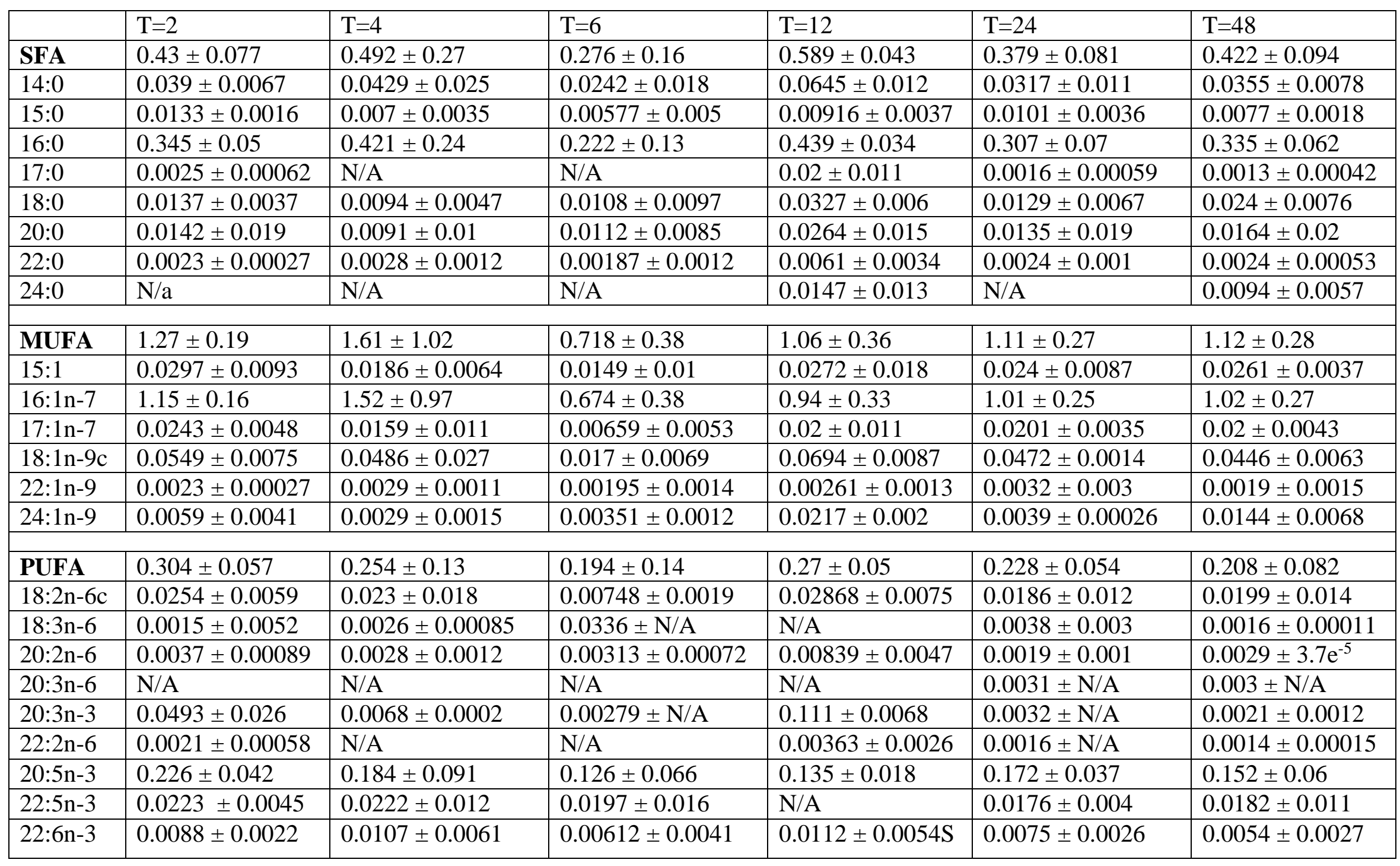




\section{Appendix 5: Complete Fatty Acid Profiles- Long-Term Temperature Ramp (Temperature Ramp \#2, Chapter 3)}

Table 1: Fatty acid profiles across time for decreasing temperature steps of the long term temperature ramp.

\begin{tabular}{|c|c|c|c|c|c|c|}
\hline & \multicolumn{3}{|l|}{$28-25^{\circ} \mathrm{C}$} & \multicolumn{3}{|l|}{$25-22^{\circ} \mathrm{C}$} \\
\hline $14: 0$ & $0.04 \pm 0.014$ & $0.038 \pm 0.019$ & $0.029 \pm 0.009$ & $0.042 \pm 0.0038$ & $0.047 \pm 0.0064$ & $0.042 \pm 0.008$ \\
\hline $16: 0$ & $0.30 \pm 0.086$ & $0.27 \pm 0.13$ & $0.19 \pm 0.0056$ & $0.32 \pm 0.028$ & $0.37 \pm 0.11$ & $0.35 \pm 0.057$ \\
\hline $17: 0$ & $0.00238 \pm 0.0007$ & $0.0005 \pm \mathrm{N} / \mathrm{A}$ & N/A & N/A & N/A & N/A \\
\hline $18: 0$ & $0.0452 \pm 0.031$ & $0.02 \pm 0.0087$ & $0.014 \pm 0.0035$ & $0.023 \pm 0.0035$ & $0.028 \pm 0.0048$ & $0.022 \pm 0.004$ \\
\hline MUFA & $0.903 \pm 0.45$ & $0.89 \pm 0.48$ & $0.58 \pm 0.21$ & $1.16 \pm 0.086$ & $1.16 \pm 0.41$ & $1.26 \pm 0.21$ \\
\hline $15: 1$ & $0.019 \pm 0.00055$ & $0.014 \pm 0.011$ & $0.015 \pm 0.004$ & $0.015 \pm 0.004$ & $0.022 \pm 0.0016$ & $0.014 \pm 0.0042$ \\
\hline $16: 1 \mathrm{n}-7$ & $0.817 \pm 0.4$ & $0.82 \pm 0.45$ & $0.53 \pm 0.19$ & $1.09 \pm 0.08$ & $1.07 \pm 0.4$ & $1.18 \pm 0.2$ \\
\hline $17: 1 \mathrm{n}-7$ & $0.0166 \pm 0.0063$ & $0.0088 \pm 0.0058$ & $0.0066 \pm 0.003$ & $0.011 \pm 0.001$ & $0.012 \pm 0.0021$ & $0.041 \pm 0.0058$ \\
\hline $18: 1 n-9 c$ & $0.066 \pm 0.011$ & $0.036 \pm 0.017$ & $0.026 \pm 0.0077$ & $0.04 \pm 0.0038$ & $0.047 \pm 0.0099$ & $0.0042 \pm 0.001$ \\
\hline $18: 2 n-6 c$ & $0.035 \pm 0.017$ & $0.018 \pm 0.014$ & $0.014 \pm 0.0031$ & $0.02 \pm 0.0031$ & $0.022 \pm 0.003$ & $0.02 \pm 0.0036$ \\
\hline $18: 3 n-6$ & $0.0018 \pm \mathrm{N} / \mathrm{A}$ & N/A & N/A & $0.0013 \pm \mathrm{N} / \mathrm{A}$ & $0.0022 \pm 0.00036$ & $0.00142 \pm 1.9 \mathrm{e}^{-5}$ \\
\hline $20: 2 n-6$ & $0.0024 \pm 0.00082$ & $0.0024 \pm 0.0008$ & $0.0015 \pm 0.0059$ & $0.0021 \pm 0.0036$ & $0.0035 \pm 0.0013$ & $0.002 \pm 0.0005$ \\
\hline $20: 3 n-6$ & N/A & N/A & N/A & N/A & N/A & N/A \\
\hline $20: 3 n-3$ & $0.0067 \pm 0.0051$ & $0.004 \pm 0.0027$ & $0.0041 \pm 0.00075$ & $0.0044 \pm 0.0018$ & $0.0078 \pm 0.0014$ & $0.004 \pm 0.0033$ \\
\hline $22: 2 n-6$ & $0.0021 \pm 0.00078$ & $0.0015 \pm 0.0004$ & $0.0011 \pm 0.00016$ & $0.0013 \pm 0.0004$ & $0.0016 \pm 0.00044$ & $0.0013 \pm 7.9 \mathrm{e}^{-5}$ \\
\hline $20: 5 n-3$ & $0.1088 \pm 0.054$ & $0.11 \pm 0.057$ & $0.072 \pm 0.021$ & $0.13 \pm 0.01$ & $0.13 \pm 0.028$ & $0.13 \pm 0.021$ \\
\hline $22: 5 n-3$ & $0.034 \pm 0.015$ & $0.018 \pm 0.015$ & $0.029 \pm 0.0088$ & $0.021 \pm 0.0034$ & $0.056 \pm 0.0054$ & $0.018 \pm 0.0033$ \\
\hline $22: 6 n-3$ & $0.011 \pm 0.0038$ & $0.011 \pm 0.0033$ & $0.0081 \pm 0.0019$ & $0.0088 \pm 0.00037$ & $0.013 \pm 0.0027$ & $0.0084 \pm 0.00045$ \\
\hline
\end{tabular}




\section{References}

Ahlgren, G., Lundstedt, L., Brett, M., and Forsberg, C. (1990). Lipid composition and food quality of some freshwater phytoplankton for cladoceran zooplankters. Journal of Plankton Research, 12:809-818. DOI:10.1093/plankt/12.4.809

Allakhverdiev, S. I., Kreslavski, V.D., Klimov, V. V., Los, D.A., Carpentier, R., and Mohanty, P. (2008). Heat stress: an overview of molecular responses in photosynthesis. Photosynthesis Research, 98:541550. DOI: $10.1007 / \mathrm{s} 11120-008-9331-0$

Anacleto, P., Maulvault, A. L., Bandarra, N.M., Repolho, T., Nunes, M.L., Rosa, R., and Marques, A. (2014). Effect of warming on protein, glycogen and fatty acid content of native and invasive clams. Food Research International, 64:439-445. DOI:10.1016/j.foodres.2014.07.023

Andersen, G. S. Pedersen, M. F., and Nielsen, S.L. (2013). Temperature acclimation and heat tolerance of photosynthesis in Norwegian Saccharina latissimi (Laminariales, Phaeophyceae). Journal of Phycology, 49:689-700. DOI: 10.1111/j.15298817.2013.12077

Angilletta, M. J., Huey, R. B., Frazier, M. R., Jr, M. J. A., Huey, R. B., and Frazier, M. R. (2016). Thermodynamic effects on organismal performance : Is Hotter Better? Physiological and Biochemical Zoology, 83:197-206. DOI:10.1086/648567

Arendt, K. E., Jonasdottir, S. H., Hansen, P. J. and Garnter, S. (2005). Effects of dietary fatty acids on the reproductive success of the calanoid copepod Temora longicornis. Marine Biology, 146:513-530. DOI:10.1007/s00227-004-1457-9

Armbrust, E. V. (2009). The life of diatoms in the world's oceans. Nature, 459:185-192. DOI: 10.1038/nature08057

Arts, M. T., Ackman, R. G., and Holub, B. J. (2001). "Essential fatty acids" in aquatic ecosystems: a crucial link between diet and human health and evolution. Canadian Journal of Fisheries and Aquatic Sciences, 58:122-137. DOI:10.1139/f00-224

Austin, J. A. and Colman, S. M. (2007). Lake Superior summer water temperatures are increasing more rapidly than regional air temperatures: A positive ice-albedo feedback. Geophysical Research Letters, 34. DOI:10.1029/2006GL029021 
Bajguz, A. (2009). Brassinosteroid enhanced the level of abscisic acid in Chlorella vulgaris subjected to short-term heat stress. Journal of Plant Physiology, 166:882-886. DOI:10.1016/j.jplph.2008.10.004

Bindoff, N.L., Willebrand, J., Artale, V., Cazenave, A., Gregory, J., Gulev, S., Hanawa, K.,

Le Quéré, C., Levitus, S., Nojiri, Y., Shum, C. K., Talley, L.D., and Unnikrishnan, A. (2007) Observations: Oceanic Climate Change and Sea Level. In: Climate Change 2007: The Physical Science Basis. Contribution of Working Group I to the Fourth Assessment Report of the Intergovernmental Panel on Climate Change [S. Solomon, D. Qin, M. Manning, Z. Chen, M.

Marquis, K.B. Averyt, M. Tignor and H.L. Miller (eds.)]. Cambridge University Press, Cambridge, United Kingdom and New York, NY, USA. p. 387-429

Brenna, J. T., and Carlson, S. E. (2014). Docosahexaenoic acid and human brain development: Evidence that a dietary supply is needed for optimal development. Journal of Human Evolution, 77:99-106. DOI: 10.1016/j.jhevol.2014.02.017

Buist, P. H. (2004). Fatty acid desaturases: selecting the dehydrogenation channel. Natural Product Reports, 21:249-262. DOI: $10.1039 / \mathrm{b} 302094 \mathrm{k}$

Burns, C. W., Brett, M. T., and Schallenberg, M. (2011). A comparison of the trophic transfer of fatty acids in freshwater plankton by cladocerans and calanoid copepods. Freshwater Biology, 56:889-903. DOI:10.1111/j.1365-2427.2010.02534.x

Bush, E. J., Loder, J. W., James, T. S., Mortsch, L. D. and Cohen, S. J. (2014). An Overview of Canada's changing climate; in Canada in a changing climate: Sector perspectives on impacts and adaptation, [F.J. Warren and D.S. Lemmen (eds.)]; Government of Canada, Ottawa, ON, p. 23-64.

Butterwick, C., Heaney, S. I., and Talling, J. F. (2005). Diversity in the influence of temperature on the growth rates of freshwater algae, and its ecological relevance. Freshwater Biology, 50:291-300. DOI: 10.1111/j.1365-2427.2004.01317.x

Calder, P. C. (2016). The impact of long-chain n-3 polyunsaturated fatty acids on human health. Nutrition Research Reviews, 18:113129. DOI:10.1079/NRR200497

Cantrell, K. B., and Walker, T. H. (2009). Influence of temperature on growth and peak

oil biosynthesis in a carbon-limited medium by Pythium irregulare. Journal of the American Oil Chemists' Society, 86:791-

797. DOI: $10.1007 / \mathrm{s} 11746-009-1409-0$ 
Carlson, S. J., Fallon, E. M., Kalish, B. T., Gura, K. M., and Puder, M. (2013). The role of the $\omega-3$ fatty acid DHA in the human life cycle. Journal of Parenteral and Enteral Nutrition, 37:15-22. DOI:10.1177/0148607112467821

Chapman, R. L. (2013). Algae: the world's most important "plants" — an introduction. Mitigation and Adaptation Strategies for Global Change, 18:5-12. DOI:10.1007/s11027-010-9255-9

Chen, H., Gu, Z., Zhang, H., Wang, M., Chen, W., Lowther, W. T., and Chen, Y. Q. (2013). Expression and purification of integral membrane fatty acid desaturases. PLOS One, 8:1-9. DOI: 10.1371/journal.pone.0058139

Cheesbrough, T. M. (1989). Changes in the enzymes for fatty acid synthesis and desaturation during acclimation of developing soybean seeds to altered growth temperature. Plant Physiology, 90(2):760-764. DOI:10.1104/pp.90.2.760

Collins, M., Knutti, R., Arblaster, J., Dufresne, J-L., Fichefet, T., Friedlingstein, P., Gao, X., Gutowski, W. J., Johns, T., Krinner, G., Shongwe, M., Tebaldi, C., Weaver, A. J. and Wehner, M.(2013) Long-term climate change: Projections, commitments and irreversibility. In: Climate change 2013: The physical science basis. Contribution of Working Group I to the Fifth Assessment Report of the Intergovernmental Panel on Climate Change [T.F. Stocker, D. Qin, G.-K. Plattner, M. Tignor, S.K. Allen, J. Boschung, A. Nauels, Y. Xia, V. Bex and P.M. Midgley (eds.)]. Cambridge University Press, Cambridge, United Kingdom and New York, NY, USA.

Colombo, S. M., Wacker, A., Parrish, C. C., Kainz, M. J., and Arts, M. T. (2016). A fundamental dichotomy in long-chain polyunsaturated fatty acid abundance between and within marine and terrestrial ecosystems. Environmental Reviews. In press. DOI: 10.1139/er-2016-0062

Crowley, T. J. (2010). Causes of climate change over the past 1000 years. Science, 289:270-277. DOI:10.1126/science.289.5477.270

Cubasch, U., Wuebbles, D., Chen, D., Facchini, M.C., Frame, D., Mahowald, N., and Winther, J-G. (2013): Introduction. In: Climate Change 2013: The physical science basis. Contribution of Working Group I to the Fifth Assessment Report of the Intergovernmental Panel on Climate Change [T.F. Stocker, D. Qin, G.-K. Plattner, M. Tignor, S.K. Allen, J. Boschung, A. Nauels, Y. Xia, V. Bex and P.M. Midgley (eds.)]. Cambridge University Press, Cambridge, United Kingdom and New York, NY, USA 
Davison, I. R. (1991). Environmental effects on algal photosynthesis: Temperature. Journal of Phycology, 27:2-8. DOI:10.1111/j.0022-3646.1991.00002.x

Dixit, S. S., Smol, J. P., Kingston, J.C. and Charles, D.F. (1992). Diatoms: Powerful indicators of environmental change. Environmental Science and Technology, 26:23-33. DOI:10.1021/es00025a002

Dobiesz, N. E., and Lester, N. P. (2009). Changes in mid-summer water temperatures and clarity across the Great Lakes between 1968 and 2002. Journal of Great Lakes Research, 35:371-384. DOI:10.1016/j.jglr.2009.05.002

Engler, M. M., and Engler, M. B. (2006). Omega-3 fatty acids role in cardiovascular health and disease. Journal of Cardiovascular Nursing, 21:17-24.

Fahl, K., and Kattner, G. (1993). Lipid Content and fatty acid composition of algal communities in sea-ice and water from the Weddell Sea (Antarctica). Polar Biology, 13:405-409. DOI:10.1007/BF01681982

Fuschino, J. R. (2010). Rising water temperature leads to diminished essential fatty acid concentrations in Scendesmus obliquus and Daphnia magna: A controlled laboratory study. MSc. Thesis, York University, 143 pages.

Fuschino, J. R., Guschina, I. A., Dobson, G., Yan, N. D., Harwood, J. L., and Arts, M. T. (2011). Rising water temperatures alter lipid dynamics and reduce N-3 essential fatty acid concentrations in Scenedesmus obliquus (Chlorophyta). Journal of Phycology, 47:763-774. DOI:10.1111/j.1529-8817.2011.01024.x

Gamal, A. A. (2010). Biological importance of marine algae. Saudi Pharmaceutical Journal, 18:1-25. DOI:10.1016/j.jsps.2009.12.001

Gladyshev, M. I., Sushchik, N. N., Dubovskaya, O. P., Makhutova, O. N., and Kalachova, G. S. (2008). Growth rate of Daphnia feeding on seston in a Siberian reservoir: The role of essential fatty acid. Aquatic Ecology, 42:617-627. DOI:10.1007/s10452007-9146-7

Gladyshev, M. I., Sushchik, N. N., Makhutova, O. N., Kalacheva, G. S., Kolmakova, A. A., Kravchuk, E. S., and Dubovskaya, O. P. (2009). Efficiency of transfer of essential polyunsaturated fatty acids along trophic chains in aquatic ecosystems. Doklady Biochemistry and Biophysics, 426:158-160. DOI:10.1134/S1607672909030089 
Gladyshev, M. I., Sushchik, N. N., and Anishchenko, O. V. (2011). Efficiency of transfer of essential polyunsaturated fatty acids versus organic carbon from producers to consumers in a eutrophic reservoir. Oecologia, 165:521-531. DOI:10.1007/s00442-010$1843-6$

Gladyshev, M. I., Sushchik, N. N., and Makhutova, O. N. (2013). Production of EPA and DHA in aquatic ecosystems and their transfer to the land. Prostaglandins and Other Lipid Mediators, 107:117-126. DOI:10.1016/j.prostaglandins.2013.03.002

Gladyshev, M. I., Sushchik, N. N., Dubovskaya, O. P., Buseva, Z. F., Makhutova, O. N., Fefilova, E. B., Feniova, I. Y., Semenchenko, V. P., Kolmakova, A. A., and Kalachova, G. S. (2015). Fatty acid composition of Cladocera and Copepoda from lakes of contrasting temperature. Freshwater Biology, 60:373-386. DOI:10.1111/fwb.12499

Guiry, M. D. and Guiry, G. M. (2017). AlgaeBase. World-wide electronic publication, National University of Ireland, Galway.

Guiry, M. D. (2012). How many species of algae are there? Journal of Phycology, 48:1057-1063. DOI:10.1111/j.15298817.2012.01222.x

Guo, F. E. N., Kainz, M. J., Sheldon, F., and Bunn, S. E. (2016). The importance of high-quality algal food sources in stream food webs - current status and future perspectives. Freshwater Biology, 61:815-831. DOI:10.1111/fwb.12755

Guschina, I.A., and Harwood, J.L. (2009). Algal lipids and effect of the environment on their biochemistry. In: Lipids in Aquatic Ecosystems. [ M. T. Arts, M. T. Brett and M. J. Kainz. (eds.)] 1-24. New York: Springer. DOI: 10.1007/978-0-387-89366-2_1

Harley, C. D., Hughes, R. A. Hultgren, K. M., Miner, B. G., Sorte, C. J.,

Thornber, C. S., Rodriguez, L. F., Tomanek, L., and Williams, S. L. (2006). The impacts of climate Change in coastal marine systems. Ecology Letters, 9:228-241. DOI: 10.1111/j.1461-0248.2005.00871.x

Hartmann, D. L., Klein Tank, A. M. G., Rusticucci, M., Alexander, L.V., Brönnimann, S.,

Charabi, Y., Dentener, F. J., Dlugokencky, E. J., Easterling, D. R., Kaplan, A., Soden, B. J., Thorne, P. W., Wild, M., and Zhai, P. M. (2013). Observations: Atmosphere and Surface. In: Climate Change 2013: The Physical Science Basis. Contribution of Working Group I to the Fifth Assessment Report of the Intergovernmental Panel on Climate Change [T.F Stocker, D. Qin, G.-K. Plattner, M. Tignor, S.K. Allen, J. Boschung, A. Nauels, Y. Xia, V. Bex and P.M. Midgley (eds.)]. Cambridge University Press, Cambridge, United Kingdom and New York, NY, USA. 
Hartwich, M., Martin-Creuzburg, D., and Wacker, A. (2013). Seasonal changes in the accumulation of polyunsaturated fatty acids in zooplankton. Journal of Plankton Research, 35:121-134. DOI:10.1093/plankt/fbs078

Hazel, R., and Williams, E. E. (1991). The role of alterations in membrane lipid composition in enabling physiological adaptation of organisms to their physical environment, Progress in Lipid Research, 29:167-227. DOI:10.1016/0163-7827(90)90002-3

Hegerl, G. C., Zwiers, F. W., Stott, P. A and Kharin, V. V. (2004). Detectability of anthropogenic changes in annual temperature and precipitation extremes. Journal of Climate, 17:3683-3700. DOI:10.1175/15200442(2004)017<3683:DOACIA >2.0.CO;2

Heino, J., Virkkala, R., and Toivonen, H. (2009). Climate change and freshwater biodiversity: detected patterns, future trends and adaptations in northern regions. Biological Reviews of the Cambridge Philosophical Society, 84:39-54. DOI: 10.1111/j.1469-185X.2008.00060.x

Hixson, S.M. and Arts, M.T. (2016). Climate warming is predicted to reduce omega-3, long-chain, polyunsaturated fatty acid production in phytoplankton. Global change biology, 22:2744-2755. DOI: $10.1111 / \mathrm{gcb} .13295$

Hixson, S. M., Sharma, B., Kainz, M. J., Wacker, A., and Arts, M. T. (2015). Production, distribution, and abundance of long-chain omega-3 polyunsaturated fatty acids: A fundamental dichotomy between freshwater and terrestrial ecosystems. Environmental Reviews, 23:414-424. DOI:10.1139/er-2015-0029

Honeyfield, D. C. and Maloney, K.O. (2015). Seasonal patterns in stream periphyton fatty acids and community benthic algal composition in six high quality headwater streams. Hydrobiologia, 744:35-47. DOI:10.1007/s10750-014-2054-7

Horrocks, L. A., and Farooqui, A. A. (2004). Docosahexaenoic acid in the diet : its importance in maintenance and restoration of neural membrane function. Prostglandins, Leukotrienes and Essential Fatty Acids, 70:361-372. DOI:10.1016/j.plefa.2003.12.011

$\mathrm{Hu}, \mathrm{H}$., and Gao, K. (2006). Response of growth and fatty acid compositions of Nannochloropsis sp. to environmental factors under elevated $\mathrm{CO}_{2}$ concentration. Biotechnology Letters, 28:987-992. DOI:10.1007/s10529-006-9026-6

Ji, Y., Xu, Z., Zou, D., and Gao, K. (2016). Ecophysiological responses of marine macroalgae 
to climate change factors. Journal of Applied Phycology, 28:2953-2967. DOI:10.1007/s 10811-016-0840-5

Kainz, M., Arts, M. T., and Mazumder, A. (2004). Essential fatty acids in the planktonic food web and their ecological role for higher trophic levels. Limnology and Oceanography, 49:1784-1793. DOI:10.4319/lo.2004.49.5.1784

Kanazawa, A. (1997). Effects of docosahexaenoic acid and phospholipids on stress tolerance of fish. Aquacultures, 155:129-134. DOI:10.1016/S0044-8486(97)00123-3

Kharin, V. V, Zwiers, F. W., Zhang, X, and Hegerl, G. C. (2007). Changes in temperature and precipitation extremes in the IPCC ensemble of global coupled model simulations. Journal of Climate, 20:1419-1444. DOI:10.1175/JCLI4066.1

Koussoroplis, A., Kainz, M. J., and Striebel, M. (2013). Fatty acid retention under temporally heterogeneous dietary intake in a cladoceran. Oikos, 122:1017-1026. DOI:10.1111/j.1600-0706.2012.20759.x

Kreslavski, V. D., Carpentier, R., Klimov, V.V., Murata, N. and Allakhverdiev, S. I. (2007). Molecular mechanisms of stress resistance of the photosynthetic apparatus. Biochemistry (Moscow) Supplement Series A: Membrane and Cell Biology, 1:185205. DOI: $10.1134 / \mathrm{S} 1990747807030014$

Lands, W. E. M. (2009). Human life: Caught in the food web. In: Lipids in Aquatic Ecosystems. [ M. T. Arts, M. T. Brett and M. J. Kainz. (eds.)] 327-354. New York: Springer. DOI: 10.1007/978-0-387-89366-2_1

Los, D. A., Ray, M.., and Murata, N. (1997). Differences in the control of the temperature-dependent express of four genes for desaturases in Synechocystis sp. PCC 6803. Molecular Microbiology, 25:1167-1175. DOI:10.1046/j.1365-2958.1997.5641912.x

Luria, S. E. and Delbrück, M. (1943). Mutations of bacteria from virus sensitivity to virus resistance. Genetics 28:491-511.

Marsh, D. (2010). Structural and thermodynamic determinants of chain-melting transition temperatures for phospholipid and glycolipid membranes. Biochimica et Biophysica Acta-Biomembranes, 1798:40-51. DOI:10.1016/j.bbamem.2009.10.010

Martin-Creuzburg, D., Wacker, A., and Basen, T. (2010). Interactions between limiting nutrients : Consequences for somatic and population growth of Daphnia magna. Limnology and Oceanography, 55:2597-2607. DOI:10.4319/lo.2010.55.6.2597 
Masclaux, H., Bec, A., Kainz, M. J., Perriere, F., Desvilettes, C., and Bourdier, G. (2012). Accumulation of polyunsaturated fatty acids by cladocerans: effects of taxonomy, temperature and food. Freshwater Biology, 57:696-703. DOI:10.1111/j.13652427.2012.02735.x

McMeans, B. C., Koussoroplis, A., and Kainz, M. J. (2015). Effects of seasonal seston and temperature changes on lake zooplankton fatty acids. Limnology and Oceanography, 60:573-583. DOI:10.1002/lno.10041

Meehl, G. A., Zwiers, F., Evans, J., Knutson, T., Mearns, L., and Whetton, P. (1996). Trends in Extreme Weather and Climate Events : Issues Related to Modeling Extremes in Projections of Future Climate Change. American Meteorological Society, 81:427-436. DOI: 10.1175/1520-0477(2000)081<0427:TIEWAC>2.3.CO;2

Meyer, A., Kirsch, H., Domergue, F., Abbadi, A., Sperling, P., Bauer, J., and Heinz, E. (2004). Novel fatty acid elongases and their use for the reconstitution of docosahexaenoic acid biosynthesis. Journal of Lipid Research, 45:1899-1909. DOI:10.1194/jlr.M400181-JLR200

Mikami, K., and Murata, N. (2003). Membrane fluidity and the perception of environmental signals in cyanobacteria and plants. Progress in Lipid Research, 42:527-543. DOI: 10.1016/S0163-7827(03)00036-5

Moisan, J. R., Moisan, T. A., and Abbott, M. R. (2002). Modelling the effect of temperature on the maximum growth rates of phytoplankton populations. Ecological Modelling, 153:197-215. DOI:10.1016/S0304-3800(02)00008-X

Murata, N., and Los, D. A. (1997). Membrane fluidity and temperature perception. Plant Physiology, 115:875-879. DOI:10.1104/pp.115.3.875

Murray, S. M., O’Brien, R. A., Mattson, K. M., Ceccarelli, C., Sykora, R. E., West, K. N., and Davis, J. H. (2010). The fluid-mosaic model, homeoviscous adaptation, and ionic liquids: dramatic lowering of the melting point by side-chain unsaturation. Angewandte Chemie International Edition, 49:2755-2758. DOI:10.1002/anie.200906169

Oger, P. M., and Cario, A. (2013). Adaptation of the membrane in Archaea. Biophysical Chemistry, 183:42-56. DOI:10.1016/j.bpc.2013.06.020

Paerl, H. W., and Huisman, J. (2009). Climate change : a catalyst for global expansion of harmful cyanobacterial blooms. Environmental Microbiology Reports, 1:27-37. DOI:10.1111/j.1758-2229.2008.00004.x 
Paerl H. W., and Paul, V. J. (2012) Climate change: links to global expansion of harmful cyanobacteria. Water Research, 46:1349-1363. DOI:10.1016/j.watres.2011.08.002

Pajunen, V., Luoto, M., and Soininen, J. (2016a). Stream diatom assemblages as predictors of climate. Freshwater Biology, 61:876886. DOI:10.1111/fwb. 12750

Pajunen, V., Luoto, M., and Soininen, J. (2016b). Climate is an important driver for stream. Global Ecology and Biogeography, 25:198-206. DOI:10.1111/geb.12399

Parrish, C. C. (2013). Lipids in marine ecosystems. ISRN Oceanography, 2013:1-17. DOI:10.5402/2013/604045

Pasquet, V., Ulmann, L., Mimouni, V., Guihéneuf, F., Jacquette, B., Morant-Manceau, A., and Tremblin, G. (2014). Fatty acids profile and temperature in the cultured marine diatom Odontella aurita. Journal of Applied Phycology, 26:2265-2271.

DOI:10.1007/s10811-014-0252-3

Patil, V., Källqvist. T., Olsen, E., Vogt, G., and Gislerød, H. R. (2007). Fatty acid composition of 12 microalgae for possible use in aquaculture feed. Aquaculture International, 15:1-9. DOI:10.1007/s10499-006-9060-3

Peng, K-T., Zheng, C-N., Xue, J., Chen, X-Y., Yang, W-D. , Liu, J-S., Bai, W., and Li, H-Y. (2014). Delta 5 fatty acid desaturase upregulates the synthesis of polyunsaturated fatty acids in the marine diatom Phaeodactylum tricornutum. Journal of Agricultural and Food Chemistry, 62:8773-8776. DOI:10.1021/jf5031086

Pereira, S. L., Leonard, A. E., Huang, Y., Chuang, L., and Mukerji, P. (2004). Identification of two novel microalgal enzymes involved in the conversion of the $\omega$ 3-fatty acid, eicosapentaenoic acid, into docosahexaenoic acid. Biochemical Journal, 384:357-366. DOI: 10.1042/BJ20040970

Perhar, G., Arhonditsis, G. B., and Brett, M. T. (2013). Modelling the role of highly unsaturated fatty acids in planktonic food web process: Sensitivity analysis and examination of contemporary hypotheses. Ecological Informatics, 13:77-98. DOI:10.1016/j.ecoinf.2012.10.005

Persson, J., and Vrede, T. (2006). Polyunsaturated fatty acids in zooplankton: variation due to taxonomy and trophic position. Freshwater Biology, 51:887-900. DOI: 10.1111/j.1365-2427.2006.01540.x 
Pottel, L, Lycke, M., Boterberg, T., Foubert, I., Pottel, H., Duprez, F., Goethals, L., and Debruyne, P. R. (2014). Omega-3 Fatty acids: physiology, biological sources and potential applications in supportive cancer care. Phytochemistry Reviews, 13:223-244. DOI: $10.1007 / \mathrm{s} 11101-013-9309-1$

Prowse, T. D., Wrona, F. J., Reist, J. D., Gibson, J. J., Hobbie, J. E., Lévesque, L. M. J., and Vincent, W. F. (2006). Climate change impacts on Arctic freshwater ecosystems and fisheries. Ambio, 35:347-358. DOI: 10.1579/0044-7447

Raven, J. A. and Geider, R. J. (1988). Temperature and algal growth. New Phytologist, 110:441-461. DOI:10.1111/j.14698137.1988.tb00282.x

Renaud, S. M., Thinh, L., Lambrinidis, G., and Parry, D. L. (2002). Effect of temperature on growth, chemical composition and fatty acid composition of tropical Australian microalgae grown in batch cultures. Aquaculture, 211:195-214. DOI: 10.1016/S00448486(01)00875-4

Rhein, M., Rintoul, S. R., Aoki, S., Campos, E., Chambers, D., Feely, R. A., Gulev, S., Johnson, G.C., Josey, S. A., Kostianoy, A., Mauritzen, C., Roemmich, D., Talley, L. D., and Wang, F. (2013). Observations: Ocean. In: Climate Change 2013: The Physical Science Basis. Contribution of Working Group I to the Fifth Assessment Report of the Intergovernmental Panel on Climate Change [T.F. Stocker, D. Qin, G.-K. Plattner, M. Tignor, S.K. Allen, J. Boschung, A. Nauels, Y. Xia, V. Bex and P.M. Midgley (eds.)]. Cambridge University Press, Cambridge, United Kingdom and New York, NY, USA

Root, T. L., and Schneider, S. H. (2006). Conservation and climate change : the challenges ahead. Conservation Biology, 20:706-708. DOI:10.1111/j.1523-1739.2006.00465.x

Rousch, J. M., Bingham, S. E., and Sommerfeld, M. R. (2003). Changes in fatty acid profiles of thermo-intolerant and thermo-tolerant marine diatoms during temperature stress. Journal of Experimental Marine Biology and Ecology, 295:145-156. DOI:10.1016/S0022-0981(03)00293-4

Rousch, J. M., Bingham, S. E., and Sommerfeld, M. R. (2004). Protein expression during heat stress in thermo-intolerant and thermotolerant diatoms. Journal of Experimental Marine Biology and Ecology, 306: 231-243. DOI:10.1016/j.jembe.2004.01.009

Ruhland, K. M., Paterson, A. M., and Smol, J. P. (2015). Lake diatom responses to warming: reviewing the evidence. Journal of Paleolimnology, 54:1-35. DOI: 10.1007/s10933-015-9837-3 
Sahu, A., Pancha, I., Jain, D., Paliwal, C., Ghosh, T., Patidar, S., Bhattacharya, S., and Mishra, S. (2013). Fatty acids as biomarkers of microalgae. Phytochemistry, 89:53-58. DOI:10.1016/j.phytochem.2013.02.001

Sala, O. E., Chapin, F.S., Armesto, J. J., Berlow, E., Bloomfield, J., Dirzo, R., Huber-Sanwald, E., Huenneke, L.F., Jackson, R. B., Kinzig, A., Leemans, R., Lodge, D.M., Mooney, H. A., Oesterheld, M., LeRoy Poff, N., Sykes, M. T., Walker, B. H., Walker, M., and Hall, D. H. (2000). Global biodiversity scenarios for the year 2100. Science, 287:1770-1774. DOI:

$10.1126 /$ science.287.5459.1770

Schlechtriem, C., Arts, M. T., and Zellmer, I. D. (2006). Effect of temperature on the fatty acid composition and temporal trajectories of fatty acids in fasting Daphnia pulex (Crustacea , Cladocera ). Lipids, 41:397-400. DOI: 10.1007/s11745-006-5111-9

Schlotz, N., Ebert, D., and Martin-Creuzburg, D. (2013). Dietary supply with polyunsaturated fatty acids and resulting maternal effects influence host-parasite interactions. BMC Ecology, 13. DOI:10.1186/1472-6785-13-41

Sicko-Goad, L., and Andresen, N. A. (1991). Effect of growth and light/dark cycles on diatom lipid content and composition. Journal of Phycology, 27:710-718.

DOI: $10.1111 / \mathrm{j} .0022-3646.1991 .00710 . \mathrm{x}$

Simopoulos, A. P. (2002). Omega-3 Fatty Acids in Inflammation and Autoimmune Diseases. Journal of the American College of Nutrition, 21:495-505. DOI:10.3733/ca.v065n03p106

Sinensky, M. (1974). Homeoviscous Adaptation-A homeostatic process that regulates the viscosity of membrane lipids in Escherichia coli. Proceedings of the National Academy of Sciences, 71:522-525.

Solovchenko, A. E. (2008). Effects of light intensity and nitrogen starvation on growth, total fatty acids and arachidonic acid in the green microalga Parietochloris incisa. Journal of Applied Phycology, 20:245-251. DOI:10.1007/s10811-007-9233-0

Sperfeld, E. and Wacker, A. (2012). Temperature affects the limitation of Daphnia magna by eicosapentaenoic acid, and the fatty acid composition of body tissue and eggs. Freshwater Biology, 57:497-508. DOI:10.1111/j.1365-2427.2011.02719.x

Staehr, P. A., and Birkeland, M.. (2006). Temperature acclimation of growth, photosynthesis and respiration in two mesophilic phytoplankton species. Phycologia, 45:648-656. DOI:10.2216/06-04.1 
Sushchik, N. N., Kalacheva, G. S., Zhila, N. O., Gladyshev, M. I., and Volova, T. G. (2003). A temperature dependence of the intraand extracellular fatty-acid composition of green algae and cyanobacterium. Russian Journal of Plant Physiology, 50:374-380. DOI: $10.1023 / \mathrm{A}: 1023830405898$

Swanson, D., Block, R., and Mousa, S. A. (2012). Omega-3 Fatty acids EPA and DHA: Health benefits throughout life. Advances in Nutrition, 3:1-7. DOI:10.3945/an.111.000893

Taylor, K. E., Stouffer, R. J. and Meehl, G. A. (2012). An Overview of CMIP5 and the experiment design. Bulletin of the American Meteorological Society, 93:485-498, DOI: 10.1175/BAMS-D-11-00094.1.

Thompson, J. D. (1991). Phenotypic plasticity as a component of evolutionary change.

Trends in Ecology and Evolution, 6:246-249. DOI:10.1016/0169-5347(91)90070-E

Tocher, D. R. (2010). Fatty acid requirements in ontogeny of marine and freshwater fish. Aquaculture Research, 41:717-732. DOI:10.1111/j.1365-2109.2008.02150.x

Trenberth, K.E., Jones, P.D., Ambenje, P., Bojariu, R., Easterling, D., Klein Tank, A.,

Parker, D., Rahimzadeh, F., Renwick, J.A., Rusticucci, M., Soden, B. and Zhai, P. (2007) Observations: Surface and Atmospheric Climate Change. In: Climate Change 2007: The Physical Science Basis. Contribution of Working Group I to the Fourth Assessment Report of the Intergovernmental Panel on Climate Change [S. Solomon,D. Qin, M. Manning, Z. Chen, M. Marquis, K.B. Averyt, M. Tignor and H.L. Miller (eds.)]. Cambridge University Press, Cambridge, United Kingdom and New York, NY, USA. p. 237-336

Usui, K., Hiraki, T., Kawamoto, J., Kurihara, T., Nogi, Y., Kato, C., and Abe, F.

(2012). Eicosapentaenoic acid plays a role in stabilizing dynamic membrane structure in the deep-sea piezophile Shewanella violacea: A study employing high pressure time-resolved fluorescence anisotropy measurement. Biochimica et Biophysica Acta, 1818:574-583. DOI:10.1016/j.bbamem.2011.10.010

Vincent, L. A., Mekis, É., Vincent, L. A., and Mekis, É. (2016). Changes in daily and extreme temperature and precipitation indices for Canada over the twentieth century changes in daily and extreme temperature and precipitation indices for Canada over the twentieth century. Atmosphere-Ocean, 44:177-193. DOI:10.3137/ao.440205 
von Elert, E. (2002). Determination of limiting polyunsaturated fatty acids in Daphnia galeata using a new method to enrich food algae with single fatty acids. Limnology and Oceanography, 47:1764-1773. DOI:10.4319/lo.2002.47.6.1764

Wacker, A., and von Elert, E. (2004). Food quality controls egg quality of the zebra mussel Dreissena polymorpha: The role of fatty acids. Limnology and Oceanography, 49:1794-1801. DOI:10.4319/lo.2004.49.5.1794

Werbrouck, E., Gansbeke, D. Van, Vanreusel, A., and Mensens, C. (2016). Temperature-induced changes in fatty acid dynamics of the intertidal grazer Platychelipus littoralis (Crustacea, Copepoda, Harpacticoida ): Insights from a short-term feeding experiment. Journal of Thermal Biology, 57:44-46. DOI:10.1016/j.jtherbio.2016.02.002

Wilby, R. L.,Orr, H., Watts, G., Battarbee, R.W., Berry, P. M., Chadd, R., Dugdale, S. J., Dunbar, M. J., Elliott, J. A., Extrence, C., Hannah, D. M., Holmes, N., Johnson, A. C., Knights, B., Milner, N. J., Ormerod, S. J., Solomon, D., Timelett, R., Whitehead, P. J., and Wood, P. J. (2010). Evidence needed to manage freshwater ecosystems in a changing climate : Turning adaptation principles into practice. Science of the Total Environment, 408:4150-4164. DOI:10.1016/j.scitotenv.2010.05.014

Winder, M., Reuter, J. E., and Schladow, S. G. (2009). Lake warming favours small-sized planktonic diatom species. Proceedings of the Royal Society B Biological Sciences, 276:427-435. DOI:10.1098/rspb.2008.1200

Woodward, G., Perkins, D.M. and Brown, L. E. (2010). Climate change and freshwater ecosystems: impacts across multiple levels of organization. Philosophical Transactions of the Royal Society B, 365:2093-2106. DOI:10.1098/rstb.2010.0055

Yashodhara, B. M., Umakanth, S., Pappachan, J. M., Bhat, S. K., Kamath, R., Choo, B. H. (2009). Omega-3 fatty acids: a comprehensive review of their role in health and disease. Postgraduate Medical Journal, 85:84-90.

DOI:10.1136/pgmj.2008.073338

Ying, L., Kang-sen, M., and Shi-chun, S. (2000). Total lipid and fatty acid composition of eight strains of marine diatoms. Chinese journal of oceanology and limnology, 18:345-349. DOI: 10.1007/BF02876083

Yongmanitchai, W., and Ward, P. (1991). Growth of and omega-3 fatty acid production by Phaeodactylum tricornutum under different culture conditions. Applied and Environmental Microbiology, 57:419-425. 